\title{
Compliance Mechanisms Under Selected Multilateral Environmental Agreements
}

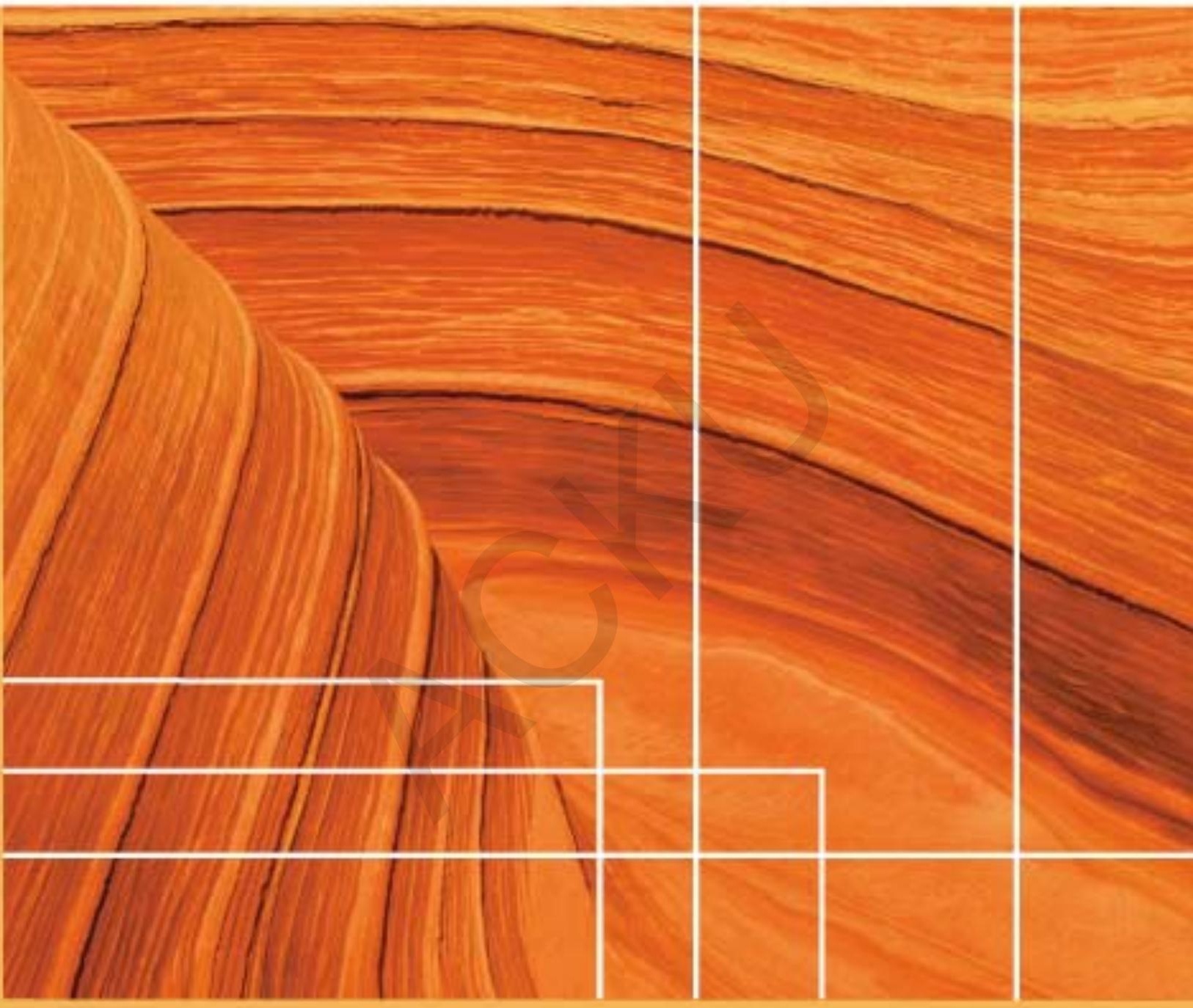


United Nations Environment Programme

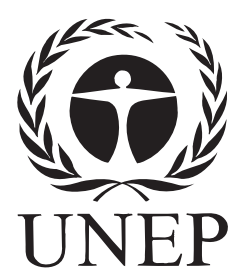

\section{COMPLIANCE MECHANISMS UNDER SELECTED MULTILATERAL ENVIRONMENTAL AGREEMENTS}


Compliance Mechanism under Selected Multilateral Environmental Agreements

ISBN: 978-92-807-2806-4

Job Number: DEL/0931/NA

Produced by the UNEP Division of Environmental Law and Conventions Director of Publication: Bakary Kante Writers/Project Coordinators: Professor Gregory Rose, Mr. Lal Kurukulasuriya, Ms. Amanthy Perera and Mr. Martin Krebs

Cover Design: Division of Communication and Public Information, UNEP

Design and Layout: UNON/Publishing Section Services/Nairobi; Paul Odhiambo

Image Credits: K. Irlmeier / Still Pictures

The Wave, water sculpted walls, USA, Arizona, Paria Canyon Vermillion Cliffs Wilderness Area,

The contents of this publication do not necessarily reflect the views or policies of UNEP or contributoring organisations or individuals.

This publication may be reproduced in whole or in part and in any form of educational or non-proper services without special permission from the copyright holder, provided acknowledgment of the source is made. UNEP would appreciate receiving a copy of any publication that uses this publication as a source. 


\section{Acknowledgments}

- his report was prepared by Professor Gregory Rose, Faculty of Law, University of Wollongong, NSW Australia (grose@uow.edu.au) in collaboration with Mr. Lal Kurukulasuriya, Director-General of the Centre for Environmental Research, Training and Information (and former Senior Advisor and Chief of the Environmental Law Branch of the Division of Policy Development and Law of UNEP) (lalkuru@eureka.Ik). Ms. Amanthy Perera provided editorial assistance.

\section{Tables}

Table 3.1 - Overview of MEA Compliance Frameworks

Table 3.2 - Performance Review Information

Table 3.3 - Multilateral Non-Compliance Response Procedures

Table 3.4 - Implementation Assistance

Table 3.5 - Non-Compliance Penalties

Table 3.6 - Dispute Resolution Procedures

Table 4.1 - Implementation Cooperation between MEA Secretariats

\section{Figures}

Figure 1 - Information Cycle

\section{Abbreviations}

Basel Convention

Biosafety Protocol

CBD

CITES

CMS

COP

DNA

EEZ

FAO

Fish Stocks Agreement

GEF

ITPGRFA

Kyoto Protocol

$\mathrm{LMO}$
Basel Convention on the Control of Transboundary Movements of Hazardous Wastes and their Disposal 1989

Cartagena Protocol on Biosafety to the Convention on Biological Diversity of 5 June 19922000

Convention on Biological Diversity 1992

Convention on International Trade in Endangered Species of Wild Fauna and Flora1973

Convention on the Conservation of Migratory Species of Wild Animals 1979

Conference of Parties

Designated National Authority

Exclusive Economic Zone

UN Food and Agriculture Organisation

Agreement for the Implementation of the Provisions of the United Nations Convention on the Law of the Sea of 10 December 1982 relating to the Conservation and Management of Straddling Fish Stocks and Highly Migratory Fish Stocks 1995

Global Environment Facility

International Treaty on Plant Genetic Resources for Food and Agriculture 2001

Kyoto Protocol to the United Nations Framework Convention on Climate Change 1997

Living Modified Organism 
London Convention

MARPOL

\section{MEA}

Montreal Protocol

MOP

$\mathrm{MOU}$

$\mathrm{NCP}$

ODS

PIC

PIC Convention

POPs

POPs Convention

Ramsar Convention

TRAFFIC

UNCCD

UNCED

UNCLOS

UNDP

UNEP

UNFCCC

UNU

Vienna Convention

WCMC

WCO

Whaling Convention

World Heritage Convention

WWF
Convention on the Prevention of Marine Pollution by Dumping of Wastes and Other Matter 1972

International Convention for the Prevention of Pollution from Ships 1973

Multilateral Environmental Agreement

Montreal Protocol on Substances that Deplete the Ozone Layer 1987

Meeting of Parties

Memorandum of Understanding

Non-Compliance Procedure

Ozone Depleting Substances

Prior Informed Consent

Rotterdam Convention on the Prior Informed Consent Procedure for Certain Hazardous Chemicals and Pesticides in International Trade 1998

Persistent Organic Pollutants

Stockholm Convention on Persistent Organic Pollutants 2001

Convention on Wetlands of International Importance especially as Waterfowl Habitat 1971

Trade Records Analysis of Flora and Fauna in International Commerce

United Nations Convention to Combat Desertification in those Countries Experiencing Serious Drought and/or Desertification, particularly in Africa 1994

United Nations Conference on Environment and Development

United Nations Convention of the Law of the Sea 1982

United Nations Development Programme

United Nations Environment Programme

United Nations Framework Convention on Climate Change 1992

United Nations University

Vienna Convention for the Protection of the Ozone Layer 1985

World Conservation Monitoring Centre

World Customs Organisation

International Convention for the Regulation of Whaling 1946

Convention for the Protection of World Cultural and Natural Heritage 1972

World Wildlife Fund 


\section{Table of Contents}

Acknowledgements ........................................................................................................ 3

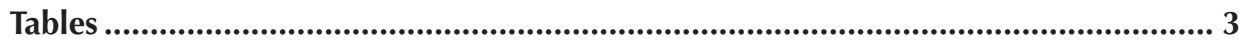

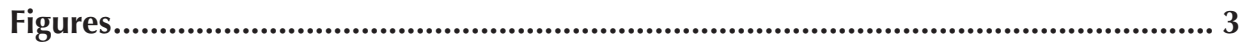

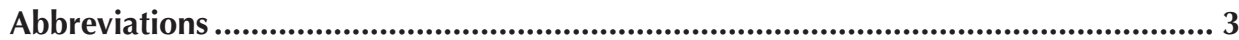

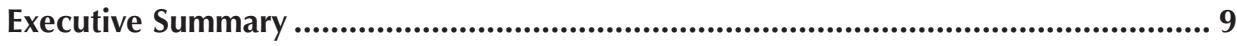

Comparative Compliance Mechanisms ................................................................. 9

(a) Performance Review Information ...................................................... 9

(b) Multilateral Procedures to Consider Non-Compliance ............................. 10

(c) Non-Compliance Response Measures .................................................. 11

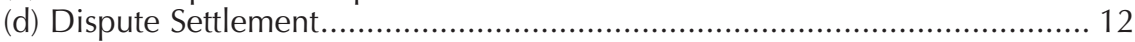

Compliance Interlinkages.............................................................................................. 13

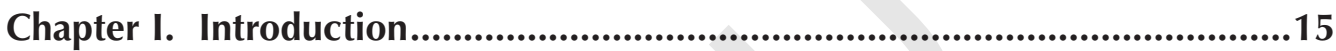

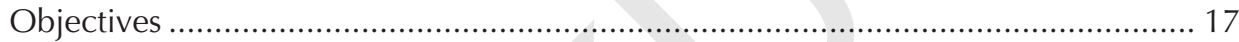

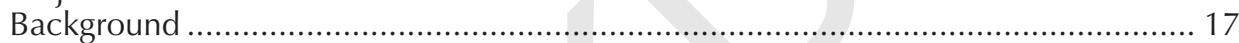

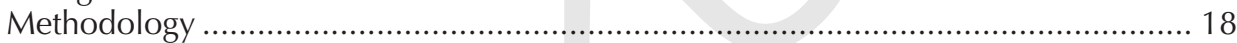

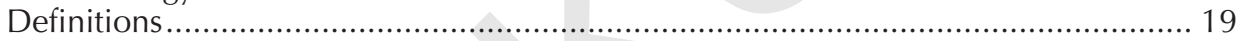

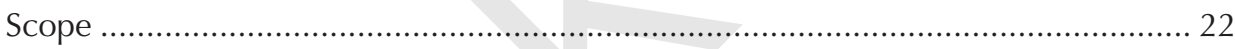

Chapter II Compliance Mechanisms Of Major Global Meas ............................25

Major Global Meas.......................................................................................... 27

Identifying Components Of Compliance Mechanisms of Meas................................ 29

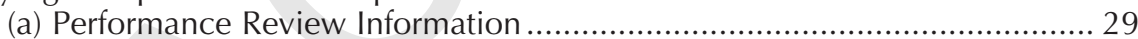

(b) Multilateral Non-Compliance Procedures ................................................ 31

(c) Non-Compliance Response Measures ...................................................... 31

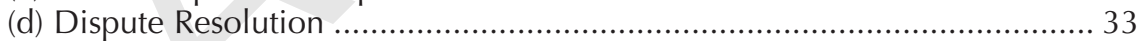

1. Nature Conservation ................................................................................................. 34

Ramsar Convention on Wetlands of International Importance especially as

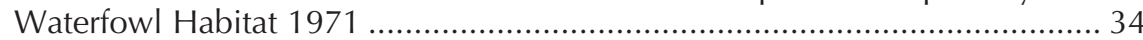

Overview.......................................................................................... 34

Compliance mechanisms..................................................................... 34

Convention Concerning the Protection of the World Cultural and Natural

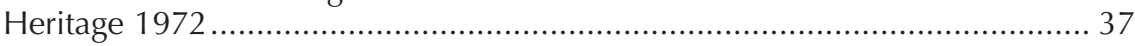

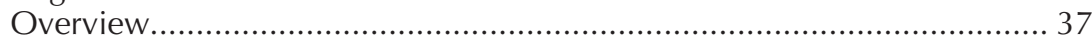

Compliance mechanisms................................................................... 37

Convention on International Trade in Endangered Species of Wild Flora

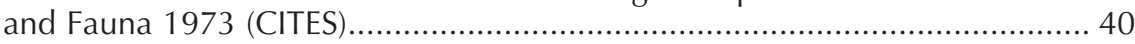

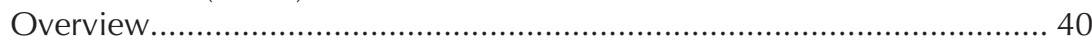

Compliance mechanisms.......................................................................... 40

Convention on the Conservation of Migratory Species of Wild Animals

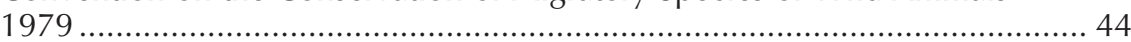

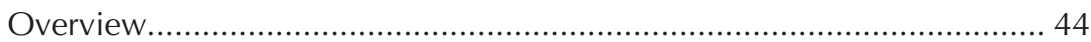

Compliance mechanisms.................................................................. 45 
Convention on Biological Diversity 1992 ................................................ 47

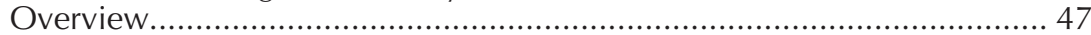

Compliance mechanisms............................................................. 47

United Nations Convention to Combat Desertification in those Countries

Experiencing Serious Drought and/or Desertification, Particularly in

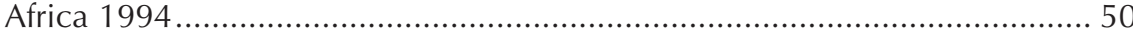

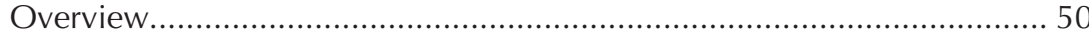

Compliance mechanisms................................................................. 50

International Treaty on Plant Genetic Resources for Food and Agriculture

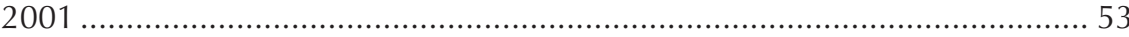

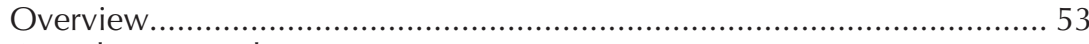

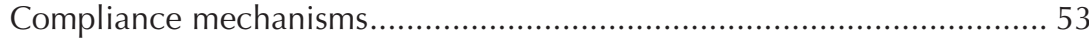

2. Hazardous Materials ......................................................................................... 56

Basel Convention on the Control of Transboundary Movements of Hazardous

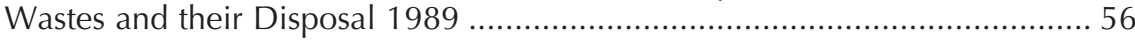

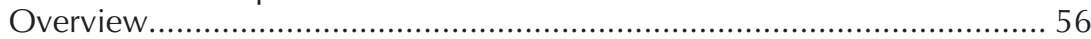

Compliance Mechanisms .................................................................. 58

Rotterdam Convention On The Prior Informed Consent Procedure For Certain

Hazardous Chemicals And Pesticides In International Trade ...................... 62

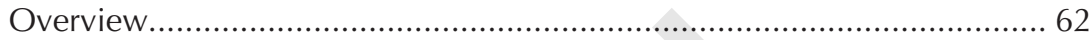

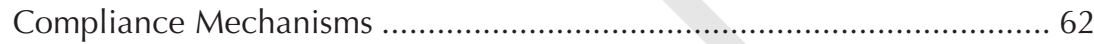

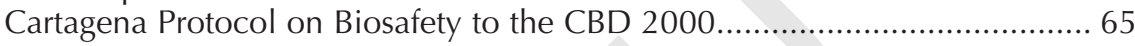

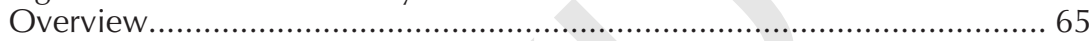

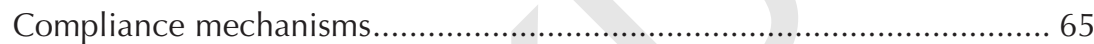

Stockholm Convention on Persistent Organic Pollutants 2001 ..................... 68

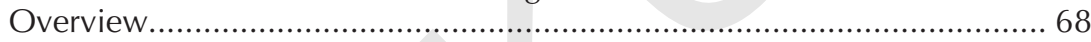

Compliance mechanisms................................................................ 68

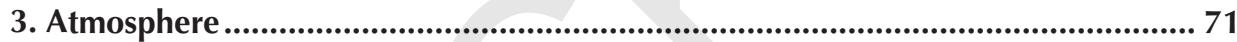

Vienna Convention for the Protection of the Ozone Layer 1985 .................... 71

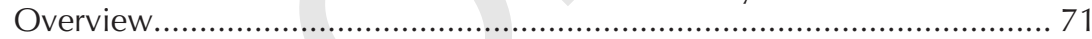

Compliance mechanisms.............................................................. 71

Montreal Protocol on Substances that Deplete the Ozone Layer 1987 .......... 74

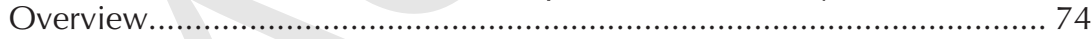

Compliance mechanisms............................................................. 74

United Nations Framework Convention on Climate Change 1992 _............... 77

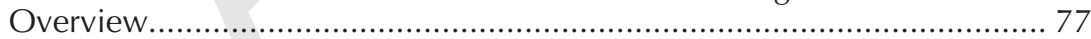

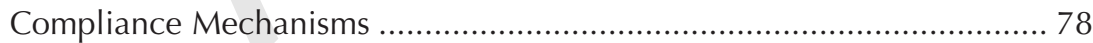

Kyoto Protocol to the United Nations Framework Convention on Climate

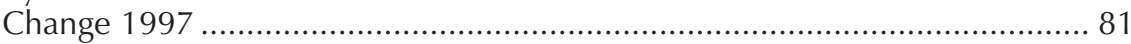

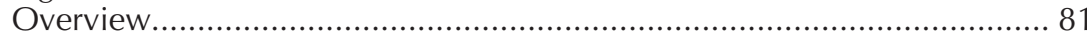

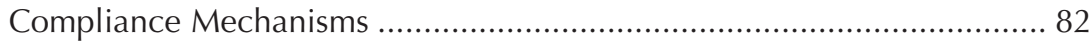

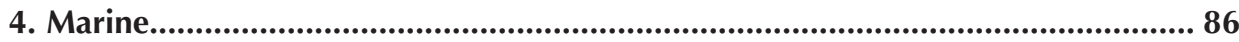

International Convention for the Regulation of Whaling 1946 ..................... 86

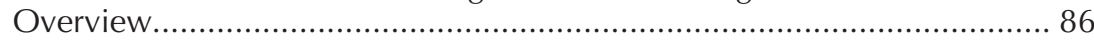

Compliance Mechanisms .............................................................. 86

London Convention on the Prevention of Marine Pollution by Dumping of

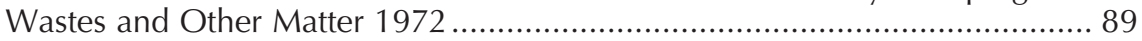

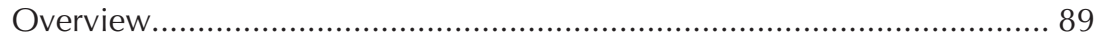

Compliance Mechamisms ....................................................... 89

United Nations Convention On The Law Of The Sea 1982 ...................... 91

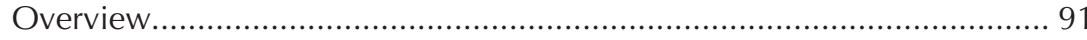



Agreement for the Implementation of the Provisions of the United Nations Convention on the Law of the Sea of 10 December 1982 Relating to the Conservation and Management of Straddling Fish Stocks and Highly Migratory Fish Stocks 1995

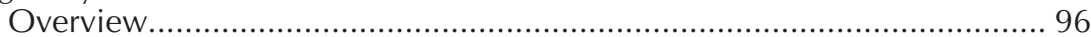

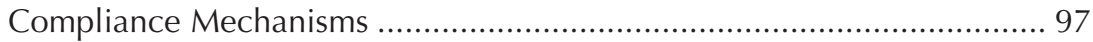

Chapter III. Comparative Analysis .......................................................101

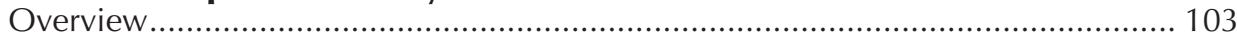

Table 3.1. Overview Of MEA Compliance Frameworks ................................... 104

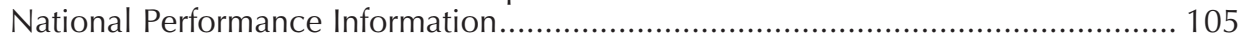

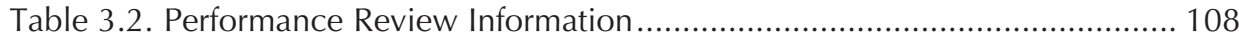

Multilateral Non-Compliance Response Procedures ........................................ 110

Table 3.3. Multilateral Non-compliance Response Procedures .............................. 112

Non-Compliance Response Measures................................................................. 113

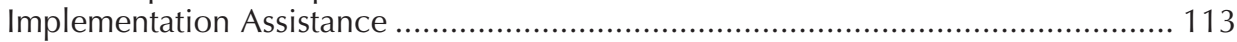

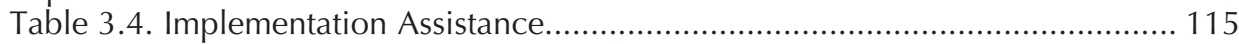

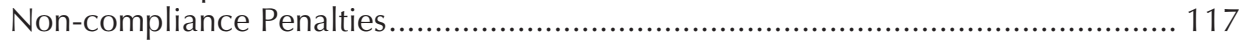

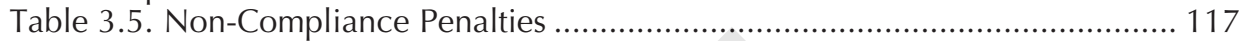

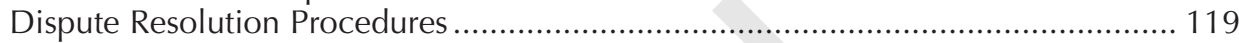

Table 3.6 Dispute Resolution Procedures ..................................................... 120

Chapter IV. Synthesis and Analysis of Law and Practice .............................123

International Efforts Towards Interlinkages In Compliance................................... 125

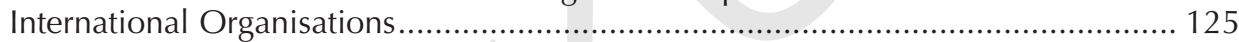

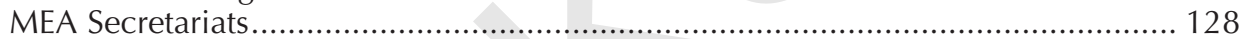

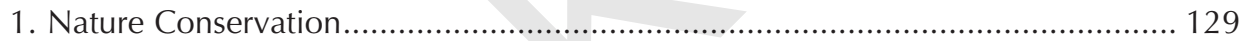

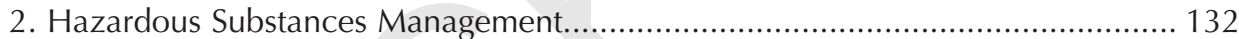

3. Atmospheric Emissions Control ..................................................................... 133

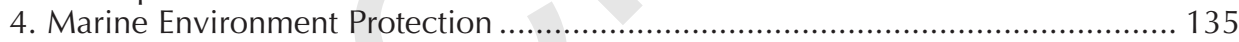

TABLE 4.1: Implementation Cooperation between MEA Secretariats ...................... 136

5. National Efforts Supporting Interlinkages In Compliance ............................... 137 
8 COMPLIANCE MECHANISMS UNDER SELECTED MULTILATERAL ENVIRONMENTAL AGREEMENTS 


\section{Executive Summary}

- his report seeks to perform a comparative analysis of compliance mechanisms under selected multilateral environment agreements (MEAs). Nineteen MEAs were selected on the basis of their being global in scope, widely ratified and representative of treaty arrangements across environmental management sectors. In order to proceed further, it was first necessary to define compliance mechanisms.

Definition of compliance mechanisms is less straight-forward than might be expected as there is no existing authoritative set of definitions. Fine distinctions need to be drawn between implementation and compliance, between international and domestic compliance mechanisms, between performance information and environmental baseline data, between verification and monitoring missions, between primary implementation assistance and non-compliance response assistance, and between penalties and compensation liabilities.

Compliance mechanisms are defined in this report under four headings:

1. A requirement for information reviewing national performance of MEA obligations ('performance review information');

2. Institutionalized multilateral procedures to consider apparent instances of noncompliance ('multilateral non-compliance procedures');

3. Multilateral measures adopted to respond to non-compliance ('non-compliance response measures'); and

4. Dispute settlement procedures.

\section{Comparative Compliance Mechanisms}

The 19 MEAs are analysed to identify their compliance mechanisms and to characterise them according to the four categories above. The comparisons between MEAs and general observations are made within each of those four categories. Almost all MEAs contain national performance review information provision requirements and most contain dispute resolution procedures but only a minority embody non-compliance procedures (Table 3.1).

\section{(a) Performance Review Information}

The most common MEA compliance mechanism and the one on which the majority of international studies and capacity building efforts focus is performance review information. Although scientific and technical data concerning environmental baselines and quality changes can feed into performance review information, it does not in itself assess national responses to international obligations. (Environmental changes may occur despite, or irrespective of, national environmental measures.) Similarly, data concerning 
operational information exchanges can be fed into performance review information, but such exchanges do not in themselves review performance (Figure 1).

Performance review information is gathered primarily through national self-reporting but a few MEAs also provide for supplementary third-party verification or monitoring (Table 3.2). Almost all MEAs require Parties to self-report on their national performance. The majority of those MEAs provide guidelines or templates for this purpose. Just less than a third of those provide for verification of data in national reports or for third-party monitoring of national reporting systems. Among the five MEAs surveyed that regulate international transactions, the two most recent do not require Parties to report the details of regulated transactions, an omission that generates gaps in the available performance information for those treaties.

Potential interlinkages in performance review information gathering arise between MEAs regulating closely related activities. In relation to self-reporting, the interlinkages can be created by harmonization of reporting formats and joint MEA reporting by a Party. For example, where MEAs regulate overlapping sites, species, substances or emissions, there is heightened potential for coordination. This performance review information will be most useful across MEAs when review requires the provision of statistical, transactional or other quantifiable data, rather than qualitative descriptive evaluations. The latter are typically more related to descriptions of policy measures that are customised to particular MEAs and may also be less factually objective.

Research work on harmonization of performance reporting formats across MEAs has been undertaken by international organisations for a decade, particularly by the World Conservation Monitoring Centre concerning biodiversity-related treaties and by the United Nations University. The secretariats of several Rio and biodiversity-related MEAs engage in regular meetings to examine opportunities for coordination.

However, to date, the research effort has focused on the biodiversity-related cluster of MEAs. It has produced proposals for harmonisation that include the development of information system models that would explore synergies during the various steps in the data collection and dissemination process, particularly through modular or consolidated reporting for the biodiversity-related MEAs. Also suggested to enhance performance review information delivery in relation to the biodiversity-related MEAs are: harmonising document cover sheets; adopting standard definitions; harmonising web sites; developing a meta-database to indicate the information that is available and its location; and developing an inter-convention web site and search engine, as well as a lessons-learned network to encourage the sharing of experience.

In relation to monitoring and verification, potential interlinkages exist in carrying out thirdparty monitoring operations and verification missions. Thus, a verification mission might be multi-tasked to assess aspects of compliance common to several MEAs.

\section{(b) Multilateral Procedures to Consider Non-Compliance}

Multilateral non-compliance procedures (NCPs) must be distinguished from traditional dispute resolution procedures, which are invoked only once sufficient damage has been 
done to the legal order for a conflict to arise. The purpose of such NCPs is to identify Parties' compliance difficulties and to facilitate better compliance in a non-adversarial manner.

Most MEAs have established or are in the process of developing a formal NCP (Table 3.3). They occur frequently under MEAs in the hazardous materials and biodiversity sectors and are most common for those concerning the atmospheric commons. In stark contrast, there are none in the marine sector. Although most of NCPs established set up an elected Implementation Committee or Compliance Committee to make recommendations, the final output is a decision by the Conference of the Parties (COP). A suggestion that a Party is non-compliant can usually be brought to the attention of an NCP administering body by the MEA secretariat, by the Party itself experiencing compliance difficulties or by other Parties, or, under a few MEAs, by a third-party body performing a monitoring role.

Potential for interlinkages between NCPs is slight as each is specific to the sensitive balance struck during its negotiation processes. However, closer coordination between MEA secretariats could enhance their capacity to trigger NCPs. Protocols for coordination of performance information between secretariats could enable them to be more effective in triggering their respective NCPs. Such coordination would be likely to be useful across MEAs within a cluster but could also be useful across MEAs that regulate related activities, such as international trade. For example, evidence of corruption of customs authorities indicating a Party's non-compliance concerning its trade-related obligations might implicate that Party in similar non-compliance under more than one MEA.

\section{(c) Non-Compliance Response Measures}

Response measures can be classified into two categories: incentives - technical and financial assistance to support improved implementation; and disincentives - penalties such as stricter requirements for performance review information.

Incentives include enhanced international cooperation with the non-compliant Party in support of implementation, such as the supply of technical or financial assistance. This priority assistance is referred to here as 'non-compliance response assistance' and must be distinguished from implementation assistance. Implementation assistance under an MEA is normally available at earlier stages in the implementation cycle, rather than as a response to non-compliance.

All of the MEAs surveyed in this paper provide some measure of basic implementation assistance to Parties that may need it at those earlier stages, always in the form of technical assistance and usually also as financial assistance (Table 3.4). A minority of the MEAs also specifically set out assistance as a non-compliance response measure. Where they do so, two provide that it is conditional on demonstration of the Party's adopting a national compliance action plan.

Disincentives to continued non-compliance can be imposed in less than a quarter of the MEAs surveyed (Table 3.5). The disincentives include requirements for additional 'noncompliance response information' or the imposition of warnings or penalties. The latter 
comprise additional obligations, suspension of privileges, trade sanctions and liabilities. Trade sanctions occur under only three of the MEAs. Liability to undertake more onerous burdens in meeting the MEA obligations can be imposed under the Kyoto Protocol. Such liability must be distinguished from compensation liability that is determined between Parties bilaterally through an arbitral process, such as a dispute resolution procedure. Only the Basel Convention Liability Protocol defines liability to compensate and this is not truly part of a multilateral NCP in any MEA.

Interlinkages across MEAs of considerations specific to a particular non-compliant Party in selection of response measures during NCP decision-making processes could maximise the effect of non-compliance responses for the non-compliant Party. Thus, the coordination of implementation assistance across MEAs to address recurrent non-compliance caused by a systemic lack of a particular environmental management capacity would be more effective than piecemeal or duplicative implementation assistance. Non-compliance response assistance measures could be easier to coordinate across MEAs than general implementation assistance measures because they are nominated as priorities through NCPs and are fewer in number than general requests for assistance. Similarly, the coordinated imposition of penalties against a serially non-compliant Party would have greater deterrent impact than ad hoc penalties. Coordination would be likely to be useful across MEAs within a cluster but could also be useful across MEAs that regulate common activities, such as international trade in or manufacturing of particular products.

\section{(d) Dispute Settlement}

MEA dispute resolution mechanisms are grouped in three clusters of compulsory procedures: negotiation, conciliation and arbitration. They may be conceived of as varying across a range of sophistication, from simple provisions that require Parties to voluntarily negotiate bilaterally in good faith to compulsory binding third-party dispute resolution procedures.

All but four MEAs have provisions on settling disputes between Parties (Table 3.6). With the exception of the dispute resolution procedures of UNCLOS and the Fish Stocks Agreement, MEA dispute resolutions procedures tend not to include compulsory binding procedures. Instead, they often comprise bilateral negotiation, compulsory conciliation and voluntary arbitration. Compulsory conciliation is invoked following the failure of negotiations, when one Party requests it, but it does not culminate in a binding determination. Disinclination to submit to the binding decisions produced by the dispute resolution procedures of arbitral or judicial tribunals could be the consequence of their adversarial nature and unpredictable and potentially expensive consequences. The trend towards use of multilateral NCPs, as opposed to adversarial dispute settlement procedures, seems to herald a focus on managing political relationships so as maintain the viability and integrity of MEAs.

Potential linkages are feasible in respect of common dispute resolution bodies, particularly within clusters, which could specify within their respective conciliation or arbitration annexes the nomination of standing panels of experts. However, this may rarely be of utility as there appears to be widespread avoidance of resort to third-party dispute resolution. 


\section{Compliance Interlinkages}

The greatest concentration of existing interlinkages between international compliance systems occurs between the biodiversity-related MEAs, other than the UNCCD (Table 4.1). Their compliance system interlinkages concern performance review information. In this connection, as noted above, harmonisation of information requirements is being explored. Interconnectivity between their respective websites and implementation assistance clearing-houses is gradually being introduced.

It is noteworthy that the biodiversity-related MEAs also enjoy the greatest concentration of interlinkages for general implementation. Other areas of concentrated MEA interlinkages concerning general implementation occur within clusters, i.e. the hazardous substances and atmosphere clusters, with the notable exception of the marine cluster. There is also a relatively high level of implementation interlinkage between the biodiversity-related and atmosphere-related clusters, comprising the only significant area of interlinkages that extend across clusters.

The success of interlinkages between MEA compliance mechanisms at the international level relies largely on the effectiveness of interlinkages in implementation across MEAs at the national level. In relation to take-up at the national level, capacity-building to enhance interlinkages in national implementation of MEAs is being delivered by some intergovernmental organisations, such as UNDP, UNEP and WCO. Several international organisations that are partly non-governmental also seek to build implementation capacity. The most significant of these is the International Network for Environmental Compliance and Enforcement (INECE), which has developed a set of environmental compliance and enforcement (ECE) indicators for assessing domestic program performance.

Such capacity building seeks to enhance national systems for domestic implementation of individual MEAs and, to a lesser extent, to build domestic interlinkages between them. However, the UNU has conducted national case studies of institutional coordination in relation to the implementation of MEAs that touch specifically upon interlinkages in domestic implementation. A brief survey of national implementation data suggests that, except for countries in North America and Europe, domestic interlinkages in implementation across MEAs are at very early stages of development and mostly concern the establishment of integrated environmental monitoring databases rather than integration of performance information. 
14

COMPLIANCE MECHANISMS UNDER SELECTED MULTILATERAL ENVIRONMENTAL AGREEMENTS 
Chapter I.

Introduction 
16 COMPLIANCE MECHANISMS UNDER SELECTED MULTILATERAL ENVIRONMENTAL AGREEMENTS 


\section{Introduction}

\section{Objectives}

This report investigates compliance mechanisms under selected multilateral environment agreements (MEAs). It seeks to contribute to UNEP's work on implementation mechanisms for international instruments. It does so specifically by identifying strategic opportunities for interlinkages and synergies in compliance mechanisms among MEAs.

First, the report defines compliance mechanisms and the scope of those covered. Then it analyses the components of compliance mechanisms and compares them, with particular focus upon components involving reporting and verification procedures. Third, law and practice in the implementation of compliance mechanisms is analysed to identify lessons that can be learned. Then conclusions are drawn as to the opportunities to enhance synergies in compliance mechanisms among MEAs. Finally, a draft action plan is recommended.

\section{Background}

The mandate for this investigation has its roots in Chapter 39 of Agenda 21, which called upon United Nations Members States to undertake activities to promote the full and prompt implementation of international agreements (Implementation mechanisms - Activity B Para. 39.7). It suggested that States could:

(a) Establish efficient and practical reporting systems on the effective, full and prompt implementation of international legal instruments; [and]

(b) Consider appropriate ways in which relevant international bodies, such as UNEP, might contribute towards the further development of such mechanisms.

To this end, UNEP has undertaken activities to promote the implementation of MEAs, focusing on strengthening the rule of environmental law. Outcomes of particular note include:

- The Malmo Declaration, Sweden, 29-31 May 2000, which provided that, whilst the evolving framework of international environmental law and the development of national law provide a sound basis for addressing the major environmental threats of the day, they must be underpinned by a more coherent and coordinated approach among international environmental instruments, including in environmental compliance (Para. 3); 
- The Programme for the Development and Periodic Review of Environmental Law for the First Decade of the 21st Century (Montevideo Programme III), that was adopted by Governing Council decision 21/23 to serve as a strategic framework for all UNEP environmental law activities in the present decade. Inter alia, it addresses the role of the judiciary in the context of capacity building for the implementation of environmental law;

- The adoption of Guidelines on Compliance with and Enforcement of Multilateral Environmental Agreements by the Seventh Special Session of the UNEP Governing Council, Cartagena, Colombia 13-15 February 2002;

- The Global Judges Symposium on Sustainable Development and the Role of Law, Johannesburg, 18-20 August 2002, that addressed building the capacity of judges to ensure the implementation of environmental laws. This Symposium was supported by a wide range of preparatory regional judicial symposia. It was followed by the Judges Ad Hoc Meeting for the Development of a Plan of Work as a Follow-Up to the Global Judges Symposium Relating to Capacity Building of Judges, Prosecutors, and Other Legal Stakeholders, Nairobi, 30-31 January 2003, and endorsed in UNEP Governing Council decision 22/17 II A on the Follow-up to the Global Judges Symposium; and

- The Round Table Dialogue on Advancing the Millennium Development Goals through the Rule of Law, held at UNEP Headquarters, Nairobi, on 16-17 February 2005.

Within UNEP, efforts to enhance synergies across MEAs are reflected in its organisational structure.

\section{Methodology}

The essential method adopted in this report is comparative. That is, it compares compliance mechanisms across MEAs.

Initially, data is gathered, analysed and compared. The first step is to select MEAs, analyse each compliance mechanism into its components, categorise them and describe them by categories. ${ }^{1}$ The second step is to compare the components by category across MEAs. This task includes survey of the academic, governmental and inter-governmental literature for

The methodology of categorization of MEAs and their classification under different headers in this study is with the authors and does not necessarily correspond with the categorization and classification of MEAs usually chosen by UNEP 
information concerning the operational qualities of particular MEA compliance mechanisms.

Then qualitative studies are undertaken. This entails the third and fourth steps in the methodology, i.e., case studies of available regional and national law to discern the qualities of State practice in implementing MEA compliance mechanisms and a literature survey of MEA compliance linkages and synergies.

Finally, the comparative data and qualitative information will be synthesised to draw conclusions about the nature and location of opportunities for interlinkages and synergies between MEA compliance mechanisms.

\section{Definitions}

The approach to terminology used here is consistent with the emerging standard usage, as indicated in UNEP's Guidelines on Compliance with and Enforcement of Multilateral Environmental Agreements (UNEP Guidelines).

The term 'compliance' is part of a range of terminology used to describe patterns of conformity with legal norms. It is to be distinguished from related terms, such as 'effectiveness', 'enforcement' and 'implementation'.2

\section{Compliance}

The UNEP Guidelines are divided into two parts: Part I - Guidelines for Enhancing Compliance with Multilateral Environmental Agreements and Part II - Guidelines for National Enforcement, and International Cooperation in Combating Violations of Laws Implementing Multilateral Environmental Agreements. In essence, Part I addresses compliance primarily from an international perspective, concerning the design of MEA regimes, although they also consider national legal regimes to enhance compliance. In contrast, Part II addresses the strengthening of national enforcement capacity. Part I is the more closely related to compliance interlinkages and synergies between MEAs because it focuses on compliance regimes and primarily on the international process. It defines compliance as

'the fulfilment by the contracting Parties of their obligations under a multilateral environmental agreement and any amendments to the multilateral environmental agreement ${ }^{\prime}{ }^{3}$

This is the basic definition of compliance that is applied in this report. However, it should be observed that compliance is not an 'all or nothing' game. The fact that a Party is not

2 Ronald Mitchell 'Compliance Theory: An Overview' in James Cameron, Werksman J. and Roderick, P., Improving Compliance with International Environmental Law (Earthscan London 1996) p. 24.

3 UNEP Guidelines on Compliance with and Enforcement of Multilateral Environment Agreements (Nairobi 2002) Part I, p 2. It should be noted that the UNEP Guidelines Part II define compliance from a domestic perspective as 'the state of conformity with obligations, imposed by a state, its competent authorities and agencies on the regulated community, whether directly or indirectly through conditions and requirements, licences and authorizations, in implementing multilateral environmental agreements.', p. 8 
fully compliant does not mean that it is fully non-compliant. Despite the binary nature of the language used, compliance occurs across a scale of shades of grey. ${ }^{4}$

\section{Compliance Mechanisms}

Compliance mechanisms are the systems adopted under MEAs to promote compliance. The components of compliance mechanisms can be analysed into four categories: (a) performance information; (b) multilateral institutional procedures; (c) non-compliance response measures; and (d) dispute settlement procedures. These are described at greater length in Chapter II.

\section{Effectiveness}

Concern to assess progress towards a variety of goals in international environmental governance has resulted in a multiplicity of meanings for 'effectiveness'. Effectiveness can, for example, relate to such goals as environmental problem solving, economic efficiency and desired changes in political behaviour. ${ }^{5}$ At times, however, effectiveness is confused with compliance. This occurs when what is assessed is progress to congruence with legal norms. For the purposes of this report it is important to distinguish compliance from effectiveness. Thus, the progress that effectiveness is taken to assess in this report is progress towards goals that concern environmental problem solving and changes in political behaviour. Thus, a statement of effectiveness entails measurement of environmental or social change over time generated by the MEA. It requires, first, proof of a causal link from the MEA to the measured change. It also requires an assessment of the relative success of the regime in solving the environmental problem that it was designed to address. The latter evaluation is possible in some cases, where the aims and objectives of the MEA are stated with precision to define quantifiable outcomes and impacts. Nevertheless, the process can be accused of being subjective when the aims and objectives of the MEA are not. ${ }^{6}$

\section{Enforcement}

Part II of the UNEP Guidelines define enforcement as

'the range of procedures and actions employed by a State, its competent authorities and agencies to ensure that organisations or persons, potentially failing to comply with environmental laws or regulations implementing multilateral environmental agreements, can be brought or returned into compliance and/or punished through civil administrative or criminal action'.?

4 Harold K. Jacobsen and Brown Weiss, E.'A Framework for Analysis' in Engaging Countries- Strengthening Compliance with International Environmental Accords (MIT Press 1998), p. 2.

5 Oran Young The Effectiveness of International Environmental Regimes (MIT Press Massachusetts 1998), p 3-6.

6 Ronald Mitchell 'Compliance Theory: An Overview' in James Cameron, Werksman J. and Roderick, P., Improving Compliance with International Environmental Law (Earthscan London 1996), p. 24.

7 UNEP Guidelines on Compliance with and Enforcement of Multilateral Environment Agreements (Nairobi 2002) Part I, p. 9. 
Thus, the meaning of enforcement as set out in the UNEP Guidelines is the ensuring of conformity with national laws that implement MEAs. That is the meaning as applied in this report also.

\section{Implementation}

A State is said to implement an international norm at the domestic level when it adopts appropriate domestic measures for the purpose of meeting its obligations under the international treaty norm. Such measures might include enacting legislation, formulating policies or allocating resources. The UNEP Guidelines Part I define implementation as

'inter alia, all relevant laws, regulations, policies, and other measures and initiatives that contracting Parties take or adopt and/or take to meet their obligations under a multilateral environmental agreement and its amendments, if any' (sic). ${ }^{8}$

The mere fact that an implementation measure is taken does not mean that it is adequate to meet a treaty obligation nor that the State is necessarily compliant with its obligation. Implementation is said to occur in three phases: first, by adopting national legal measures; second, by enforcing them; and third, by reporting on the implementation measures. ${ }^{9}$ The latter, reporting, is an obligation that also forms part of an MEA's compliance mechanism. It is dealt with below in greater detail in the context of compliance mechanisms.

\section{Interlinkages}

Interlinking in the context of separate compliance mechanisms of individual MEAs is the construction of relationships between them. The nature of these relationships will usually take the form of coordination of inputs and outputs, such as compliance information inputs and assistance outputs. To identify coordination opportunities requires an analysis and understanding of the various elements of compliance mechanisms of MEAs. The elements are identified with the objective of generating synergies between them. Thus, identification of opportunities to construct interlinkages is the preliminary conceptual groundwork necessary to achieve synergies.

\section{Monitoring}

Monitoring can refer to scientific and technical monitoring of environmental conditions or to performance monitoring of implementation of MEA obligations. Scientific and technical monitoring is undertaken by bodies that are often independent of but work in cooperation with the MEA Parties and secretariat. However, the type of monitoring that is the focus of this paper is that of national performance in implementing MEA obligations. Performance monitoring may address a Party's establishment of systems to implement the MEA but does not involve review of accuracy of particular data.

8 UNEP Guidelines on Compliance with and Enforcement of Multilateral Environment Agreements (Nairobi 2002) Part I, p 2.

9 Philippe Sands Principles of International Environmental Law ( ${ }^{\text {nd }}$ edn) (Cambridge University Press 2003) p. 174. 


\section{Multilateral Environmental Agreements (MEAs)}

For the purpose of this study, MEAs are treaties that are open to universal participation by States. Often, MEAs articulate objectives in addition to specific obligations. The objectives usually concern an MEA's intended broad effect on the environment or society. They are relevant to a study of the MEA's effectiveness but less relevant to a review of compliance. For the purposes of clarity in a compliance review, it is helpful to refer to obligations individually, i.e. as set out in particular treaty provisions, rather than to compliance with a treaty overall as the latter involves an implicit generalisation. ${ }^{10}$ The methodology for selection of particular MEAs for analysis is set out in Chapter 2.

\section{Synergies}

Synergy is described in the Oxford Dictionary as 'Interaction or cooperation of two or more organisations ... to produce a combined effect that is greater than the sum of their separate effects. ${ }^{\prime 11}$ As applied to the study of compliance mechanisms of MEAs, synergy refers to the production of greater effectiveness and efficiency in effects than the MEA compliance mechanisms can achieve separately. For example, greater effects might be achieved through complementarity and mutual reinforcement. The complementarity and mutual reinforcement are the products of appropriate linkages between the separate compliance mechanisms of MEAs. Thus, synergy is the output of interlinkages between MEAs.

\section{Verification}

Verification is a process undertaken to test the accuracy of data or information provided by a Party to the MEA Secretariat. The process is undertaken by a third Party, such as the Secretariat or an NGO, or by them in combination with other Parties to the treaty.

\section{Scope}

This report studies interlinkages and synergies in major global MEAs. The MEAs that are surveyed here are exclusively global. There are several pragmatic reasons for this approach.

First, conferences of Parties and secretariats to global MEAs address relatively similar compliance regimes, resources and challenges. This creates likely opportunities for interlinkages between various global MEAs at the international institutional level.

Second, there is a high degree of overlap between the Parties to global MEAs. This is simply because they are intended to be universal and often are very widely ratified. Consequently,

10 Ronald Mitchell 'Compliance Theory: An Overview' in James Cameron, Werksman J. and Roderick, P., Improving Compliance with International Environmental Law (Earthscan London 1996), p. 5-6.

11 Concise Oxford Dictionary $10^{\text {th }}$ edn OUP 1999 
there are relatively rich opportunities for interlinkages between various global MEAs at the multilateral and national levels.

Third, the circumstances to which regional environmental treaties apply are more diverse than those for global MEAs. Many of them are unconnected with UNEP. The conferences of Parties and secretariats that serve regional environmental treaties sometimes serve several treaties for the same region and, therefore, share very similar compliance regimes, resources and challenges. Parties to regional environmental treaties are typically also Parties to other environmental treaties for the same region. This suggests that there are very likely to be potential interlinkages between environmental treaties for a particular region and that these can be conveniently examined as distinct regional groups.

Interlinkages between regional environmental treaties and global MEAs addressing similar subjects certainly do exist. As a separate further exercise, the opportunities for interlinkages between subject-related global, regional and bilateral MEAs deserve examination. However, that task can be distinguished from the examination of interlinkages between global MEAs. Due to the number and diversity of bilateral and regional MEAs (there are many more regional environmental treaties than global MEAs), they are beyond the practical resources available for the current exercise.

Compliance mechanisms are the subject of this report. Although compliance mechanisms seek to achieve national implementation and enforcement of MEAs, so as to promote the international effectiveness of MEAs, implementation enforcement and effectiveness issues are not the subjects of examination here. 'Compliance', 'Enforcement' and 'Effectiveness' are defined and distinguished in the 'Definitions' section above. 
24

COMPLIANCE MECHANISMS UNDER SELECTED MULTILATERAL ENVIRONMENTAL AGREEMENTS 


\section{Chapter II. Compliance mechanisms of major global MEAs}


26

COMPLIANCE MECHANISMS UNDER SELECTED MULTILATERAL ENVIRONMENTAL AGREEMENTS 


\section{Compliance mechanisms of major global MEAs}

This chapter first selects MEAs, in order to analyse each compliance mechanism into its components, categorise them and describe them. It gathers and analyses data for each MEA. The data is compared across MEAs in Chapter III.

\section{Major Global MEAs}

The nineteen global MEAs that are examined here are those that are considered 'major'. They are so considered because they have entered into force and have a large number of Parties.

The MEAs are organised for examination into groups that cover common, overlapping or related subjected matter. For example, those with objectives that concern primarily an aspect of nature conservation are clustered together. This approach might be contested because all aspects of the natural environment are inter-related. Further, it might be suggested that interlinkages and synergies between MEAs could be strongly determined by factors other than their environmental subject matter. For example, factors such as common servicing by the same United Nations organisation might be a sensible basis for categorisation. Nevertheless, there is a tendency for MEAs with similar subject matters to be serviced by the same United Nations body. For example, UNEP services most of the hazardous substances conventions (concerning waste, persistent organic pollutants and aspects of genetically modified organisms, although regulated chemicals are administered jointly with FAO). Ultimately, however, this report also undertakes a comparative analysis of the MEAs across clusters. Therefore, the issue of clustering of MEAs according to primary subject matter is not of central importance as it does not predicate the outcome of the comparative analysis.

This chapter examines compliance mechanisms within four clusters of MEAs: (1) nature conservation; (2) hazardous substances management; (3) atmospheric emissions controls; and (4) marine environment protection. The major global MEAs that have been selected for analysis in the four clusters are set out as follows:

\section{Nature Conservation}

- Wetlands - Convention on Wetlands of International Importance especially as Waterfowl Habitat 1971

- Heritage - Convention for the Protection of World Cultural and Natural Heritage 1972

- Endangered species - Convention on International Trade in Endangered Species of Wild Fauna and Flora 1973 
- Migratory species - Convention on the Conservation of Migratory Species of Wild Animals 1979

- Biological diversity - Convention on Biological Diversity 1992

- Deserts - United Nations Convention to Combat Desertification in those Countries Experiencing Serious Drought and/or Desertification, particularly in Africa 1994

- Plant genetic resources - International Treaty on Plant Genetic Resources for Food and Agriculture 2001

\section{Hazardous Materials}

- Hazardous wastes - Basel Convention on the Control of Transboundary Movements of Hazardous Wastes and their Disposal 1989

- Dangerous chemicals - Rotterdam Convention on the Prior Informed Consent Procedure for Certain Hazardous Chemicals and Pesticides in International Trade 1998

- Biosafety - Cartagena Protocol on Biosafety to the Convention on Biological Diversity of 5 June 1992, 2000

- Persistent organic pollutants - Stockholm Convention on Persistent Organic Pollutants 2001

\section{Atmospheric Emissions}

- Ozone layer - Vienna Convention for the Protection of the Ozone Layer 1985

- Ozone depleting substances - Montreal Protocol on Substances that Deplete the Ozone Layer 1987

- Climate change - United Nations Framework Convention on Climate Change 1992

- Greenhouse gas emissions reductions - Kyoto Protocol to the United Nations Framework Convention on Climate Change 1997

\section{Marine Environment}

- Whaling - International Convention for the Regulation of Whaling 1946

- Sea dumping - Convention on the Prevention of Marine Pollution by Dumping of Wastes and Other Matter 1972

- UNCLOS - United Nations Convention on the Law of the Sea 1982

- Fish Stocks - Agreement for the Implementation of the Provisions of the United Nations Convention on the Law of the Sea of 10 December 1982 relating to the 


\section{Identifying Components of Compliance Mechanisms of MEAs}

To compare particular compliance mechanisms across MEAs, it is necessary to first identify the details of what it is that we wish to compare. Therefore, each compliance mechanism is analysed into its detailed components, which are described and categorised.

The components of the compliance mechanisms within each MEA are categorised under four headings:

(a) Performance review information - requirements for information reviewing national performance of MEA obligations;

(b) Multilateral non-compliance procedures - institutionalised multilateral procedures to consider apparent instances of non-compliance;

(c) Non-compliance response measures - multilateral measures adopted to respond to non-compliance; and

(d) Dispute resolution - dispute settlement procedures.

\section{(a) Performance Review Information}

Many MEAs require their Parties to exchange information as part of their primary operational obligations. For example, they might be required to provide information on proposed environmentally sensitive trade transactions or industrial developments, on ambient environmental conditions or on environmental technologies. This operational information is to be distinguished from MEA requirements for performance review information.

In relation to their performance, Parties are often required to report on the measures they have taken to implement a particular MEA, usually by submitting annual reports on their relevant laws or policies. Some MEAs provide for a third Party, such as a Secretariat, to monitor or verify the performance and require the Parties to cooperate with such monitoring or verification of their performance. Often, operational and performance information are inter-related, as data from operational information exchanges are fed into performance review.

A related form of performance review is regime review, which concerns review of the regime's performance overall, rather than individual Party performance. For example, statistical data processed from sources including the Parties' operational information exchanges and their performance information can help the Secretariat and the COP to assess whether targets have been met and to identify future priorities. 
Collection of performance review information is necessary to determine a Party's compliance situation. Therefore, in examining compliance, this report focuses on performance review information.

\section{Figure 1: Information Cycle}

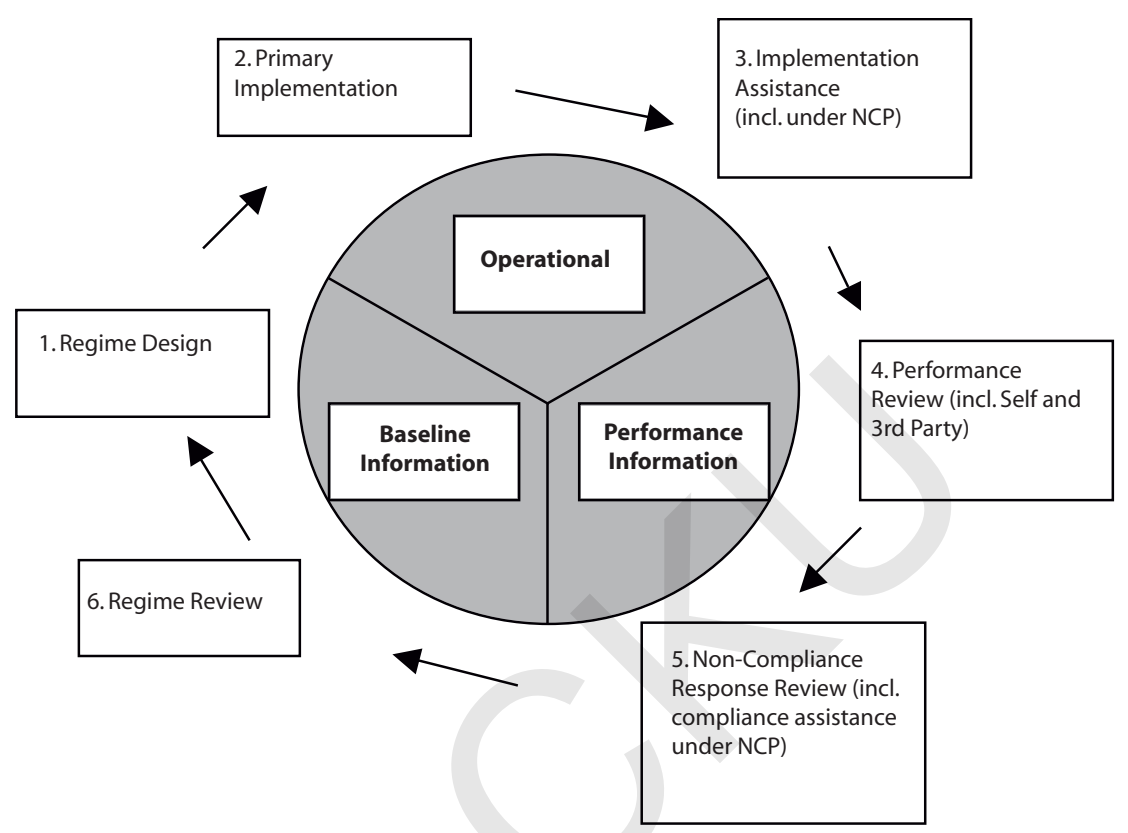




\section{(b) Multilateral Non-Compliance Procedures}

Most MEAs provide for the development of a formal, multilateral NCP. When developed, this usually comes in the form of an elected committee, called an Implementation Committee or Compliance Committee. A Party's alleged non-compliance may be referred to the Committee for consideration (or it may, itself, refer its own inability to comply) and the Committee then makes a recommendation on the matter to the COP. Usually, the final output is a decision by the COP. The purpose of such procedures is to identify compliance difficulties and to facilitate better compliance in a non-adversarial manner. Normally, reference can be made to the Committee once non-compliance is already an issue, or to prevent such non-compliance arising. In that respect, multilateral NCPs may be distinguished from traditional dispute resolution procedures, which are usually invoked only once sufficient damage has been done to the legal order for a conflict to arise.

Despite the simple dichotomy in the notions of compliance and non-compliance, performance information will usually indicate a degree of compliance rather than perfect compliance or absolute non-compliance. A Party may be compliant to a degree, across a measure of shades of grey. The degree of compliance may in circumstances be so poor that the Party can be determined to be substantially non-compliant. Substantial failures to submit national performance information can conceal national non-performance of primary operational obligations and, therefore, is often treated as a failure to meet a primary operational obligation.

\section{(c) Non-Compliance Response Measures}

When an instance of substantial non-compliance is identified under a non-compliance procedure, a response is necessary at the multilateral level. The response needs to be tailored to the particular circumstances of the case. Non-compliance usually stems from lack of human, material and financial resources and/or lack of political will. ${ }^{12}$ The response measures available can be classified into two categories: incentives - technical and financial assistance to support improved implementation; and disincentives - penalties such stricter requirements for performance review information. These are sometimes referred to as 'carrots and sticks'.

(i) Incentives are the usual response and include enhanced international cooperation with the non-compliant Party in support of implementation, such as the supply of technical or financial assistance. Thus, a COP might direct priority financial and technical assistance to a non-compliant Party. This assistance may be subject to conditions such as the adoption of a national program of implementation actions. This priority or conditional assistance is referred to here as 'non-compliance response assistance' and must be distinguished from regular cooperative assistance under the MEA.

12 Montini, M, Improving Compliance with Multilateral Environmental Agreements through Positive Measures: The Case of the Kyoto Protocol on Climate Change' in Kiss, A, Shelton, D and Ishibashi, K (eds.), Economic Globalization and Compliance with International Environmental Agreements (Kluwer Law International, The Hague, 2003), p.159. 
Technical assistance includes: capacity-building mechanisms in the form of training and workshops, which address issues relating to lack of human resources and know-how; technology transfers and exchange of information mechanisms to address issues relating to the lack of materials; and financial provisions to address resource issues. ${ }^{13}$ (It is noteworthy that information exchange obligations arise also in the context of technical assistance.) Financial assistance often comes in the form of a Trust Fund or a financial mechanism from which the Parties provide funding for relevant projects. One of the most important financial mechanisms is the Global Environment Facility (GEF), which was established in 1991 and provides funding to projects falling within the categories of biological diversity, climate change, international waters, ozone layer depletion, land degradation and persistant organic pollutants $(\mathrm{POPs})^{14}$. When invoked under a NCP, technical and financial assistance might be made conditional on demonstration of the Party's demonstration of bona fides in redressing the non-compliance failure, such as by adopting domestic legislation or a national action plan.

(ii) In some cases, disincentives to continued non-compliance can be imposed. For example, a COP might impose additional, stringent and customised performance review information obligations on a non-compliant Party and direct that the information provided be subject to verification. The additional required information can be termed 'non-compliance response information'. These additional reporting requirements must be distinguished from their regular performance review information counterparts.

Other disincentives to non-compliance are warnings and penalties. The latter may include additional obligations or suspension of privileges. For example, a non-compliant Party might be warned that its rights under the MEA regime could be suspended. The suspension of rights may involve the imposition of limited trade sanctions, as can occur under the Montreal Protocol on Substances that Deplete the Ozone Layer and the Kyoto Protocol to the United Nations Framework Climate Change Convention. Penalties imposed through the multilateral process of the NCP can be distinguished from compensation liabilities. The latter can be imposed under the terms of the MEA or a protocol but often needs to be determined between Parties bilaterally through an arbitral process or other form of dispute resolution procedure.

Thus, responses to non-compliance vary, from requiring additional reports (non-compliance response information as distinguished from regular performance review information), to recommending conditional assistance measures (non-compliance response assistance,

13 Ibid p.163.

14 Ibid. 
as distinguished from regular implementation support assistance), to imposition of liabilities and the suspension of a Party's rights under the convention.

\section{(d) Dispute Resolution}

MEA mechanisms to settle disputes can be grouped in three clusters of procedures: Negotiation, Conciliation and Arbitration.

Negotiation In the event of a dispute, Parties must submit to negotiation. Thus, there is no obligation to pursue binding arbitration.

Conciliation Generally, these provisions provide that Parties must submit to negotiation or other peaceful means as the first port of call. If the dispute is not resolved within a specified period of time (usually 12 months), Parties must then submit to conciliation in accordance with a procedure that is either annexed to the Convention or to a COP resolution. The conciliation procedure is not automatically triggered. Thus, once the requisite period has lapsed, one of the Parties must request it. However, Parties can bypass the conciliation procedure in favour of arbitration before the International Court of Justice or in accordance with an arbitration procedure, which, again, is either annexed to the Convention or to a COP resolution. The arbitration process is not compulsory and can only be invoked where both Parties have notified the Secretariat that they accept this means of dispute resolution.

Arbitration Unlike conciliation, arbitration is binding. In marked contrast to the weak dispute resolution procedures described above, which avoid imposing compulsory, binding arbitration on Parties, UNCLOS sits in a category of its own. It has compulsory, binding arbitration for specific disputes (i.e. disputes concerning the sea-bed). Generally, however, the arbitration procedure is invoked if the dispute has not been resolved through negotiation. Conciliation is an option where negotiations fail, but is invoked only if one Party requests it and the other accepts the invitation. Otherwise, Parties have the right to invoke to compulsory arbitration procedures and the forum in which the proceedings are to take place. 


\section{Ramsar Convention on Wetlands of International Importance especially as Waterfowl Habitat 1971}

\section{Overview}

The Ramsar Convention on Wetlands of International Importance especially as Waterfowl Habitat (the Ramsar Convention) entered into force on 21 December 1975. It provides that Parties must designate at least one wetland to be included in the 'List of Wetlands of International Importance', which should be selected according to its international significance in terms of ecology, botany, zoology, limnology or hydrology. ${ }^{15}$ Parties have a duty to promote the conservation of listed wetlands. ${ }^{16}$ However, Parties are also obliged to promote the conservation of wetlands and waterfowl by establishing nature reserves on wetlands regardless of whether those wetlands are included on 'The Ramsar List' or not. ${ }^{17}$

\section{Compliance mechanisms}

\section{(a) Performance Review Information}

National Reports on the implementation of the Convention were presented at COP 1 (1980) at the invitation of the Bureau. COP 2 (1984) recommended that all Parties submit reports to the Bureau six months before each ordinary COP. ${ }^{18}$ The Ramsar Bureau also conducts on-site monitoring to review implementation. ${ }^{19}$

Performance review information is supplemented by the wetlands inventory program. In Resolution VII.20, the Parties recognised the importance of developing a national inventory of wetlands. ${ }^{20}$ The resolution urged Parties to give the highest priority to the task of completing a comprehensive wetland inventory. The Framework for Wetland Inventory was developed in response to Resolution VII.20 to provide guidance on developing a wetland inventory program and in conducting associated identification, monitoring and implementation activities.

\footnotetext{
15 World Heritage Convention, Article 2.

16 World Heritage Convention, Article 3.

17 World Heritage Convention, Article 4.

18 Ramsar Recommendations 2.1 and 4.3.

19 Vol. 11(2) Review of European Community and International Environmental Law, 2002, p.183.

20 Ramsar Website, <http://www.ramsar.org/key guide inventory e.htm > (7/10/05).
} 


\section{(b) Multilateral Non-Compliance Procedures}

The Montreux Record was established at COP 4 (1990) and formalised at COP 5 (1993). ${ }^{21}$ The Record focuses attention on threatened Ramsar sites listed on the 'Record of Ramsar sites where changes in ecological character have occurred, are occurring or are likely to occur'.$^{22}$ It is coupled with a Monitoring Procedure that allows the Bureau23 ${ }^{23}$ to consult with a Party when it comes to the Bureau's attention that a Ramsar-listed site within that Party's jurisdiction is likely to be degraded due to anthropogenic interference. The Bureau can invite the Party concerned to submit additional reports, monitor the site, negotiate a solution and it may bring the matter to the attention of the Standing Committee, which can bring the issue to the COP. ${ }^{24}$ Technical assistance may also be provided.

\section{(c) Non-Compliance Response Mechanisms}

The provisions of the Ramsar Convention related to support for implementation can be applied by the Standing Committee to address non-compliance.

Technical Assistance Parties must encourage research and the exchange of information and promote training regarding wetlands. ${ }^{25}$ The Convention also stipulates that Parties must consult with other Parties about the implementation of the Convention, especially with regard to transfrontier wetlands, shared water systems, shared species and development projects affecting wetlands. ${ }^{26}$

Guidelines have been produced for the implementation of the wise use of wetlands, ${ }^{27}$ for developing and implementing National Wetland Policies, ${ }^{28}$ reviewing laws and institutions to promote the conservation and wise use of wetlands ${ }^{29}$ and for international cooperation. $^{30}$

At COP-7 the Bureau was directed to establish a clearinghouse and liaise with other international organisations for information exchange on indigenous knowledge systems and participatory approaches. ${ }^{31}$

Financial Assistance The Ramsar Convention was adopted before implementation assistance funds became widespread features in international multilateral environmental agreements. The COP adopts a core budget administered by the Ramsar Bureau. ${ }^{32}$ Contributions to the budget come from the Parties, who contribute in proportion to their usual percentage contribution to the UN budget, although there is also cooperation with funding institu-

21 Ramsar Resolution 5.4 and Recommendation 4.8.

22 Annex 1 to Recommendation 4.7.

23 The Bureau is now named "The Secretariat"

24 Ramsar Recommendation 4.7.

25 Ramsar, Article 4.

26 Ramsar, Article 5.

27 Ramsar Recommendations 3.3 and 4.10 and Resolutions 5.6 and 5.7.

28 Ramsar Resolution 7.6.

29 Ramsar Resolution 7.7.

30 Ramsar Resolution 7.19.

31 Ramsar Resolution 7.8.

32 Ramsar Website, <http://www.ramsar.org/brochure-e.htm> (8/9/05). 
tions such as the World Bank and the GEF. A Ramsar Small Grants Fund was established in 1990. Funds come partly from the Convention's core budget, but largely from donations by Parties and others. It is administered by the Bureau under the supervision of the Standing Committee, pursuant to the Terms of Reference for the Financial Administration of the Convention, for activities to implement wetland conservation and wise use projects. ${ }^{33}$ Developing countries can apply for assistance by official request from a competent national authority.

\section{(d) Dispute Resolution}

COP-1 (1980) identified the need for a dispute resolution procedure. ${ }^{34}$ A Task Force was established to consider this and other proposed amendments. However, the dispute resolution amendment was eventually abandoned. ${ }^{35}$

33 Ramsar Resolution 4.3.

34 Ramsar Recommendation 1.8.

35 Ramsar Website, <http://www.ramsar.org/lib/lib legal e.htm> (8/9/05). 


\section{Convention Concerning the Protection of the World Cultural and Natural Heritage 1972}

\section{Overview}

The Convention Concerning the Protection of the World Cultural and Natural Heritage (World Heritage Convention) entered into force on 17 December 1975. The World Heritage Convention defines world heritage in two categories: first, cultural heritage, which are monuments, buildings and sites of outstanding universal value in terms of history, art, aesthetics, science or ethnology; ${ }^{36}$ and natural heritage, being natural features, geological formations, threatened species habitats and sites of outstanding universal value from an aesthetic, scientific or conservation point of view. ${ }^{37}$ The World Heritage Convention leaves it for each Party to identify World Heritage properties within its territory. ${ }^{38}$ However, it also places a general duty on each Party to actively identify and to protect such properties. ${ }^{39}$

\section{Compliance mechanisms}

\section{(a) Performance Review Information}

Each Party must submit a periodic report every six years on the implementation of the World Heritage Convention. ${ }^{40}$ Annex 7 to the Operational Guidelines outlines the formatting requirements and the explanatory notes.

Operational Guideline 169 provides for a reactive monitoring system whereby Parties must submit a report to the World Heritage Committee each time exceptional circumstances occur or work is undertaken which may have an effect on the state of conservation of the property. Reactive monitoring is also required in respect of properties inscribed or about to be inscribed onto the List of World Heritage in Danger. Where a property is being considered for inscription onto the List of World Heritage in Danger, the Committee must develop a programme of corrective measures. In doing so, the Committee may send thirdparty observers to evaluate the threats to the property. ${ }^{41}$

The reactive monitoring procedures does make provision for information that may be received from third-party sources, although the secretariat will verify the source and the content of the information with the Party concerned and request its comments. ${ }^{42}$ Under

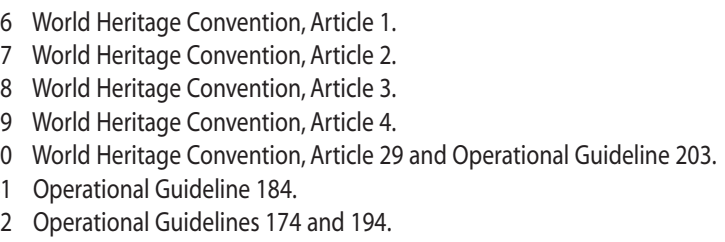


Operational Guideline 171, the Committee requests that Parties cooperate with any Advisory Bodies which the Committee may have requested to carry out monitoring and reporting on its behalf on the progress of work undertaken to preserve properties in the World Heritage List.

\section{(b) Multilateral Non-Compliance Procedures}

There are no non-compliance procedures established by the Convention or the COP.

\section{(c) Non-Compliance Response Mechanisms}

Despite the absence of any formal NCP, the World Heritage Convention does have modest measures in place to assist Parties in their implementation. These measures can be usefully addressed to instances of likely non-compliance.

Technical Assistance The Convention establishes a process for making requests for international assistance to protect listed properties. ${ }^{43}$ Assistance may involve: studies concerning the artistic, scientific and technical problems raised by the protection; conservation, presentation and rehabilitation of the cultural and natural heritage; technical assistance; training; supplying equipment; low-interest or interest-free loans; and the granting of nonrepayable subsidies. ${ }^{44}$

Operational Guideline 212 provides that the World Heritage Committee is to seek to develop capacity-building opportunities among the Parties to the Convention. One such capacity-building initiative is the Global Training Strategy, which is linked to the Global Strategy for a Representative, Balanced and Credible World Heritage List and Periodic Reporting. ${ }^{45}$ There are also provisions for cooperation in awareness raising and education. ${ }^{46}$

Financial Assistance The World Heritage Fund for the Protection of World Cultural and Natural Heritage of Outstanding Universal Value was established under Article 15 of the Convention. It is a Trust Fund maintained through compulsory and voluntary contributions by Parties, as well as donations to provide assistance to Parties. Funding is available for world heritage identification and protection, emergency assistance, and for educational, information and promotional activities. ${ }^{47}$ Parties contribute a set amount every two years. ${ }^{48}$ Where the reactive monitoring procedures have been invoked, the World Heritage Committee may authorise the provision of emergency funding from the World Heritage Fund as well as technical assistance in order to prevent the deletion of any property from the World Heritage List. $^{49}$

43 World Heritage Convention, Articles 19-22.

44 World Heritage Convention, Article 22.

45 Operational Guideline 213.

46 Operational Guidelines 217-222.

47 Operational Guideline 235.

48 World Heritage Convention, Article 16.

49 Operational Guidelines 170, 176, 183 and 189. 
In addition, the World Heritage Committee has established a Reserve Fund to meet requests for assistance resulting from natural disasters and emergencies. ${ }^{50}$ Funds in trust are another source of funding; these are donations by specific countries to support specific projects. ${ }^{51}$

Penalties Failure to provide the compulsory contribution for the current year or the preceding year excludes the non-compliant Party from membership of the World Heritage Committee. $^{52}$

\section{(d) Dispute Resolution}

There are no dispute resolution mechanisms in the Convention.

50 UNESCO Financial Regulations, reg. 5.1.

51 http://whc.unesco.org/pg.cfm?cid=150 (7/10/05).

52 World Heritage Convention, Article 16.5. 


\section{Convention on International Trade in Endangered Species of Wild Flora and Fauna 1973 (CITES)}

\section{Overview}

The Convention on International Trade in Endangered Species of Wild Flora and Fauna (CITES) entered into force on 1 July 1975. It establishes a permit system to control imports and exports of wild fauna and flora. CITES lists controlled flora and fauna in three appendices. ${ }^{53}$ Appendix I covers all species threatened with extinction that are or may be affected by trade. Commercial trade in these species is essentially banned and can only be authorised in exceptional circumstances. Appendix II covers species which are not currently threatened with extinction but which may become so unless trade in such specimens is controlled under the Convention. Appendix III covers species that any Party has identified as being subject to national regulation for the purpose of preventing or restricting exploitation and as requiring the cooperation of other Parties to control trade. Parties are required to establish national Scientific Authorities, to advise on the endangered status of native species of flora and fauna, and a Management Authority to regulate their trade. ${ }^{54}$

\section{Compliance mechanisms}

\section{(a) Performance Review Information}

Pursuant to Article VI.6, each Party must maintain records of trade in species listed in Appendices I, II and III, which cover: the names and addresses of exporters and importers; the number and type of permits and certificates granted; the States with which such trade occurs; the numbers or quantities and types of specimens; names of species as included in Appendices I, II and III; and, where applicable, the size and sex of the specimens in question.

In addition, Parties must prepare:

- Periodic reports on their implementation of the Convention;

- Annual reports containing a summary of the information specified in Article VIII, which must be transmitted to the Secretariat; and

- Biennial reports on legislative, regulatory and administrative measures taken to enforce the provisions of the Convention. ${ }^{55}$ 
Annual reports must be submitted by 31 October for the previous trade year, although extensions are available on written request. ${ }^{56}$ The requirement for biennial reporting has been largely unimplemented, although at COP-11 (2000) Parties were called upon to comply. ${ }^{57}$

Resolution 11.17 consolidates all reporting resolutions and decisions. Guidelines on reporting were introduced in 1982 following Resolution 3.10, which have recently been revised and updated..$^{58}$ Decision 13.90 directs the Secretariat to identify ways to reduce the reporting burden on Parties and report at COP-14 on the results of this work.

The Scientific Authority of each Party has obligations to monitor the export permits granted by the State for Appendix II specimens and the actual exports of such specimens. ${ }^{59}$ Additionally, the Parties, NGOs such as the TRAFFIC Network and international bodies such as the World Customs Organisation and Interpol, perform monitoring functions and report infractions to the Secretariat. ${ }^{60}$ TRAFFIC is an international wildlife trade monitoring network that was founded in 1976 as a joint programme between the WWF and IUCN-The World Conservation Union. ${ }^{61}$ It works cooperatively with the CITES Secretariat in implementing the Convention, its mission being to ensure that wildlife trade does not threaten nature conservation. ${ }^{62}$ The Secretariat also conducts ad hoc verification missions to assess a Party's compliance with the Convention. ${ }^{63}$

\section{(b) Multilateral Non-Compliance Procedure}

Under Article VXIII, if the Secretariat is satisfied that any species in Appendices I or II is being adversely affected or that the Convention is not being effectively implemented it will communicate this issue to the relevant Party's Management Authority. The Party must propose remedial action.

COP-11 (2000) adopted a formal NCP, which can be invoked where Parties fail to meet their reporting requirements and potentially, their financial obligations under the Trust Fund. ${ }^{64}$ Resolution 11.3 states that if a major implementation problem is brought to the Secretariat's attention, the Secretariat and the non-compliant Party are to work together to resolve the problem. The Secretariat is to offer advice on technical assistance as required. If a solution cannot be readily achieved, the Secretariat must bring the matter to the attention

56 CITES Resolution 11.17.

57 CITES Doc. 7.19,'Report on National Reports under Article III, Paragraph 7, of the Convention', prepared by the Secretariat for COP-7; CITES Decision 11.38 (ex-9.20); Reeves, R, Policing International Trade in Endangered Species: the CITES Treaty and Compliance, Earthscan Publications, London, 2002, p.67.

58 See SC45 Doc 13.2 'Guidelines for the Preparation of Annual Reports'; Reeves, R, Policing International Trade in Endangered Species: the CITES Treaty and Compliance, Earthscan Publications, London, 2002, p.63.

59 CITES, Article IV.3.

60 Reeves, R, Policing International Trade in Endangered Species: the CITES Treaty and Compliance, Earthscan Publications, London, 2002, p.69.

61 http://www.traffic.org/about/what is.html (3/11/05).

62 http://www.traffic.org/about/ and http://www.traffic.org/about/what is.html (3/11/05).

63 Reeves, R, Policing International Trade in Endangered Species: the CITES Treaty and Compliance, Earthscan Publications, London, 2002, p.75.

64 At the Standing Committee's 46 ${ }^{\text {th }}$ meeting, the Secretariat considered that Article XI.3 (a) and Resolution 11.2 can form the basis of formal action for dealing with fiscally non-compliant Parties: Reeves, R, Policing International Trade in Endangered Species: the CITES Treaty and Compliance, Earthscan Publications, London, 2002, p.155. 
of the Standing Committee, which may pursue the matter directly with the non-compliant Party to find a solution. The Secretariat must keep all Parties informed of such implementation problems and any actions taken to resolve them. Resolution 11.17 provides that a failure to submit a report by 31 October for trade in the previous year constitutes a major problem, which the Secretariat must refer to the Standing Committee for solution in accordance with Resolution 11.3.

The COP employs non-compliance responses, which include: requiring the Secretariat to issue security paper (i.e. watermarked and of identifiable authenticity) for permits and certificates to reduce instances of forgery and to confirm permits for a period of time; issuing formal warnings; the Secretariat suspending cooperation with the non-compliant Party; the Secretariat conducting on-site verifications; the Standing Committee recommending suspension of trade in CITES-listed species with the non-compliant Party and specifying the conditions to be met before the trade restrictions can be lifted. ${ }^{65}$

\section{(c) Non-Compliance Response Mechanisms}

At the Standing Committee's $46^{\text {th }}$ meeting, the Secretariat presented the Committee with a range of possible responses for non-compliance, some of which are already in use, in an attempt to revise Resolution 11.3. The range included: providing advice; informal warnings; additional self-reporting; public notification of non-compliance; on-site verification; action plans; suspending legal rights and privileges (i.e. suspension of trade in one or all CITES specimens, voting restrictions, ineligibility of Standing Committee membership and of participation in committees and working groups and ineligibility to receive documents for meetings); and financial penalties. ${ }^{66}$ However, the Committee declined to revise Resolution 11.3 and instead, directed the Secretariat to prepare a discussion paper for COP-12 (2002). ${ }^{67}$ An open-ended intersessional working group was established at the $50^{\text {th }}$ meeting of the Standing Committee to finalise a set of guidelines for complying with the Convention, however these have not been completed. ${ }^{68}$

Technical Assistance Resolution 3.4 encourages Parties to include technical assistance in bilateral and multilateral aid programmes. In addition, Parties receive assistance with the identification of CITES species pursuant to Article XII.2(f), which states that the Secretariat must periodically publish and distribute to Parties current editions of Appendices I, II and III together with any information that would facilitate the identification of specimens included in those Appendices. In response, the Secretariat and a Committee of Experts have developed an Identification Manual. ${ }^{69}$

Capacity-building workshops are conducted for Management Authority staff and enforcement officers while legal officers are trained under the National Legislation Project. The

65 Reeves, R, Policing International Trade in Endangered Species: the CITES Treaty and Compliance, Earthscan Publications, London, 2002, p.93.

66 CITES SC46 Doc.11.3,'Possible measures for Non-compliance', CITES Secretariat (March 2002); Reeves, R, Policing International Trade in Endangered Species: the CITES Treaty and Compliance, Earthscan Publications, London, 2002, p.157.

67 CITES COP 12, Doc.8,'Report of the Chairman', para.40.

68 UNCCD COP 7, Items 13(b) and (c) of the provisional agenda, Executive Summary, paras 18-20.

69 Reeves, R, Policing International Trade in Endangered Species: the CITES Treaty and Compliance, Earthscan Publications, London, 2002, p.238. 
latter aims to help Parties draft appropriate laws and policies for the implementation of the Convention. ${ }^{70}$

Financial Assistance CITES has no funding mechanism to facilitate compliance. Initially, the Secretariat was funded by UNEP. However, the 1979 Bonn amendment to Article $\mathrm{XI}$, which entered into force on 13 April 1987, conferred financial powers to the COP, and funding from UNEP was gradually phased out. A Trust Fund was established with an agreed scale of contributions to finance, inter alia, technical assistance to the Parties. At COP-12 (2002) the Parties adopted procedures and guidelines for the approval of externally funded projects. ${ }^{71}$

Penalties The failure to nominate a Scientific Authority in accordance with Article IX of the Convention was dealt with by Resolution 10.3. It called upon Parties to refuse export permits from Parties that have not given the Secretariat details of a Scientific Authority for more than one interval between regular meetings of COP. At the same time, it encouraged technical assistance to Scientific Authorities with a view to facilitating compliance.

\section{(d) Dispute Resolution}

Where there is a dispute over the interpretation or application of the provisions of the Convention, Parties can opt for negotiation. They can proceed onto arbitration with the Permanent Court of Arbitration, provided there is mutual consent. ${ }^{72}$

\footnotetext{
70 CITES Resolution 8.4.

71 CITES Resolution 12.2.

72 CITES, Article XVIII.
} 


\section{Convention on the Conservation of Migratory Species of Wild Animals 1979}

\section{Overview}

The Convention on the Conservation of Migratory Species of Wild Animals (CMS) entered into force on 1 November 1983. It aims to conserve and manage migratory species of wild animals through the action of Range States, i.e. those States exercising jurisdiction within the range of any such species. Under Article II, Parties are encouraged to promote, cooperate in and support research relating to migratory species and to provide immediate protection to the endangered migratory species listed in Appendix I. Parties are also encouraged to conclude agreements with other Range States for the conservation and management has been developed under the auspies of the Convention on the conservation of Migratory Species of Wild Animals (CMS) having unfavourable conservation status listed in Appendix II. ${ }^{73}$ One of the Secretariat's functions is to promote, under the Conference of the Parties, the conclusion of Agreements (Art.IX.4 (g)). The Scientific Council may recommend the Conference of the Parties (i) conservation and management measures to be included in Agreements (Article VIII.5(d) of the convention); and (ii) scientific solutions to problems relating to migratory species habitats (Art. VIII.5 (e)).

73 CMS Articles IV \& V.1.These Agreements and Memoranda of Understanding include:

- $\quad$ Agreement on the Conservation of Seals in the Wadden Sea 1990 (between Denmark, Germany and The Netherlands);

- $\quad$ Agreement on the Conservation of Populations of European Bats 1991;

- $\quad$ Agreement on the Conservation of Small Cetaceans of the Baltic and North Seas 1991;

- $\quad$ Agreement on the Conservation of African-Eurasian Migratory Waterbirds 1995

- Agreement on the Conservation of Cetaceans of the Black Sea, Mediterranean Sea and Contiguous Atlantic Area 1996;

- $\quad$ Agreement on the Conservation of Allbatrosses and Petrels 2001

- $\quad$ Memorandum of Understanding concerning Conservation Measures for the Siberian Crane 1993;

- Memorandum of Understanding on Conservation Measures for the Slender-billed Curlew 1994;

- Memorandum of Understanding concerning Conservation Measures for Marine Turtles of the Atlantic Coast of Africa 1999;

- Memorandum of Understanding on the Conservation and Management of the Middle-European Population of the Great Bustard 2001;

- Memorandum of Understanding on the Conservation and Management of Marine Turtles and their Habitats of the Indian Ocean and South-East Asia 2001;

- Memorandum of Understanding concerning Conservation and Restoration of Bukhara Deer 2002

- Memorandum of Understanding concerning Conservation Measures for the Aquatic Warbler 2003;

- Memorandum of Understanding on the Conservation and Management of the West African populations of the African Elephant (signed at CoP8, Nairobi, 22 November 2005);

- Memorandum of Understanding on the Conservation and Management of the Saiga Antelope (signed at CoP8, Nairobi, 23 November 2005). 


\section{Compliance mechanisms}

\section{(a) Performance Review Information}

Parties have obligations to report on their implementation efforts to conserve those migratory species in Appendices I and II that pass through their jurisdiction and also must monitor such migratory species and keep the Secretariat informed of the species' status. $^{74}$ Resolution 6.5 recommended that the format of national reports be simplified and that the content be standardised to encourage Parties to provide information that directly relates to the implementation of the CMS Strategic Plan. Parties were encouraged to trial this new reporting format for COP-7 (2002). At COP-7, Resolution 7.8 commended the new reporting format and recommended that the final version be sent to the Standing Committee for approval and adoption at its $26^{\text {th }}$ meeting. The new reporting format requires, inter alia, performance review information with respect to how Parties are implementing the Strategic Plan. ${ }^{75}$

Article $\mathrm{V}$ sets out criteria for the substance of regional Agreements negotiated under the auspices of Article IV. Such Agreements should establish the appropriate machinery to monitor their effectiveness and reporting obligations.

\section{(b) Multilateral Non-Compliance Procedures}

The CMS and the COP do not specify any non-compliance procedures. However, the Standing Committee, established by Resolution 1.1, mainly for inter-sessional implementation review and guidance to the Secretariat on policy and budgetary matters, has a regional representation. That gives a possibility of dealing with non-compliance, e.g. through proposals to the Conference for the improvement of rules of procedures. Secondly, the coordination and existing inter linkages between CMS and its Agreements facilitate multilateral NCP. In that regard, the agreements establish activities reports to the CMS conference of the Parties, and the Memoranda of understanding are generally administered by the Secretariat. At some extent, as the Scientific Council composition includes nominated experts on their own merit that could be compared to a "third body" for monitoring the implementation and recommending specific solutions to the Conference on species status assessment.

\section{(c) Non-Compliance Response Mechanisms}

As there is no formal NCP, so there are no formal non-compliance response mechanisms. However, a range of support measures for implementation can be directed to assist Parties experiencing compliance difficulties.

Technical Assistance Workshops have been held to assist Parties in complying with their monitoring obligations. For example, in 1999 an international workshop took place in Bonn, Germany, to celebrate the $20^{\text {th }}$ anniversary of the Convention and present new

74 CMS Article VI.

75 COP7 2002,'Proposed Format for National Reports'. 
research and monitoring technologies. ${ }^{76}$ Resolution 7.8 instructed the Secretariat to provide technical capacity to facilitate the transfer of knowledge on the CMS Information System to developing countries. It also calls for Parties to contribute to the ongoing development and maintenance of the CMS Information System and the CMS Global Register of Migratory Species. The Secretariat provides, on request and resources permitting, Technical and Scientific assistance on migratory species, e.g. parties lists and regional lists of species, conservation measures, etc.

Financial Assistance UNEP-WCMC provides the Secretariat and administers the Convention's Trust Fund. A new fundraising strategy was launched at COP-8 (2005). , It is expected that the new association called 'Friends of $\mathrm{CMS}^{\prime}$ will play a key role for its implementation and the enforcement of the CMS partnership. The eighth Conference of the parties has adopted a new Voluntary contribution Trust Fund for the Convention, under establishment and administration by UNEP. ${ }^{77}$

\section{(d) Dispute Resolution}

Parties are to resolve disputes relating to the interpretation or application of the Convention through negotiation and, if necessary, arbitration at the Permanent Court of Arbitration.

76 CMS Website, <http://www.cms.int/news/PRESS/nwPR1999/nw990627.htm> (7/10/05).

77 CMS Website, <http://www.cms.int/bodies/COP/cop8/cop8 mainpage.htm $>$ (8/9/05). 


\section{Convention on Biological Diversity 1992}

\section{Overview}

The Convention on Biological Diversity (CBD) entered into force on 29 December 1993. Article 1 outlines the three objectives of the Convention: the 'conservation of biological diversity, the sustainable use of its components, and the fair and equitable sharing of the benefits arising out of the utilization of genetic resources.' The CBD promotes interState cooperation for the conservation and sustainable use of biological diversity, ${ }^{78}$ and especially of technical and scientific cooperation. ${ }^{79}$ This has facilitated many bilateral and multilateral projects. The Convention aims to achieve the conservation of biological diversity by: identifying and monitoring of the components of biological diversity and of the processes and activities that threaten those components; ${ }^{80}$ providing for in-situ and ex-situ conservation; ${ }^{81}$ and integrating the conservation and sustainable use of biological resources into national decision-making. ${ }^{82}$

\section{Compliance mechanisms}

\section{(a) Performance Review Information}

The reporting provisions of the CBD are sparse. Article 26 of the CBD calls upon Parties to report upon their measures to implement the $\mathrm{CBD}$ and the effectiveness of those objectives. COP-2 (1995) decided that the first national reports should be delivered to COP-4 in 1998 and adopted guidelines for the preparation of reports were adopted at COP-2 ${ }^{83}$

In addition to the reporting obligations, Article 7 provides that each Party must monitor the components of biological diversity set out in Annex I for the purposes of in-situ and ex-situ conservation.

\section{(b) Multilateral Non-Compliance Procedures}

There is no established NCP. However, Decision VII/30 established the Ad Hoc Openended Working Group on Review of Implementation of the Convention. Of particular interest is the Working Group's mandate 'to consider progress in the implementation of the Convention...to review the impacts and effectiveness of existing processes under the

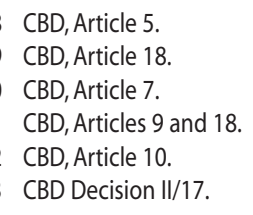


Convention, such as meetings of the Conference of the Parties, the Subsidiary Body on Scientific, Technical and Technological Advice, national focal points and the Secretariat... and to consider ways and means of identifying and overcoming obstacles to the effective implementation of the Convention.' ${ }^{84}$ At its first meeting, the Working Group recommended that the COP investigate the obstacles to implementation at national level and ways to overcome those obstacles. ${ }^{85}$ This Working Group may potentially develop into a non-confrontational means of dealing with instances of non-compliance and providing non-compliance response assistance.

\section{(c) Non-Compliance Response Mechanisms}

Technical Assistance The CBD contains obligations on promoting and cooperating with respect to: research and training; ${ }^{86}$ public education and awareness; ${ }^{87}$ information exchange; ${ }^{88}$ and access to technical and scientific cooperation. ${ }^{89}$ The Convention established a clearing-house mechanism (CHM) to ensure that all Parties have access to the information and technologies required to implement the Convention. The CHM was set up at COP-1 (1994) and is funded through the Convention's regular budget and through voluntary contributions. ${ }^{90}$ It promotes cooperation in six key areas: tools for decision-making; training and capacity building; research; funding; technology transfer; and the repatriation of information. ${ }^{91}$ The CHM provides universal access to Convention records, case studies, national and other reports, initiatives and programmes and technical and scientific information. ${ }^{92}$ It also seeks to increase public awareness of the Convention's programmes and links experts to relevant work programmes.

At COP-4 (1998), Decision IV/2 recommended that Parties organise a CHM steering committee or working group to build up the information contained in the $\mathrm{CHM}$ at all levels, including country profiles, biodiversity strategies and action plans, legislation, scientific and technological information and financial sources. Numerous CHM regional workshops have been conducted since 1997. In 1999, an independent review of the pilot phase of the $\mathrm{CHM}$ took place, culminating in the development of a strategic plan and long-term program of work. ${ }^{93}$

An Informal Advisory Committee, which is coordinated by the Executive Secretary, oversees the $\mathrm{CHM}^{94}$ The continuation and mandate of the Committee, as well as its operational procedure, were reviewed at COP-7 (2004), ${ }^{95}$ which decided to extend the Committee's mandate and review its continuation and operation at COP-9. A network of CHM National Focal Points has been established to facilitate technical and scientific cooperation.

84 Decision VII/30, para 23

85 Recommendation 5(b).

86 CBD, Article 12.

87 CBD, Article 13

88 CBD, Article 17.

89 CBD, Article 18.

90 CBD Decisions $\mathrm{l} / 3$ and $\mathrm{l} / 9$.

91 CBD Website, <http://www.biodiv.org/chm/default.aspx > (8/9/05).

92 CBD Website, $<$ http://www.biodiv.org/chm/default.aspx $>$ (8/9/05).

93 CBD Website, <http://www.biodiv.org/chm/default.aspx $>$ (8/9/05).

94 CBD Decision III/4 and IV/2.

95 CBD Decision V/14. 
Financial Assistance In relation to funding, Article 20 states that each Party is to provide financial support and incentives for national projects that implement the objectives of the Convention. Developed Parties are also expected to provide additional funding to developing Parties to enable the latter to implement the Convention. Developed Parties may provide funding through regional, bilateral and multilateral channels.

Article 21 provides for a mechanism to provide financial resources on a grant or concessional basis to help developing Parties. COP-1 (1994) decided that the GEF would continue to serve as the institutional structure to operate the financial mechanism under the Convention on an interim basis, in accordance with Article 39 of the Convention. ${ }^{96} \mathrm{COP}-3$ (1996) adopted the Memorandum of Understanding between the COP of the CBD and the Council of the GEF. The Memorandum of Understanding allows the GEF, in permanently operating the financial mechanism under the Convention, to take guidance from the COP in funding activities to implement the Convention. ${ }^{97}$ COP-3 (1996) also requested the financial mechanism to provide funding for capacity building in developing countries, particularly in relation to IT training and pilot projects to implement the $\mathrm{CHM} .{ }^{98}$ Guidance has also been provided to the financial mechanism at COPs. ${ }^{99}$

\section{(d) Dispute Resolution}

Article 27 provides that the Parties shall seek solution by negotiation where there is a dispute concerning the application of the Convention. If the dispute is not resolved, they may seek mediation by a third Party.

The Convention provides that disputes can be settled through arbitration in accordance with Part I of Annex II, conciliation in accordance with Part II of Annex II or through the International Court of Justice. However, Parties must firstly submit a declaration that they accept Arbitration or the International Court of Justice as a compulsory means of dispute resolution. Otherwise, the dispute must be submitted to conciliation in accordance with Part II of Annex II if negotiation and mediation fail to reach a solution.

\footnotetext{
CBD Decision $\mathrm{l} / 2$.

CBD Website, <http://www.biodiv.org/chm/background.asp\#> (8/9/05).

CBD Decision III/4.

See CBD Decision III/5, Decision VI/11, Decision IV/13, Decision V/13 and Decision VII/20.
} 


\section{United Nations Convention to Combat Desertification in those Countries Experiencing Serious Drought and/or Desertification, Particularly in Africa 1994}

\section{Overview}

The United Nations Convention to Combat Desertification in those Countries Experiencing Serious Drought and/or Desertification, Particularly in Africa (UNCCD) entered into force on 26 December 1996. The objective of the Convention is to promote an integrated approach to combating desertification and mitigating the effects of serious drought and/or desertification, through effective actions at all levels, supported by international co-operation and partnership arrangements. ${ }^{100}$

The Convention distinguishes between affected developing Parties and developed Parties. Article 5 requires affected developing Parties to give due priority to combating desertification, establish strategies within the framework of sustainable development plans, address the underlying causes of desertification, promote awareness of the problem and strengthen relevant existing legislation. Article 6 requires developed Parties to actively support the efforts of affected developing Parties to combat desertification by providing financial assistance and mobilising funding.

There are five Annexes to the Convention dealing with the implementation of the Convention in five regions affected by desertification: (I) Africa; (II) Asia; (III) Latin America and the Caribbean; (IV) Northern Mediterranean; and (V) Central and Eastern Europe. The African Annex is the most detailed and contains provisions for financial mechanisms and resources, co-ordination, partnership and follow-up arrangements.

\section{Compliance mechanisms}

\section{(a) Performance Review Information}

Article 9 of the UNCCD requires affected developing Parties and Parties that are members of Regional Implementation Annexes to prepare National Action Programmes in order to identify the factors contributing to desertification in their countries and to describe practical measures to combat them. The Regional Implementation Annex for Africa and the Northern Mediterranean specify that their national action programmes must contain provisions for monitoring the implementation of the Convention. ${ }^{101}$

In addition, Parties must communicate to the COP at its ordinary sessions reports on implementation measures. ${ }^{102}$ Affected developing Parties must provide reports of strate-

100 UNCCD, Article 2.1.

101 Annex I, Article 8.3(e) and Annex IV, Article 5(f).

102 UNCCD, Article 26. 
gies developed pursuant to Article 5 and their NAPs. ${ }^{103}$ Developed Parties must provide information on the measures undertaken to assist in the preparation and implementation of Action Programmes, including information on financial resources they have provided. ${ }^{104}$

\section{(b) Multilateral Non-Compliance Procedures}

Under Article 27, the COP is empowered to consider and adopt procedures and institutional mechanisms to resolve issues regarding implementation. At COP-6 (2003), the Parties convened an Open-Ended Ad Hoc Group of Experts to make recommendations on such procedures and institutional mechanisms. ${ }^{105} \mathrm{~A}$ report has been complied which summarises non-compliance mechanisms that have been developed in other biodiversityrelated as well as the cluster of chemical Conventions. The report recommends that COP-7 (2005) may wish to consider requesting the Group to develop a compliance model for consideration. ${ }^{106}$

\section{(c) Non-Compliance Response Mechanisms}

Technical Assistance Numerous articles provide for technical cooperation between Parties. Article 6(e) requires developed Parties to promote and facilitate access by affected Parties to appropriate technology, knowledge and know-how in combating desertification. Article 16 provides that Parties agree to integrate and coordinate the collection, analysis and exchange of short-term and long-term data and information to ensure the systemic observation of land degradation. Article 17 states that Parties undertake to promote technical and scientific cooperation. Article 18 provides that Parties undertake to promote, finance and/or facilitate the financing of the transfer, acquisition, adaptation and development of environmentally sound, economically viable and socially acceptable technologies relevant to combating desertification. This cooperation is to be conducted bilaterally or multilaterally. Parties are also required to fully utilize existing national, subregional and international information systems and clearing houses for the dissemination of information on available technologies; facilitate technology cooperation through financial assistance; and facilitate access by affected developing Parties to technology on favourable terms. Finally, Article 19 provides that Parties recognize the importance of capacity building.

Financial Assistance In relation to financial assistance, Article 4.2(h) provides that in pursuing the objectives of the Convention, the Parties will promote the use of existing bilateral and multilateral financial mechanisms and arrangements that mobilise and channel substantial financial resources to affected developing Parties. ${ }^{107}$ While all Parties must make every effort to ensure that adequate financial resources are available for programmes to combat desertification, ${ }^{108}$ the financial burden to provide, seek out and mobilize funding is the responsibility of the developed Parties. ${ }^{109}$

103 UNCCD, Article 9.1.

104 UNCCD, Article 9.2.

105 UNCCD Decision 22/COP 6.

106 UNCCD COP 7, Items 13(b) and (c) of the provisional agenda, Executive Summary, Para 52.

107 See also UNCCD, Article 4.3 .

108 UNCCD, Article 20.

109 UNCCD, Article 5. 
Article 21 establishes a Global Mechanism to promote the mobilisation of funds to developing Parties. The International Fund for Agricultural Development (IFAD) was selected at COP-1 (1997) to house the Global Mechanism, which operates in conjunction with the World Bank and the UNDP. ${ }^{110}$ The mechanism seeks to promote greater coordination of funding and greater effectiveness in the use of funds.

COP-5 (2001) enhanced the UNCCD's financial base following strong support for a proposal by the GEF Council to designate land degradation as another focal area for funding. ${ }^{111}$

\section{(d) Dispute Resolution}

Disputes must be settled through negotiation or other peaceful means. ${ }^{112}$ Parties have the choice of opting for arbitration under procedures to be adopted by the COP in an annex as soon as practicable, or in the International Court of Justice, provided they have given written notice. If the dispute takes more than 12 months to settle or the Parties have not opted for arbitration, it must be submitted to conciliation. Arbitration and conciliation procedures are yet to be adopted. ${ }^{113}$

110 UNCCD Decision 24/COP.1.

111 UNCCD Decision 9/COP.5.

112 UNCCD, Article 28.

113 COP 7 UNCCD, Items 13(b) and (c) of the provisional agenda, p.14. 


\section{International Treaty on Plant Genetic Resources for Food and Agriculture 2001}

\section{Overview}

When the text of the CBD was adopted in 1992, member countries also adopted Resolution 3 of the 'Nairobi Final Act', which recognised the need to resolve issues relating to plant genetic resources under the auspices of the United Nations Food and Agricultural Organisation. ${ }^{114}$ The International Treaty on Plant Genetic Resources for Food and Agriculture (Plant Genetic Resources Treaty) was signed on 3 November 2001 and entered into force on 29 June 2004.

The objectives of the Plant Genetic Resources Treaty are the conservation and sustainable use of plant genetic resources for food and agriculture (PGRFA) and the fair and equitable sharing of benefits arising out of their use, in accordance with the CBD. ${ }^{115}$ Under Article 5, Parties are required to: survey and inventory PGRFA; promote the collection of PGRFA and relevant associated information on those that are under threat or are of potential use; promote or support farmers and local communities' efforts to manage and conserve their PGRFA; promote in situ conservation of wild crop relatives and wild plants for food production; and monitor the maintenance of the viability, degree of variation, and the genetic integrity of collections of PGRFA. ${ }^{116}$ Article 6 obliges Parties to develop and maintain appropriate policy and legal measures that promote the sustainable use of PGRFA. Article 10 establishes the Multilateral System to facilitate access to PGRFA. Multilateral access is limited to the crops and forages listed in Annex I and is achieved through transfer agreements. ${ }^{117}$

\section{Compliance mechanisms}

\section{(a) Performance Review Information}

The Plant Genetic Resources Treaty does not require the submission of performance review reports from the Parties. In respect of verification, the Secretary has the right to access and inspect all activities that are directly related to the conservation and exchange of the material covered by Article 15.1. That provision deals with accessing ex situ collections of PGRFA held in trust by the International Agricultural Research Centres (IARCs) of the Consultative Group on International Agricultural Research (CGIAR).

114 Commission on Genetic Resources for Food and Agriculture, <http://www.fao.org/ag/cgrfa/IU.htm $>$ (8/9/05).

115 PGRFA Treaty, Article 1.

116 PGRFA Treaty, Article 5.1.

117 PGRFA Treaty, Article 12.4 . 
To a limited degree, performance review might be constructed by collecting together the operational information required to be exchanged in the course of transactions regulated by the Treaty. Parties providing PGRFA under the Multilateral System must provide all available data and information on the product being supplied. ${ }^{118}$ Under Article 5.1(f), Parties are also required to monitor the maintenance of the viability, degree of variation, and the genetic integrity of collections of PGRFA. Under Article 17, Parties must cooperate to establish a global information system (called the Global Information System) to facilitate the exchange of information on scientific, technical and environmental matters related to PGRFA. The expectation is that such exchange of information will assist in benefit sharing, by making information on PGRFA available to all Parties. In developing the Global Information System, cooperation must be sought from the Clearing-House Mechanism of the CBD. Parties agree to make available information through the Global Information System, including catalogues and inventories, information on technologies, results of technical, scientific and socio-economic research, including characterization, evaluation and utilization, regarding PGRFA in Annex I. ${ }^{119}$

\section{(b) Multilateral Non-Compliance Procedures}

Article 21 requires the Governing Body to, at its first meeting, consider and approve procedures and operational mechanisms, including monitoring, to promote compliance with the provisions of the Treaty. The Interim Committee for the Treaty, the Commission on Genetic Resources for Food and Agriculture, has convened an Open-ended Working Group to consider the issue of non-compliance at COP-1 (2005). ${ }^{120}$

\section{(c) Non-Compliance Response Mechanisms}

The Plant Genetic Resources Treaty contains extensive assistance provisions that might be applied as non-compliance response mechanisms.

Technical Assistance Article 5.1 provides that Parties must, in cooperation with other Parties where appropriate, promote an integrated approach to the exploration, conservation and sustainable use of PGRFA while Article 5.1(e) encourages Parties to cooperate to promote the development of an efficient and sustainable system of ex situ conservation and the development and transfer of appropriate technologies for this purpose. The Treaty provides that international cooperation is to be directed to: assisting developing Parties in their conservation and sustainable use of PGRFA; promoting conservation, evaluation, documentation, genetic enhancement, plant breeding and seed multiplication; sharing, providing access to and exchanging PGRFA as well as information and technology in accordance with Part IV; and implementing the funding strategy in Article 18. ${ }^{121}$ Under Article 8, Parties agree to promote the provision of technical assistance to contracting Parties.

118 PGRFA Treaty, Article 12.3(c).

119 PGRFA Treaty, Article 13.2(a).

120 FAO Website, <http://www.fao.org/ag/cgrfa/compliance.htm > (17/9/05).

121 PGRFA Treaty, Article 7.2(a), (b) and (d). 
Article 13 states that benefits accruing from PGRFA accessed through the Multilateral System must be shared through the exchange of information, transfer of technology, capacity building and funding. These benefits should flow to farmers in developing countries embodying traditional lifestyles.

The provision then expands on each form of assistance. Exchange of information was dealt with in (a) above. In relation to technology transfer, Parties undertake to provide and/or facilitate access to technologies for the conservation, characterisation, evaluation and use of PGRFA that are within the scope of the Multilateral System. ${ }^{122}$ Access to technology for developing countries must be provided on fair and favourable terms, although intellectual property rights are still protected. ${ }^{123}$ In relation to capacity building, Parties agree to give priority to: programmes for scientific and technical education and training in conservation and sustainable use of PGRFA; strengthening facilities for conservation and sustainable use of PGRFA; and scientific research. ${ }^{124}$ Again, the emphasis is on assisting developing countries. Article 13.3(d) deals with the sharing of commercial benefits under the Multilateral System. The multilateral transfer agreements must include a requirement that any recipient who commercialises a PGRFA product by incorporating material from the Multilateral System must make a payment to the financial mechanism established under Article 19.3(f). The details of these terms and conditions are to be ironed out at the first meeting of the Governing Body.

Financial Assistance Article 19.3(f) requires the Governing Body to set up a Trust Fund. Article 18 deals with funding priorities. Developed Parties are required to provide, and developing Parties to avail themselves of, financial resources, including through bilateral and multilateral channels and through the Trust Fund. Funding priorities will be given to the implementation of agreed plans and programmes for farmers in developing countries who conserve and sustainably utilize PGRFA. ${ }^{125}$

\section{(d) Dispute Resolution}

Parties must ensure that opportunities to seek recourse are available under their legal systems where contractual disputes arising under multilateral transfer agreements arise. ${ }^{126}$

In respect of disputes concerning the interpretation or application of the Treaty, Parties must firstly opt for negotiation and then, if necessary, mediation by a third Party. Parties may, at any time, declare that for disputes not resolved through negotiation or mediation, they accept arbitration in accordance with Part 1 of Annex II or the International Court of Justice as compulsory means of dispute resolution. Otherwise, the dispute must be submitted to conciliation in accordance with Part 2 of Annex II.

122 PGRFA Treaty, Article 13.2(b)(i).

123 PGRFA Treaty, Article 13.2(b) (iii).

124 PGRFA Treaty, Article 13.2(c).

125 PGRFA Treaty, Article 18.5 .

126 PGRFA Treaty, Article 12.5 . 


\section{Hazardous Materials}

\section{Basel Convention on the control of Transboundary Movements of Hazardous Wastes and their Disposal 1989}

\section{Overview}

The Basel Convention on the Control of Transboundary Movements of Hazardous Wastes and their Disposal (the Basel Convention) entered into force on 5 May 1992. The Convention regulates the transboundary import and export of hazardous wastes and obliges Parties to ensure that such wastes are managed and disposed of in an environmentally sound manner. ${ }^{127}$

Article 2.1 defines wastes as 'substances or objects that are disposed of or are intended to be disposed of or are required to be disposed of by the provisions of national law.' To 'dispose of' a waste means any of the operations set out in Annex IV, which may include resource recovery, recycling, reclamation, direct re-use or alternative use. Article 1 defines 'hazardous wastes' as those that belong to any of the waste streams contained in Annex I, unless they do not possess any of the hazard characteristics in Annex III. Further lists of waste are contained in Annex VIII (wastes that are presumed to be hazardous) and Annex IX (wastes that are presumed not to be hazardous), which were adopted at COP-4 (1998) and entered into force on 6 November 1998. The Convention also addresses 'other wastes', defined in Annex II as 'categories of wastes requiring special consideration' (i.e. household wastes and their residues). The Convention does not cover radioactive waste that is already covered by other international control systems. ${ }^{128}$ Parties to the Convention adopted a decision at COP-3 (1995) to ban the movement of hazardous wastes from States listed in Annex VII (Members of OECD, EC and Liechtenstein) to States not listed in Annex VII. ${ }^{129}$ At the time of writing, the ban has not yet entered into force.

The Basel Convention operative provisions have been grouped into three categories for the purposes of this Chapter.

1. Waste management Under Article 4(2)(a)-(d), each Party must take appropriate measures to: ensure that the generation of hazardous wastes is reduced to a minimum; ensure the availability of adequate disposal facilities as close as possible to the source of generation of waste; ensure that persons involved in the management of hazardous wastes take such steps as are necessary to

127 Basel Website, <http://www.basel.int/pub/basics.html> (8/9/05).

128 Basel Article 1(3).

129 See Kummer, Katharina International Management of Hazardous Wastes: the Basel Convention and Related Legal Rules, Oxford University Press, Oxford, c1995 1999. 
prevent pollution; and ensure that a transboundary movement of hazardous wastes is reduced to a minimum and is conducted in a manner that will protect human health and the environment.

2. Control system for transboundary movements Under Article 4(5), Parties shall not permit the export of hazardous wastes or other wastes to a non-Party or the import of hazardous waste from a non-Party ${ }^{130}$. Parties may exercise the right to prohibit the import or export of hazardous wastes and must inform other Parties of this decision. ${ }^{131}$ In the case of each transboundary movement, the consent of States of export, import and transit is required. This consent must be obtained through a system of notifications. States are obliged to prevent the export or import of wastes if they will not be managed according to principles of environmentally sound management (ESM). ${ }^{132}$ Thus, the regulatory system under the Basel Convention is one of prior informed consent. Wastes are to be packed and labelled according to international standards and must be accompanied by a movement document. ${ }^{133}$ There is a duty to re-import shipments that cannot be completed in accordance with the terms of the contract between the exporter and disposer (the contract specifies the ESM requirement). ${ }^{134}$

3. Illegal traffic All transboundary movements of hazardous and other wastes that do not fully conform to the control system of the Convention constitute illegal traffic $^{135}$. Illegal traffic is considered criminal and Parties should introduce appropriate national/domestic legislation to prevent and punish illegal traffic $^{136}$. For cases of illegal traffic, Article 9 of the Convention allocates the responsibility for the environmentally sound disposal of the wastes in question among the different States and entities concerned.

130 Unless the Party has entered into a bilateral, multilateral or regional agreement or arrangement with the non-Party regarding transboundary movement of such wastes that does not derogate from the environmentally sound management of such wastes (Article 11).

131 Basel Articles 4(1)(a) and 13(2)(d)).

132 Basel Article 4(2)(e) and (g).

133 Basel Article 4(7)(b) and (c).

134 Basel Articles 8.

135 Basel Article 9.1.

136 Basel Article 4.3 and 9.5 . 


\section{Compliance Mechanisms}

\section{(a) Performance Review Information}

Under Article 13(3), Parties must transmit reports to the COP each year. The reports must provide information on: competent authorities and focal points; transboundary movements of hazardous wastes; efforts to achieve reductions in waste; available qualified statistics compiled by them on how the production, transportation and disposal of hazardous wastes affects human health and the environment; bilateral, multilateral or regional agreements entered into pursuant to Article 11 of the Convention; accidents in the transboundary movement or disposal of waste and measures taken to deal with them; disposal options within national jurisdictions; measures undertaken to develop technologies to reduce or eliminate the production of hazardous wastes; and any other matters the COP deems relevant.

Article 10.2(b) obliges Parties to co-operate in monitoring the effects of the management of hazardous wastes on human health and the environment, although this does not constitute third-party monitoring of performance. Article 19 imposes monitoring obligations on the Parties. ${ }^{137}$ The provision states that any Party, which has reason to believe that another Party has breached the Convention, may inform the Secretariat and the Party against whom the allegations are made.

\section{(b) Multilateral Non-Compliance Procedures}

In Decision V/16, COP-5 (1999) requested the Legal Working Group to develop a draft decision for the establishment of a compliance mechanism. A Compliance Committee was established at COP-6 (2002). Its Terms of Reference state that the Committee shall be 'nonconfrontational, transparent, cost-effective and preventative in nature, simple, flexible, non-binding and oriented in the direction of helping Parties to implement the provisions of the Basel Convention'. ${ }^{138}$ The Committee may receive submissions from the Secretariat or Parties in relation to non-compliance issues. The Party whose compliance is in question is given the opportunity to present its responses and comments to the Committee. A Party that concludes that it is or will be unable to fully implement or comply with its obligations despite its efforts, may also present a submission to the Committee with regard to its own compliance difficulties. The Committee investigates the cause of the compliance difficulties and gives advice, non-binding recommendations or information, after consultation with the Party, to assist it with resolving these difficulties ${ }^{139}$. The Committee may also decide to make recommendations to the $\mathrm{COP}^{140}$.

137 Article 19 is entitled 'verification'. This report broadly defines verification as a process of checking the accuracy of performance review reports. Monitoring is concerned with observing a Party's performance and notifying the relevant Convention body of breaches. The substance of article 19 accords with the definition of monitoring in this report and is therefore classed as a monitoring obligation.

138 Basel Decision VI/12, Appendix, para 2.

139 Basel Decision VI/12, Appendix, para. 19.

140 Basel Decision Vl/12, Appendix, para. 20. 
The Committee also has a mandate to review general issues of compliance ${ }^{141}$. At COP-7 (2004) Parties approved the 2005-2006 Work Programme for the Compliance Committee, ${ }^{142}$ focusing on identifying and analysing difficulties relating to: reporting obligations under the Basel Convention; designation and functioning of national competent authorities and focal points; and development of national legislation to implement effectively the Basel Convention.

\section{(c) Non-Compliance Response Mechanisms}

As indicated above, the Compliance Committee can take two types of actions in response to a submission. As a clear illustration of the non-confrontational nature of the non-compliance procedure, the Committee may provide the Party, after coordination with that Party, with advice, non-binding recommendations and information. These could relate to, among other things, the establishment and strengthening of domestic or regional regulatory regimes, the facilitation of financial and technical assistance, the elaboration of voluntary compliance action plans and follow-up arrangements for progress reporting to the Committee. They aim at resolving the compliance concerns with regard to that Party. For these actions it is thus not necessary for the Committee to refer the issue to the $\mathrm{COP}^{143}$.

Additionally, the Committee may submit recommendations to the COP, but only if the Committee considers it necessary to pursue further measures to address a Party's compliance difficulties, in light of the objective and nature of the mechanism and taking into account the cause, type, degree and frequency of the difficulties, as well as the capacity of the Party in question. Measures that may be taken by the COP include prioritization of technical assistance, capacity building and funding, or a cautionary statement and advice regarding future compliance. ${ }^{144}$

Technical Assistance Under Article 10, the Parties must cooperate with each other to improve and achieve the ESM of hazardous wastes. They must, upon request, make information available with a view to promoting the ESM of hazardous and other wastes, and cooperate in monitoring the effects of managing hazardous wastes on human health and the environment. Parties must also cooperate in: the development and implementation of environmentally sound low-waste technologies and the improvement of existing technologies; the transfer of technology and management systems related to the ESM of hazardous wastes and other wastes; developing technical capacity among Parties that need and request assistance in this area; and developing technical guidelines. ${ }^{145}$ Regional centres for training and technology transfers have been established to assist in training and technology transfer. ${ }^{146}$ The Secretariat has also produced a Manual for the Implementation of the Basel Convention, which was approved at COP-3, ${ }^{147}$ a Guide to the Control System, which was approved by COP-4, and a Training Manual on Illegal Traffic ${ }^{148}$, and organises related

\footnotetext{
141 Basel Decision VI/12, Appendix, para 21.

142 Basel Decision VII/30.

143 Basel Decision Vl/12, Appendix, para. 19.

144 Basel Decision VI/12, Appendix, paras 9-20.

145 Basel Article 10.

146 Basel Article 14(1) and Decisions I/13, II/19 and III/19.

147 Basel Decisions I/3 and III/8.

148 Adopted at the fifth session of the Open-ended Working Group of the Basel Convention (decision OEWG-V/9) on behalf of the COP, as mandated by decision VII/34.
} 
training seminars. ${ }^{149}$ In addition, technical guidelines on the management of specific waste streams and on the development of inventories have also been prepared by the Secretariat. All such materials are available, free of charge, on the website of the Convention (www. basel.int).

Financial Assistance Parties are also required to consider the establishment of a revolving fund to provide assistance in emergency cases and, indeed, they requested the $\mathrm{Ad}$ Hoc Working Group of Legal and Technical Experts to consider the elements that would be required in establishing such a fund at COP-1 (1992). ${ }^{150}$ The Basel Convention has established a Trust Fund for the Implementation of the Convention as well as a Technical Cooperation Trust Fund to Assist Developing Countries, which was enlarged at COP-6 to address compliance in cases of emergency. ${ }^{151}$

Penalties The Convention does not provide for penalties to be imposed on Parties for non-compliance. It does, however, set out which State (or non-State actor) should be responsible or liable when the requirements and procedures under the Convention are not complied with. The Convention relies upon Parties to adopt domestic measures to provide for penalties for non-State actors for non-compliance

Article 8 imposes a duty on States of export to ensure that hazardous materials are reimported where the transboundary movement cannot be completed in accordance with the terms of the contract. Article 9 defines illegal traffic as transboundary movements that: occur without notification to all States concerned; occur without the consent of a State concerned; occur where consent was obtained through fraud or misrepresentation; do not conform in a material way with the documents; or that contravene the Convention or the principles of international law. Where the conduct of the exporter results in illegal traffic, the State of export must ensure the waste is re-imported and otherwise disposed of in accordance with the Convention. Where the conduct of the importer or disposer is responsible for illegal traffic, the State of import must ensure the waste is disposed of in an environmentally sound manner. Where responsibility for illegal traffic cannot be assigned to either exporter/generator or importer/disposer, Parties shall ensure through co-operation that the wastes in question are disposed of as soon as possible in an environmentally sound manner.

At COP-5 (1999) the Parties adopted the Basel Protocol on Liability and Compensation, which establishes a liability and compensation regime for damage that arises from the movement of transboundary wastes. As under the Convention, penalties upon non-State actor are to be established under national law, and to be imposed by national mechanisms. The Protocol has not yet entered into force.

\section{(d) Dispute Resolution}

Disputes relating to the interpretation, application or compliance with the Convention must initially be resolved through negotiation or any other peaceful means. However, if

149 Basel Decisions $1 / 20$ and III/20.

150 Basel Article 14(2) and Decisions 1/14, II/2, III/3.

151 Basel Decisions II/27, V/18 and VI/14. 
the Parties concerned cannot settle their dispute, the dispute must be submitted to the ICJ or to arbitration pursuant to Annex VI on Arbitration, provided that the Parties to the dispute consent. A Party may declare that it recognizes as compulsory ipso facto and without special agreement in relation to any other Party accepting the same obligation the submission of the dispute to the ICJ and/or to arbitration. ${ }^{152}$

152 Basel Decisions I/3 and III/8. 


\section{Rotterdam Convention on the Prior Informed Consent Procedure for Certain Hazardous Chemicals and Pesticides in International Trade}

\section{Overview}

The Rotterdam Convention on the Prior Informed Consent Procedure for Certain Hazardous Chemicals and Pesticides in International Trade (the PIC Convention) entered into force on 24 February 2004. The aim of the Convention is to promote shared responsibility and cooperative efforts among Parties in the international trade of certain hazardous chemicals in order to protect human health and the environment from potential harm and to contribute to their environmentally sound use. ${ }^{153}$ The Convention gives legal force to the implementation of the Prior Informed Consent procedure (PIC procedure). Through the PIC procedure, the Secretariat to the PIC Convention acts as a clearing-house through which decisions of importing countries as to whether they wish to import certain chemicals are compiled and circulated to other Parties. Parties can also use the Secretariat to exchange information about characteristics of chemicals to inform an importing Party about their dangers and use.

The chemicals that are subject to the PIC procedure are listed in Annex III in accordance with recommendations from the Chemical Review Committee. ${ }^{154}$ Once a chemical is listed in Annex III, Parties must communicate their import decisions to the Secretariat. ${ }^{155}$ The Secretariat then summarises and compiles the responses and provides them to the other Parties. ${ }^{156}$ The import decision can be a final decision to consent, to consent subject to conditions or to not consent. Otherwise, it can be an interim response or a request for further information. ${ }^{157}$

\section{Compliance Mechanisms}

\section{(a) Performance Review Information}

There are no performance review self-reporting obligations in the PIC Convention. However, its working provisions entail detailed operational information exchanges that embody some information relevant to assessment of performance. For example, when a country takes action to ban or severely restrict a chemical, its Designated National Authority (DNA) must inform the Secretariat within 90 days of this action. The Secretariat

\footnotetext{
153 PIC Convention, Article 1.

154 PIC Convention, Articles 5.5, 6 and 7.

155 PIC Convention, Article 10.

156 PIC Convention, Article 10. Redgwell, C,'Regulating Trade in Dangerous Substances', Kiss, A, Shelton, D and Ishibashi, K, Economic Globalization and Compliance with International Environmental Agreements, Kluwer Law International, The Hague, 2003 , p.83. 157 PIC Convention, Article 10.
} 
then informs the other Parties. ${ }^{158}$ (Parties must establish DNAs to be the contact points for information exchange and for communicating consents under the PIC procedure. ${ }^{159}$ ) Where a chemical that is banned or severely restricted by a Party is exported from another Party's territory, the exporting Party must provide exporting notification to the importing Party, in accordance with Annex V. ${ }^{160}$ If these notifications were compiled into a database, they would go some way towards the formation of a perspective to the Parties' performance.

\section{(b) Multilateral Non-Compliance Procedure}

Article 17 requires the COP to develop and approve procedures and institutional mechanisms for determining non-compliance with the provisions of the PIC Convention and for treatment of Parties found to be in non-compliance. At COP-1 (2004), the Parties convened an Open-ended Ad Hoc Working Group on Article 17, with a view to preparing for and carrying forward deliberations on the issue. ${ }^{161}$ The Working Group met before and during COP-2 (2005) but failed to agree on critical issues (i.e. equitable geographical representation; "triggers" that would lead to NCP; available non-compliance response measures; and handling of performance information) and, so, will meet and report again to COP-3 (2006)..$^{162}$

\section{(c) Non-Compliance Response Mechanisms}

The implementation support mechanisms of the PIC Convention may be used targeted to address non-compliance. However, they tend to be bilateral in operation and are, therefore, not ideally suited to deployment under a multilateral NCP.

Technical Assistance Article 10(4) (b) provides that a Party may request assistance in evaluating whether an Annex III chemical should be imported. Article 11(1)(c) provides that each exporting Party shall advise and assist importing Parties, upon request and as appropriate: to obtain further information to help them to take action in respect of imports; and to strengthen their capacities and capabilities to manage chemicals safely during their life-cycle.

Article 14 requires each Party to facilitate: the exchange of scientific, technical, economic and legal information concerning the chemicals within the scope of the Convention; the provision of publicly available information on domestic regulatory actions relevant to the objectives of the Convention; and the provision of information to other Parties, directly or through the Secretariat, on domestic regulatory actions that substantially restrict one or more uses of the chemical, as appropriate.

158 PIC Convention, Article 5.

159 PIC Convention, Article 4.

160 PIC Convention, Article 12.

161 PIC Convention Decision 1/10.

162 UNEP/FAO/RC/COP.2/19 Report of the Conference of the Parties to the Rotterdam Convention on the Prior Informed Consent Procedure for Certain Hazardous Chemicals and Pesticides in International Trade on the work of its second meeting (12 October 2005 ) Para. 61. 
Article 16 states that the Parties shall cooperate in promoting technical assistance for the development of the infrastructure and the capacity necessary to manage chemicals to enable implementation of this Convention. Parties with more advanced programmes for regulating chemicals should provide technical assistance, including training, to other Parties in developing their infrastructure and capacity to manage chemicals throughout their life cycle.

Financial Assistance At COP-1 (2004), the Parties called upon the Secretariat to conduct a study into the possible options for financial mechanisms to enable developing countries to implement adequately the provisions of the Convention. ${ }^{163}$ The study was discussed at COP-2 (2005) but the Parties could not agree on a choice of financial mechanism, instead calling on the Secretariat to revisit the options in light of discussion at COP-2 and to report on the revised study at COP-3 (2006). ${ }^{164}$

\section{(d) Dispute Resolution}

Parties must settle disputes concerning the interpretation or application of the Convention through negotiation or other peaceful means of their own choice. However, a Party may declare in writing that, with respect to any dispute concerning the interpretation or application of the Convention, it recognises arbitration or the International Court of Justice as a compulsory means of dispute resolution in relation to any Party accepting the same obligation. Otherwise, if the Parties to a dispute have not accepted arbitration or the International Court of Justice, or if they have not been able to settle their dispute within twelve months following notification by one Party to another that a dispute exists between them, the dispute must be submitted to a conciliation commission at the request of any Party to the dispute. The conciliation commission shall render a report with recommendations. ${ }^{165}$ At COP-1 (2004), Resolution 1/11 adopted an arbitration and conciliation procedure for purposes of Article 20. These can be found in Annex VI.

163 PIC Convention Decision 1/15.

164 UNEP/FAO/RC/COP.2/19 Report of the Conference of the Parties to the Rotterdam Convention on the Prior Informed Consent Procedure for Certain Hazardous Chemicals and Pesticides in International Trade on the work of its second meeting (12 October 2005 ) Para. 78.

165 PIC Convention, Article 20. 


\section{Cartagena Protocol on Biosafety to the CBD 2000}

\section{Overview}

Article 19(3) of the CBD provides that the Parties shall consider the need for a Protocol to the Convention, particularly in relation to the safe transfer, handling and use of living modified organisms (LMOs) resulting from biotechnology that may impact on the conservation and sustainable use of biological diversity. The First Extraordinary Meeting of the CBD COP adopted the Cartagena Protocol on Biosafety to the Convention on Biological Diversity on 29 January 2000 in Montreal, Canada. It entered into force on 11 September 2003.

The Protocol aims to 'contribute to ensuring an adequate level of protection in the field of the safe transfer, handling and use of LMOs resulting from modern biotechnology' in accordance with the precautionary approach as set out in Principle 15 of the Rio Declaration on Environment and Development. ${ }^{166}$ It applies to the transboundary movement, transit, handling and use of LMOs. ${ }^{167}$ The Protocol establishes an Advance Informed Agreement (AIA) procedure (i.e. a prior informed consent procedure), whereby Parties are required to ensure that their exporters notify the National Authority of the importing Party prior to the transboundary movement of LMOs that fall within the scope of the Protocol. ${ }^{168}$ The destination Party must then make a decision, based on a risk assessment, as to whether to import an LMO. ${ }^{169}$

\section{Compliance mechanisms}

\section{(a) Performance Review Information}

Parties are required to monitor the implementation of their obligations under the Protocol and to submit reports to the CBD COP (serving as the meeting of the Parties (MOP) to the Protocol) on their implementation efforts. ${ }^{170}$ Parties are also required to nominate a national focal point to liaise with the Secretariat. ${ }^{171}$

\section{(b) Multilateral Non-Compliance Procedures}

Article 34 provides that the COP-MOP must consider and approve at its first meeting cooperative procedures and institutional mechanisms to promote compliance and address non-compliance. The COP-MOP established a Compliance Committee and adopted procedures and mechanisms on compliance in Protocol Decision I/7.

166 Biosafety Protocol, Articles 1 and 10.

167 Biosafety Protocol, Article 4.

168 Biosafety Protocol, Article 8.

169 Biosafety Protocol, Articles 10 and 15.

170 Biosafety Protocol, Article 33.

171 Biosafety Protocol, Article 19. 


\section{(c) Non-Compliance Response Mechanisms}

The Committee's rules of procedure were adopted in Protocol Decision II/1. Under the rules of procedure, the Compliance Committee can take various measures to promote compliance and address non-compliance including: providing advice or assistance; making recommendations to the COP-MOP regarding the provision of financial and technical assistance, technology transfer, training and other capacity-building measures; request the non-compliant Party to develop a compliance action plan; invite the Party to submit reports; and report to the COP-MOP on the non-compliant Party's efforts to address the issue. The COP-MOP may, upon the Committee's recommendation, issue a caution, request the Executive Secretary to publish cases of non-compliance in the Biosafety Clearing-House or, in cases of repeated non-compliance, take such measures as to be decided at COPMOP-3. Article 27 states that the COP-MOP will adopt a process in respect of liability and redress for damage resulting from the movement of LMOs.

Technical Assistance Article 20 establishes a Biosafety Clearing-House to facilitate the exchange of scientific, technical, environmental and legal information on, and experience with LMOs, and to assist Parties to implement the Protocol. It serves as a means through which information on import bans and conditions is made available to Parties. Parties are required to make available to the Clearing-House information on: existing laws and guidelines; bilateral, regional and multilateral agreements; risk assessments or environmental reviews of LMOs; decisions about the importation or release of LMOs; and performance review reports submitted pursuant to Article 33. There are exceptions for confidential information. ${ }^{172}$

Article 22 specifically deals with capacity building. It states that Parties shall cooperate in developing and strengthening human resources and institutional capacities in biosafety in developing Parties, either through existing organisations or the involvement of the private sector. Cooperation in capacity building shall include scientific and technical training in the proper and safe management of biotechnology, and in the use of risk assessment and risk management for biosafety, and the enhancement of technological and institutional capacities in biosafety. Article 11.9 invites Parties to indicate their needs for financial and technical assistance and capacity building with respect to LMOs intended for direct use as food or feed or for processing. Parties must cooperate to meet those needs pursuant to Articles 22 and 28. The COP-MOP must take the needs of developing Parties into account in providing funding guidance to the financial mechanism, which is discussed below. ${ }^{173}$ The guidance to the financial mechanism of the Convention, as set out in relevant COP decisions, applies to the provisions of Article 28.

At COP-MOP-1 (2004), the Parties endorsed an Action Plan for Building Capacities for the Effective Implementation of the Protocol and a Coordination Mechanism. ${ }^{174}$

Financial Assistance The Protocol adopts the financial mechanism created under Article 21 of the CBD as its own financial mechanism. ${ }^{175}$ The COP-MOP prepares draft guidance

172 Biosafety Protocol, Article 21

173 Biosafety Protocol, Article 28

174 Biosafety Protocol, Decision I/5

175 Biosafety Protocol, Article 28.2. 
for financial support for consideration by the CBD COP; so that such guidance might be included in the latter's guidance to the financial mechanism. ${ }^{176}$ Following COP-MOP-1 (2004), the CBD COP provided detailed guidance to the funding mechanism in Decision VII/20. In Protocol Decision II/5, the COP-MOP encouraged the GEF and the Executive Secretary to the CBD to continue their collaborative support for the Protocol's implementation. The GEF has already provided funding to assist countries to prepare for the Protocol's entry into force. A UNEP-GEF project provided developing countries with assistance in developing biosafety frameworks and participating in the Biosafety Clearing-House. ${ }^{177}$

Penalties In accordance with Article 27 of the Biosafety Protocol, COP-1 established a negotiation process to adopt a liability protocol. Negotiations are currently ongoing.

\section{(d) Dispute Resolution}

The Protocol adopts the CBD dispute resolution procedures by virtue of Article 32 of the Protocol (CBD provisions relating to Protocol apply to Protocol) and Article 27.5 of the CBD, which states that the dispute resolution provisions of the CBD apply to any Protocol except as otherwise provided in the Protocol concerned.

176 Biosafety Protocol, Article 28.3.

177 CBD Website, <http://www.biodiv.org/biosafety/issues/finance.aspx> (8/9/05). 


\section{Stockholm Convention on Persistent Organic Pollutants 2001}

\section{Overview}

The Stockholm Convention on Persistent Organic Pollutants (POPs Convention) entered into force on 17 May 2004. It aims to protect human health and the environment from the most dangerous persistent organic pollutants, including the 'dirty dozen', by helping Parties to switch to safer alternatives and to clean up existing stockpiles. ${ }^{178}$ The Convention divides chemicals in three groups: intentionally produced chemicals; unintentionally produced chemicals; and stockpiles. Annexes A and B list intentionally produced chemicals, which are mainly pesticides. Annex A deals with chemicals which are to be eliminated while Annex B deals with those which are to be restricted. Parties are required to prohibit and/or take the necessary measures to eliminate the production, import and export of Annex A chemicals and to restrict the production and use of Annex B chemicals. ${ }^{179}$ In addition, Annex A or B chemicals may only be imported or exported for their environmentally sound disposal or for a use that is permitted for that Party under Annexes A or B. ${ }^{180}$

Annex $C$ lists persistent organic pollutants, which are formed and released unintentionally from anthropogenic sources. Pursuant to Article 5, Parties must take measures to reduce the total releases derived from anthropogenic sources of Annex $\mathrm{C}$ chemicals, with the goal of their continuing minimisation and ultimate elimination. Parties are also obliged to reduce or eliminate releases from stockpiles and wastes of Annex A, B and C chemicals. ${ }^{181}$ Wastes containing POPs are to be handled, collected, transported and stored in an environmentally sound manner and in accordance with international rules (e.g. the Basel Convention). ${ }^{182}$

\section{Compliance mechanisms}

\section{(a) Performance Review Information}

Parties must provide the COP with reports on their implementation and on the effectiveness of their implementation measures in meeting the Convention's aims. They must also provide the Secretariat with statistical data on their total quantities of production, import and export of the listed chemicals or reasonable estimates and a list of States from which or to which it has imported or exported each substance. ${ }^{183}$ This reporting obligation ties in with the Parties' obligation to develop and endeavour to implement a plan for the implementation of their obligations under the Convention, submit that plan to the COP within

178 POP Convention, Article 1 and Greg's chapter.

179 POP Convention, Article 3(1).

180 POP Convention, Article 3(2) and (3).

181 POP Convention, Article 6.

182 POP Convention, Article 6(1)(d).

183 POP Convention, Article 15. 
two years of the date on which the Convention enters into force for it to review and update the plan. Interim guidelines have been developed to assist Parties. ${ }^{184}$

Although primarily related to scientific baseline information, rather than performance review information, Parties are to undertake appropriate monitoring of POPs, including monitoring of their sources and releases into the environment; presence, levels and trends in humans and the environment; environmental transport, fate and transformation; effects on human health and the environment; socio-economic and cultural impacts; release reduction and/or elimination and harmonized methodologies. ${ }^{185}$

\section{(b) Multilateral Non-Compliance Procedure}

The COP is required to develop and approve procedures and institutional mechanisms for determining non-compliance with the provisions of the Convention and for appropriate penalties. $^{186}$

\section{(c) Non-Compliance Response Mechanisms}

Although not yet specified under its NCP, the POPs Convention's provisions that support implementation are well adapted for use in a targeted fashion as non-compliance response mechanisms.

Technical Assistance The Convention provides for the provision on technical assistance to developing Parties. ${ }^{187}$ Technical assistance includes technical assistance for capacitybuilding relating to the implementation of the obligations under the Convention. ${ }^{188}$ Under Article 9, Parties must facilitate or undertake the exchange of information relevant to the reduction or elimination of the production, use and release of POPs and alternatives to POPs. The Secretariat serves as a clearing-house mechanism for information on POPs including information provided by the Parties, intergovernmental organisations and NGOs. Parties must encourage and/or undertake appropriate research, development, monitoring and cooperation pertaining to POPs. In doing so, they must: support and develop international programmes or organisations aimed at defining, conducting, assessing and financing research and data collection and monitoring; support national and international efforts to strengthen scientific and technical research capabilities; and consider the concerns and needs of developing Parties with regard to technical and financial resources with a view to improving their capability to participate in the above mentioned efforts. ${ }^{189}$

Financial Assistance Parties undertake to provide financial support to national activities that are geared towards implementing the Convention. Developed Parties undertake to provide financial resources to developing Parties in accordance with the financial mechanism

184 Article 7(1). See also POP Website, <http://www.pops.int/documents/implementation/nips/> (8/9/05).

185 POP Convention, Article 11.

186 POP Convention, Article 17.

187 POP Convention, Article 12.

188 POP Convention, Article 12.

189 POP Convention, Article 11(2)(a)-(c). 
established under Article 13(6) or to provide financial resources through other bilateral, regional and multilateral means. ${ }^{190}$ At their first meeting, Parties must adopt and provide guidance to the financial mechanism. ${ }^{191}$ In the interim, the GEF is the principal entity entrusted with the operations of the financial mechanism. ${ }^{192}$ The GEF and the Swedish Government have funded workshops to assist Parties in strengthening their national chemicals management programs with respect to the implementation and ratification of this Convention. ${ }^{193}$ At COP-1 (2005), Parties requested the GEF to develop a new focal area and operational procedures to support the implementation of the Convention. ${ }^{194}$

\section{(d) Dispute settlement}

Parties must settle the disputes through negotiation or other peaceful means at first instance. Parties have the option of accepting arbitration (in accordance with procedures to be adopted by the COP) or the International Court of Justice as compulsory means of dispute resolution. These can only be used in relation to Parties accepting the same obligation. Where Parties do not accept these means, or if they have not been able to settle the dispute within 12 months following notification by one Party to another that a dispute exists between them, the dispute must be submitted to a conciliation commission. Procedures relating to the conciliation commission are to be included in an annex to be adopted by COP-2. ${ }^{195}$

190 POP Convention, Article 13(1)-(3).

191 POP Convention, Article 13(7).

192 POP Convention, Article 14.

193 POP Convention Website, <http://www.pops.int/documents/implementation/gef/> (8/9/05).

194 POP Convention Decision I/2.

195 POP Convention, Article 18. 


\section{Atmosphere}

\section{Vienna Convention for the Protection of the Ozone Layer 1985}

\section{Overview}

The Vienna Convention for the Protection of the Ozone Layer entered into force on 22 September 1988. Parties are obliged to take measures to protect human health and the environment against adverse effects likely to result from human activities that modify the ozone layer. ${ }^{196}$ There are no targets or timetables for action. Instead, there is an outline of general obligations on the Parties, which focus on obligations to undertake research on the ozone layer, in particular on the effects of human activities on the ozone layer and how these may be addressed. ${ }^{197}$ It establishes a framework for future international legal measures to protect the ozone layer by providing for future protocols. ${ }^{198}$

\section{Compliance mechanisms}

\section{(a) Performance Review Information}

Parties must transmit to the COP information on the measures adopted by them in the implementation of the Convention and of protocols to which they are Party. ${ }^{199}$ COP-1 (1989) decided that each Party shall submit these reports every two years and shall include the socio-economic and commercial information on the substances referred to in Annex I and directed the Secretariat to prepare a format for reporting. ${ }^{200}$

Other extensive information collection obligations are related to scientific observations of various aspects of the ozone layer, human effects upon it and the impacts of modification of the ozone layer, rather than to performance review. For example, Parties also agree, under Article 3, to promote or establish joint or complementary programmes for systematic observation of the ozone layer and in ensuring the collection, validation and transmission of research and observational data through appropriate world data centres. ${ }^{201}$ At COP-3 (1993), the Parties decided that for the purposes of Article 3 of the Vienna Convention, which deals with cooperation for research and systematic observations, it would be adequate for the Parties to the Convention to report data under the Montreal Protocol on all substances controlled by the Protocol. ${ }^{202}$

\footnotetext{
196 Vienna Convention, Article 2(1).

197 Vienna Convention, Articles 2 and 3.

198 Vienna Convention, Article 8.

199 Vienna Convention, Article 5.

200 Vienna Convention Decision I/2.

201 Vienna Convention, Article 3.

202 Vienna Convention Decision III/4.
} 
There are no provisions or COP decisions for the adoption of a non-compliance procedure.

\section{(c) Non-Compliance Response Measures}

In the absence of any NCP, it is noted here that there are mechanisms in place under the Vienna Convention for the mutual support of Parties in their implementation efforts. These are in place to assist with the primary task of implementation and are not in fact utilised non-compliance response mechanisms. They are noted here merely to indicate that there is assistance available to Parties for implementation.

COP-2 (1991) noted that the information exchange obligations under Annex II of the Convention would largely be fulfilled by Parties reporting on data concerning the handling of ozone depleting substances each calendar year and by exchanging information and reporting on scientific activities in accordance with the Montreal Protocol. The COP called on all Parties to the Convention, whether or not Parties to the amended Protocol, to provide such data and information. ${ }^{203}$

Technical Assistance Under Article 4, Parties must facilitate and encourage the exchange of scientific, technical, socio-economic, commercial and legal information, which is elaborated in Annex II. Annex II, paragraph 1 states that Parties recognise that the collection and sharing of information is an important means of implementing the Convention and that Parties must therefore exchange scientific, technical, socio-economic, business, commercial and legal information. Annex II paragraphs 3 to 6 elaborate on the type of scientific, technical, socio-economic and legal information to be provided. Parties must cooperate in promoting the development and transfer of technology and knowledge, particularly though: facilitation of the acquisition of alternative technologies by other Parties; provision of information on alternative technologies and equipment; supplying necessary equipment and facilities for research and systematic observations; and appropriate training of scientific and technical personnel. ${ }^{204}$

Financial Assistance COP-1 (1989) established a Trust Fund (later to become the 'Multilateral Fund') and Parties were invited to make voluntary contributions to it. ${ }^{205}$ The Parties agreed to cooperate to enhance the capabilities of developing countries to contribute to ozone science research through the organisation of workshops and the identification of appropriate institutions for scientific and financial assistance. ${ }^{206}$ At COP-4 (1996), the Parties invited the GEF to support the monitoring of ozone and UV radiation and related research in developing countries.

203 Vienna Convention Decision II/2. 204 Vienna Convention, Article 4(2). 205 Vienna Convention, Decision I/9. 206 Vienna Convention Decision I/5. 


\section{(d) Dispute Resolution}

Parties are to resolve disputes concerning the interpretation or application of this Convention by negotiation. If negotiations fail, they may jointly request mediation by a third Party. Parties may declare in writing that, for a dispute not resolved through negotiation or mediation, they accept arbitration (with procedures that were adopted by the $\mathrm{COP}^{207}$ ) or the International Court of Justice as compulsory means of dispute resolution. Otherwise, the dispute will be submitted to conciliation. A conciliation commission will be created upon the request of one of the Parties to the dispute. The commission renders 'a final and recommendatory award, which the Parties shall consider in good faith.' ${ }^{208}$

207 Vienna Convention, Decision I/7. 208 Vienna Convention, Article 11. 


\section{Montreal Protocol on Substances that Deplete the Ozone Layer 1987}

\section{Overview}

The Montreal Protocol on Substances that Deplete the Ozone Layer (the Montreal Protocol) entered into force on 1 January 1989. The Protocol lists controlled substances in Annexes A (CFCs and Halons), B (Other halogenated CFCs, carbon tetrachloride and methyl chloroform), C (Hydrochloroflurocarbons and Hydrobromoflurocarbons) and E (Methyl bromide). Annex D contains a list of products containing controlled substances specified in Annex A.

Articles $2 \mathrm{~A}$ to $2 \mathrm{I}$ set out the targets that Parties must achieve with respect to each of these controlled substances and the period of time within which the targets must be met. Developing Parties are given a grace period, allowing a delay of 10 years before being required to take steps to meet these targets. ${ }^{209}$ Article 4 bans the import of the controlled substances listed in the Annexes with non-Parties. However, Article 4B requires each Party to establish and implement a licensing system for the import and export of new, used, recycled and reclaimed controlled substances in the Annexes, by 1 January 2000 or within three months of the date of entry into force of the Article for it, whichever is the later. Article 4A provides that where a Party is unable, despite having taken all practicable steps to comply with its obligations under the Protocol, to cease production of a controlled substance for domestic consumption by its specified phase-out date, other than for uses agreed by the Parties to be essential, it must ban the export of used, recycled and reclaimed quantities of that substance, unless it is being exported for the purpose of destruction.

\section{Compliance mechanisms}

\section{(a) Performance Review Information}

Each Party must provide statistical data to the Secretariat on its annual production of each of the controlled substances. Data must also be provided on amounts of each substance used for feedstocks, destroyed by technologies approved by the Parties, or imported from and exported to Parties and non-Parties for the year during which provisions concerning the substances entered into force for that Party, and for each year thereafter. ${ }^{210}$ Parties must provide statistical data on the annual imports and exports of each of the controlled substances in Group II of Annex A and Group I of Annex C that have been recycled. ${ }^{211}$

209 Montreal Protocol, Article 5.

210 Montreal Protocol, Article 7. The Parties' reduction targets in relation to controlled substances are calculated as a percentage of baseline figures. Most controlled substances have a baseline set in 1986. National data for baselines must be provided to the Secretariat within three months of becoming a Party (Article 7).

211 Montreal Protocol, Article 7(3). 
As well as the annual reports, Parties must submit to the Secretariat every two years a summary of the research, development, public awareness and exchange of information activities that they have undertaken pursuant to Article $9 .^{212}$

\section{(b) Multilateral Non-Compliance Procedure}

The Montreal Protocol was the first MEA to design a NCP. Under Article 8, Parties were obliged to consider and approve procedures and institutional mechanisms for determining non-compliance. In 1989, Decision I/8 established an Open-ended Ad Hoc Working Group of Legal Experts to develop NCPs. The Parties approved an interim mechanism for determining non-compliance, namely, an Implementation Committee, and directed the Working Group to elaborate on these procedures by MOP-4 (1992). ${ }^{213}$ The interim NCP provided that any Party and the Secretariat could report a non-compliant Party to the Implementation Committee. The non-compliant Party would then be given notice of the allegation and an opportunity to respond. The Committee was to seek an amicable resolution to the situation and report to the MOP. ${ }^{214}$ The MOP could decide upon steps for full compliance or request the Committee to make recommendations.

A permanent non-compliance mechanism was adopted at MOP-4 (1992). ${ }^{215}$ It continued the Implementation Committee as the body to receive and consider reports of non-compliance. As with the interim procedure, non-compliant Parties are given notice of the allegations and an opportunity to respond and the Committee must report any recommendations to the MOP.

The permanent non-compliance mechanism was reviewed and amended at MOP-10. The amendments, inter alia, required the Implementation Committee to report persistent patterns of non-compliance to the MOP and make appropriate recommendations in order to maintain the integrity of the Protocol. ${ }^{216}$

\section{(c) Non-Compliance Response Measures}

In response to the recommendations of the Implementation Committee, the MOP may authorise any of the following: assistance for the collection and reporting of data; technical assistance; technology transfer and financial assistance; information transfer and training; the issuing of a caution; or the suspension of specific rights and privileges under the Protocol.

Technical Assistance Article 9 states that the Parties shall cooperate in promoting research, development and the exchange of information on: best technologies for improving the containment, recovery, recycling or destruction of controlled substances or reducing their emissions; possible alternatives to controlled substances, to products containing such

212 Montreal Protocol, Article 9(3).

213 Montreal Protocol Decisions II/5 and III/2.

214 YBIEL, Vol.1, 1990, p.78.

215 Montreal Protocol Decision IV/5.

216 Montreal Protocol Decision X/10. 
substances and to products manufactured with them; and the costs and benefits of relevant control strategies. Parties must also cooperate in promoting public awareness of the environmental effects of the emissions of controlled substances. Article 10A provides that each Party shall take steps to ensure that the best available environmentally safe substitutes are transferred to developing Parties and that the transfers occur under fair and favourable conditions.

Financial Assistance At MOP-1 (1989), the Parties agreed to consider at MOP-2 (1990) the development of a programme which would include workshops, demonstration projects, training courses, the exchange of experts and the provision of consultants on control options, taking into account the special needs of developing countries as well as the exploration of ways to promote the exchange and transfer of environmentally sound substitutes and alternative technologies. ${ }^{217}$ This issue was primarily addressed through the amendment of Article 10. ${ }^{218}$ Amended Article 10 establishes a financial mechanism. It requires that Parties shall establish a mechanism for the purposes of financial and technical cooperation, including the transfer of technologies, to enable developing Parties to comply with control measures. This financial mechanism includes a Multilateral Fund, which finances, inter alia, clearing-house functions to facilitate technical cooperation, distribute information, hold workshops and training sessions and facilitate and monitor other multilateral, regional and bilateral cooperation for developing Parties. The Multilateral Fund is financed by developed Parties and controlled by its own Executive Committee, which is elected on a geographically representative basis by the MOP. It works in cooperation and with the assistance of the World Bank, UNEP, UNDP or other appropriate agencies.

Penalties The Montreal Protocol was the first MEA to incorporate multilaterally determined penalties into its range of non-compliance responses. Under the NCP the MOP can issue warnings, although this has happened only once. The power to suspend rights and privileges includes those concerning production, consumption, trade, transfer of technology, assistance for industrial rationalisation, financial mechanism and institutional arrangements. The suspension of rights has never been exercised.

\section{(d) Dispute Resolution}

The dispute resolution procedure in Article 11 of the Vienna Convention applies to the Protocol by virtue of Article 11(6) of the Convention, which states that the provisions of Article 11 apply with respect to any protocol. Article 14 of the Protocol provides that the provisions of the Convention relating to its protocols shall apply to the Montreal Protocol.

217 Montreal Protocol Decision I/4.

218 Montreal Protocol Decision II/2. 


\section{United Nations Framework Convention on Climate Change 1992}

\section{Overview}

The United Nations Framework Convention on Climate Change (UNFCCC) entered into force on 21 March 1994. It aims to achieve stabilisation of greenhouse gas concentrations in the atmosphere at a level that would prevent dangerous anthropogenic interference with the climate system. ${ }^{219}$ Such a stabilisation level should be achieved 'within a time-frame sufficient to allow ecosystems to adapt naturally to climate change, ensure food production is not threatened and to enable economic development to proceed in a sustainable manner.'220 The level and the timeframe are omitted from the provision.

All Parties have general obligations to develop domestic and, if possible, regional programmes and measures to mitigate climate change; promote and cooperate in the development, application and diffusion of technologies, practices and processes that control, reduce or prevent anthropogenic emissions of greenhouse gases outside the scope of the Montreal Protocol; promote conservation and enhancement of sinks and reservoirs of all greenhouses gases outside the scope of the Montreal Protocol; cooperate in preparing for adaptation to climate change; and promote scientific and technical cooperation. ${ }^{221}$

Developed countries are required to lead climate change mitigation by adopting policies and measures limiting anthropogenic greenhouse gas emissions. Under Article 4.2, these policies and measures should 'recognise' that, a return to 'earlier emission levels' by the year 2000 would 'Contribute' to modification of longer-term climate change trends. ${ }^{222}$ The year 2000 passed without any Party achieving the Convention's stated aim. However, the Parties were to 'review the adequacy' of the aim under Article 4.2 at their first Conference. ${ }^{223}$ The result of that review was the 1997 Kyoto Protocol, discussed below.

The guiding legal principles for implementation are set out in Article 3 and include: inter-generational equity; common but differentiated responsibility between developed and developing countries; the precautionary principle; sustainable development; and an open international economic system. Of these principles, the most clearly reflected in the UNFCCC text is differentiated responsibility. Differentiated responsibilities for developed Parties are specified in two matters. Special obligations are imposed upon them to: (1) adopt 'policies and measures' to reduce their greenhouse gas emissions under Article 4.2; and (2) provide 'new and additional financial resources' to developing Parties under Article 4.3. Annex I contains a list of the developed countries that includes most 'western' countries and ex-Soviet bloc countries. Annex II lists from among those Annex I Parties only the 'western' countries that are obliged to provide financial and technological assistance.

219 UNFCCC, Article 2.

220 UNFCCC, Article 2.

221 UNFCCC, Article 4.1.

222 UNFCCC, Article 4.2(a).

223 UNFCCC, Article 4.2(d). 


\section{Compliance Mechanisms}

\section{(a) Performance Review Information}

Article 12 requires all Parties to submit: a national inventory of anthropogenic emissions by sources and removals by sinks of all greenhouse gases (but not controlled by the Montreal Protocol) using agreed methodologies; a general description of their steps to implement the aims of the Convention; and any other relevant information. This obligation falls upon both developed and developing country Parties but, as indicated below, the former are to assist the latter to meet their inventory obligations. Developed country Parties must also provide a detailed description of policies and measures that they have adopted to implement their commitment under Article 4.2. Developed Parties, particularly each listed in Annex II, must provide information on measures that they have taken in accordance with their assistance commitments in Article 4.3, 4.4 and 4.5. At COP-5 (1999), a consultative group of experts was established to assist developing countries in meeting their reporting obligations. ${ }^{224}$

Developed Parties must submit information on greenhouse gas emissions and removals on an annual basis. ${ }^{225}$ Least-developed countries (LDCs) submit National Adaptation Programmes of Action (NAPAs) on their needs and priorities for adaptation. ${ }^{226}$ Article 4.9 and decision 5/CP.7 recognised the specific needs and special situations of the LDCs with regard to funding and transfer of technology. That decision established an LDC work programme that included the development of NAPAs. Decision 28/CP.7 sets out the guidelines while decision 29/CP.7 establishes an LDC Expert Group (LEG) to provide guidance and advice on the preparation and implementation of NAPAs.

The UNFCCC may authorize verification missions to review implementation. ${ }^{227}$

\section{(b) Multilateral Non-Compliance Procedure}

Article 13 provides that the COP shall consider the establishment of a multilateral consultative process (MCP) for the resolution of questions regarding implementation. Decision 10/CP.4 established the multilateral consultative process in the form of a Multilateral Consultative Committee. Parties may submit questions concerning their own or another Party's implementation to the Committee, which may then provide advice or recommendations on the procurement of technical and financial resources for the resolution of a Party's difficulties or provide advice on the compilation and communication of information. The conclusions and recommendations must be sent to the Party concerned for comment. Although COP-5 was supposed to bring the multilateral consultative process into opera-

224 UNFCCC, Decision 8/CP.5.

225 UNFCCC, Article 4(1). See also UNFCC Website, <http://unfccc.int/national reports/items/1408.php > (8/9/05).

226 See also UNFCC Website, <http://unfccc.int/national_reports/items/1408.php> (8/9/05).

227 See Wang, $\mathrm{X}$ and Wiser, $\mathrm{G}$, The Implementation and Compliance Regimes under the Climate Change Convention and its Kyoto Protocol', Vol. 11(2) Review of European Community and International Environmental Law, 2002, pp.183, 185. 
tion following resolution of outstanding issues regarding the composition of the MCP, the COP has not yet done so. ${ }^{228}$

\section{(c) Non-Compliance Response Measures}

The technical or financial resources in relation to which the MCP is to advise are well established under the UNFCCC.

Technical Assistance At COP-7 and, as a part of the Marrakesh Accords, the Parties agreed to work together on a set of technology transfer activities. These activities have five main themes: technology needs and needs assessments; technology information; enabling environments; capacity building; and mechanisms for technology transfer. ${ }^{229}$ The Marrakesh Accords also provide for the establishment of an Expert Group on Technology Transfer (EGTT) to facilitate and advance technology transfer activities. ${ }^{230}$ Further, the Secretariat has developed a clearing-house mechanism to facilitate the flow of, and access to, information on developing and transferring safe technologies. ${ }^{231}$

Financial Assistance Developed Parties, specifically those listed in Annex II, must additionally provide 'new and additional financial resources' to developing countries to meet the full implementation costs of the Convention. ${ }^{232}$ These concern inventories and any voluntary measures the developing countries take towards mitigation of the greenhouse gas emissions. Further, they must take all practicable steps to promote, facilitate and finance, as appropriate, the transfer of, or access to, environmentally sound technologies and know-how to other Parties, particularly to developing countries to enable them to implement the provisions of the Convention. ${ }^{233}$

Article 11 of the Convention establishes a financial mechanism for the provision of financial resources to developing countries on a grant or concessional basis, including for the transfer of technology. The operations of the financial mechanism are entrusted in the COP to develop. The provision also states that developed Parties may also provide, and developing country Parties avail themselves of, financial resources related to the implementation of the Convention through bilateral, regional and other multilateral channels.

COP-4 designated the GEF as an operating entity of the financial mechanism on an ongoing basis. ${ }^{234}$ The Marrakesh Accords adopted at COP-7 expanded the scope of activities to which the GEF may provide funding to include activities to adapt to climate change and to build their national capacities to address it. ${ }^{235}$ COP-4 also established the Special Climate

228 See Wang, $\mathrm{X}$ and Wiser, G, 'The Implementation and Compliance Regimes under the Climate Change Convention and its Kyoto

Protocol', Vol.11 (2) Review of European Community and International Environmental Law, 2002, p.186 and Decision.

229 UNFCCC Website, $<$ http://unfccc.int/cooperation and support/technology/items/1126.php $>$ (8/9/05).

230 UNFCCC Decision 4/CP.7.

231 UNFCCC Website, <http://unfccc.int/cooperation_and_support/technology/items/1126.php> (8/9/05).

232 UNFCCC, Article 4.3.

233 UNFCCC, Article 4.5.

234 UNFCCC Decision 3/CP.4.

235 UNFCCC Website, <http://unfccc.int/cooperation and support/funding/items/2807.php > (8/9/05). 
Change Fund, the Least Developed Countries Fund and the Adaptation Fund, which are separate from the GEF Trust Fund but managed by the GEF. ${ }^{236}$

\section{(d) Dispute Resolution}

Parties must resolve disputes concerning the interpretation or application of the Convention by negotiation or other peaceful means. They may declare in writing that they accept the arbitration procedures adopted by COP-1,237 or that they accept submission to the International Court of Justice as compulsory means of dispute resolution. Otherwise, the dispute will be submitted to compulsory conciliation after twelve months following notification by one Party to another that a dispute exists between them. A conciliation commission will be created to render 'a final and recommendatory award, which the Parties shall consider in good faith.'238

236 The Adaptation Fund is relevant to the Kyoto Protocol. See UNFCCC Website, $<$ http://unfccc.int/cooperation_and_support/funding/items/2807.php $>$ (8/9/05). 237 Kyoto Protocol Decision I/7.

238 Kyoto Protocol, Article 11. 


\section{Kyoto Protocol to the United Nations Framework Convention on Climate Change 1997}

\section{Overview}

The third Conference of the Parties to the UNFCCC adopted the Kyoto Protocol to the Climate Change Convention on 11 December 1997. The Kyoto Protocol entered into force on 16 February 2005.

The Protocol quantifies emission limitations and reduction commitments of the greenhouse gases listed in Annex A for the Parties listed in Annex I of the UNFCCC. While each Annex I Party is assigned an individual target amount, the aim is that the aggregate Annex I targets will reduce overall emissions of such gases by at least 5 per cent below 1990 levels by the commitment period of 2008 to $2012 .^{239}$

Article 2 outlines the policies and measures that may be implemented by each Party to achieve their commitments, elaborating on UNFCCC Article 4.1. These include: protection and enhancement of sinks and reservoirs of greenhouse gases; promotion of sustainable forms of agriculture; and development of sources of renewable energy. Although the Protocol was intended to fill in the regulatory framework of the UNFCCC, it was insufficient of its own and further regulatory development was required for the Protocol itself once the text had been adopted. In 1998 UNFCCC COP-4 adopted the 'Buenos Aires Plan of Action,' which sought to operationalize the Protocol.

The Protocol provides for a number of flexibility mechanisms to assist Annex I Parties to achieve their emission reduction commitments.

Annex I Parties may reach agreement to meet commitments jointly, thus adjusting their relative emissions commitments between themselves, provided their total combined emissions do not exceed the sum of the amounts set out for them in Annex B. ${ }^{240}$ This mechanism is useful only in the context of a highly integrated economic bloc such as the European Union, which seeks to protect industrial development within particular members.

The Protocol provides for joint implementation projects that enhance sinks or reduce emissions to be undertaken jointly by Annex I Parties. The resultant 'emission reduction units' can be transferred from the project's host country to benefit the project's investor country. However, any such project must be supplemental to domestic actions for the purposes of achieving the commitments under Article $3 .^{241}$

239 Kyoto Protocol, Article 3.1.

240 Kyoto Protocol, Article 4.

241 Kyoto Protocol, Article 6. 
The Protocol establishes the Clean Development Mechanism, which allows Annex I Parties to invest in projects that enhance sinks or reduce emissions in non-Annex I countries. ${ }^{242}$ Annex I Parties may use the certified emission reductions accruing from such projects to contribute to compliance with their commitments under Article 3.

Annex I Parties are also allowed to trade emissions reductions between them. ${ }^{243}$ Thus, where a developed country has reduced its emissions beyond its obligations as set out in Annex B, it is in 'credit'. It can then sell this credit to a developed country that would find it more expensive to reduce its emissions.

\section{Compliance Mechanisms}

\section{(a) Performance Review Information}

Accurate reporting is essential under the Kyoto Protocol, given the quantified nature of its targets. Its performance review information requirements are the most robust and sophisticated among all current MEAs.

There are different reporting obligations for Annex I and non-Annex I Parties. Article 7 provides for regular self-reporting by UNFCCC Annex I Parties. It states that each Party shall, inter alia, submit the necessary supplementary information to demonstrate compliance with its commitments in its annual emissions inventory and its national communication submitted under the UNFCCC. Reporting guidelines were adopted by the UNFCCC COP ${ }^{244}$. The reporting requirements of the Protocol supersede the reporting requirements under the UNFCCC for Annex I Parties to both instruments. Closely linked, are the obligations to establish national systems for estimating emissions and national registries to track transactions in emissions units. ${ }^{245}$

In addition, the Marrakesh Accords require Annex I Parties to submit three additional reports: a report at the beginning of the commitment period to determine allocated target amounts; a report at the end of the commitment period to assess compliance with Article 3; and a report on 'demonstrable progress' under Article 3.2, which is to be submitted approximately half-way through the commitment period. ${ }^{246}$

Article 8 establishes a third-party process for independent review of self-reported information. This has been mandatory for Annex I Party inventories since 2003. ${ }^{247}$ The process aims at providing a 'thorough and comprehensive technical assessment of all aspects of the implementation by a Party to this Protocol' and should be completed within one year of submission of the national report to the Secretariat. There are three stages in the review process. First, there is an 'initial check' to verify whether the inventory is complete and

242 Kyoto Protocol, Article 12.

243 Kyoto Protocol, Article 17.

244 UNFCCC Decisions 22/CP.7 and 22/CP.8.

245 Kyoto Protocol, Article 5.1 and Decision 19/CP.7.

246 Yamin, F and Depledge, J, The International Climate Change Regime Guide to Rules, Institutions and Procedures (Cambridge University Press, Cambridge, 2004) p.344.

247 http://unfccc.int/national reports/annex i ghg inventories/review process/items/2762.php (3/11/05). 
properly formatted. ${ }^{248} \mathrm{~A}$ 'synthesis and assessment' follows, which involves compiling and comparing inventory information. ${ }^{249}$ The final stage is individual review, which involves an inventory review by an expert review team or experts in their home country. ${ }^{250}$ Expert review teams are led by two experts, one from a non-Annex I Party and one from an Annex I Party. ${ }^{251}$ Essentially, the Protocol inherits the UNFCCC's monitoring and verification procedures. However, the Protocol makes provision for the elaboration of such procedures following the first COP-MOP. ${ }^{252}$

Non-Annex I Parties also have reporting obligations: they must include details about their programs and activities undertaken pursuant to Article 10 in their national communications. ${ }^{253}$ (Annex I Parties also have this obligation. ${ }^{254}$ )

\section{(b) Multilateral Non-Compliance Procedure}

The NCP under the Protocol is the most elaborate of those adopted under MEAs thus far. Article 18 provides that the UNFCCC COP, which serves as the MOP to the Protocol, shall approve appropriate and effective procedures and mechanisms to determine and to address cases of non-compliance with the Protocol. The NCP was adopted at the UNFCCC COP-7 (2001). ${ }^{255}$ It entered into force at the first meeting of the Protocol's COP-MOP (2005) and its Compliance Committee met for the first time in 2006.

The NCP may be triggered by a Party with respect to itself, or by another Party, by the Secretariat or by Expert Review Teams under Article 8. Its functional body is a Compliance Committee consisting of two branches: the Facilitative Branch and the Enforcement Branch. ${ }^{256}$

The Facilitative Branch is responsible for facilitating the Protocol's implementation and determines whether Annex I Parties are complying with the following obligations:257

- Qualified emissions limitation or reduction commitments under Article 2;

- Reporting requirements and methodologies under Articles 4, 5.1, 5.2 and 7.1; and

- Eligibility requirements to access the mechanisms under Articles 6 (emission reduction units), 12 (clean development mechanism) and 17 (emissions trading).

248 http://unfccc.int/national_reports/annex_i_ghg_inventories/review_process/items/2762.php (3/11/05).

249 http://unfccc.int/national reports/annex i ghg inventories/review process/items/2762.php (3/11/05).

$250 \mathrm{http}: / /$ unfccc.int/national_reports/annex_i ghg_inventories/review_process/items/2762.php (3/11/05).

$251 \mathrm{http}: / /$ unfccc.int/national reports/annex_i ghg_inventories/review_process/items/2762.php (3/11/05).

252 See also Articles 6.2, 12.7 and 17.

253 Kyoto Protocol, Article 10.1(f).

254 Kyoto Protocol, Article 10(b) (ii).

255 UNFCCC Decision 24/CP.7.

256 UNFCCC Website, <http://unfccc.int/kyoto_mechanisms/compliance/items/3024.php> (8/9/05).

257 Yamin, F and Depledge, J, The International Climate Change Regime Guide to Rules, Institutions and Procedures, Cambridge University

Press, Cambridge, 2004, p.393. 
Eligibility to access the mechanism is determined by the following criteria: whether the Party has ratified the Protocol; its calculated assigned amount of GHG emissions; whether it has developed a national system for estimating emissions and removals of GHG within its jurisdiction; whether the Party has established a national registry to record and monitor the movement of certain substances; and meeting the annual reporting requirements on emissions and removals. ${ }^{258}$

\section{(c) Non-Compliance Response Mechanisms}

The Facilitative Branch may provide advice, facilitate the provision of technical and financial assistance including technology transfer and capacity building (having regard to UNFCCC Articles 4.3, 4.4 and 4.5) or provide recommendations to the non-compliant Party (having regard to Article 4.7 of the UNFCCC). ${ }^{259}$

Technical Assistance Article 10 reaffirms and expands upon the existing commitments under UNFCCC Article 4.1. It requires Parties to take into account UNFCCC Articles 4.3, 4.5 and 4.7 in formulating cost-effective national and regional programmes to improve the quality of local emission factors and to mitigate the effects of climate change. Parties must cooperate in the promotion of effective modalities for the development, promotion, facilitation and financing of the transfer of, or access to, environmentally sound technologies pertinent to climate change. ${ }^{260}$ Parties must also cooperate in scientific and technical research and in the development of training and development programmes, including capacity building. ${ }^{261}$

Financial Assistance Article 11 incorporates the financial mechanism under the UNFCCC to assist developing countries to meet their commitments under UNFCC Article 4.1. Article 11.2 provides that developed Parties and Annex II Parties must provide new and additional financial resources to meet the agreed full costs incurred by developing Parties in implementing their commitments under UNFCCC Article 4.1, as now covered by Article 10(a) of the Protocol. The guidance provided to the financial mechanism (i.e. the GEF) under the UNFCCC, applies to all relevant respects to Article $11 .{ }^{262}$ As previously noted, the Marrakesh Accords established an Adaptation Fund, reflecting the need for additional funding for the climate change focal area of the GEF. ${ }^{263}$ The Adaptation Fund was under the guidance of the UNFCCC COP until the entry into force of the Protocol. ${ }^{264}$ The Adaptation Fund is to be operated by the GEF but is separate from the GET Trust Fund. ${ }^{265}$

258 http://unfccc.int/kyoto mechanisms/items/1673.php (3/11/05).

259 Yamin, F and Depledge, J, The International Climate Change Regime Guide to Rules, Institutions and Procedures, Cambridge University Press, Cambridge, 2004, p.392.

260 Kyoto Protocol, Article 10(c).

261 Kyoto Protocol, Article 10(d) and (e).

262 Kyoto Protocol, Article 11.2.

263 Yamin, F and Depledge, J, The International Climate Change Regime Guide to Rules, Institutions and Procedures, Cambridge University Press, Cambridge, 2004, p.290. See also UNFCCC Decision 7/CP.7, paragraph 1.

264 Yamin, F and Depledge, J, The International Climate Change Regime Guide to Rules, Institutions and Procedures, Cambridge University Press, Cambridge, 2004, p.290.

265 Yamin, F and Depledge, J, The International Climate Change Regime Guide to Rules, Institutions and Procedures, Cambridge University Press, Cambridge, 2004, p.290. 
Penalties The Kyoto Protocol sets out the most prescriptive and potentially costly penalties for non-compliance under current MEAs. However, to the extent that they purport to modify the legal rights of the Parties under the Protocol, there is a legal question hanging as to whether the penalty mechanisms currently adopted by resolution must be adopted by amendment in order to entail binding legal consequences. ${ }^{266}$ Article 18 of the Protocol specifies that any mechanisms entailing binding consequences must be adopted by means of an amendment to the Protocol. UNFCCC Decision 24/CP.7 adopted the procedures and mechanisms relating to compliance that were negotiated in the Marrakech Accords, and recommended that COP-MOP-1 adopt those procedures and mechanisms as well. At COP-MOP-1, the procedures set out in Decision 24/CP.7 were approved and adopted in full, although 'without prejudice' to consideration of the need to amend of the Kyoto Protocol in accordance with Article 18. The Subsidiary Body on Implementation was tasked with considering the amendment issue and reporting to COP-MOP-3 (2007).

The NCP provides that the Enforcement Branch may, when a Party is non-compliant, determine whether to adjust or correct a Party's emission commitments, where the Party and the expert review team under Article 8 disagree. ${ }^{267}$ Where any Party breaches Articles 5.1, 5.2, 7.1 or $7.4,{ }^{268}$ the Enforcement Branch may declare that the Party is non-compliant, and request a compliance action plan. ${ }^{269}$ Where an Annex I Party does not meet the eligibility requirements to use the flexibility mechanisms under Articles 6, 12 and 17, the Enforcement Branch can suspend the Party from accessing the flexibility mechanisms. ${ }^{270}$

\section{(d) Dispute Resolution}

The Protocol adopts the dispute resolution procedure in the UNFCCC. UNFCC Article 14.8 provides that the dispute resolution procedures in Article 14 apply to any related legal instrument that the COP adopts.

266 Gregory Rose,'A Compliance System for the Kyoto Protocol' 7(2) UNSW Law Journal Forum (2001) 37-42 UNSW Law Journal, p.591. 267 Yamin, F and Depledge, J, The International Climate Change Regime Guide to Rules, Institutions and Procedures, Cambridge University Press, Cambridge, 2004, p.393.

268 Article 7.4 deals with reviewing guidelines for the preparations of national communications by Annex I Parties.

269 Yamin, F and Depledge, J, The International Climate Change Regime Guide to Rules, Institutions and Procedures, Cambridge University Press, Cambridge, 2004, p.393.

270 Yamin, F and Depledge, J, The International Climate Change Regime Guide to Rules, Institutions and Procedures, Cambridge University Press, Cambridge, 2004, p.393. 


\section{International Convention for the Regulation of Whaling 1946}

\section{Overview}

The International Convention for the Regulation of Whaling entered into force on 10 November 1948. The preamble states that the aim of the Convention is to 'establish a system of international regulation for the whale fisheries to ensure proper and effective conservation and development of whale stocks... and thus make possible the orderly development of the whaling industry.'

Article III establishes the International Whaling Commission. The Commission may adopt regulations for protected and unprotected species, open and closed seasons, open and closed waters, size limits, time, methods and intensity of whaling, types of equipment to be used, methods of measurement and catch returns and other records. ${ }^{271}$ Article IX requires Parties to take measures to implement the Convention and punish infractions.

The Convention lacks provisions for the regular assessment of whale populations, and whale hunting for the purposes of scientific research is excluded from the operation of the Convention. ${ }^{272}$ In 1982, the Convention Schedule was amended to require a 'comprehensive assessment' of whale populations prior to lifting the ban on commercial whaling that was imposed in that year. ${ }^{273}$

\section{Compliance Mechanisms}

\section{(a) Performance Review Information}

The Whaling Convention does not have in place a system for coherent review of performance of the Parties in implementing the Convention. It does, however, require that the Parties submit certain information on some of their activities under the Convention.

Parties must provide information on all permits issued for the purposes of the exemption for scientific research to the Commission as well as the results of the scientific research. ${ }^{274}$

\footnotetext{
271 Whaling Convention, Article V.1.

272 Whaling Convention, Article VIII.1.

273 Gregory Rose and Paleokrassis G.'Compliance with International Environmental Obligations - A Case Study of the International Whaling Convention' James Cameron, Werksman J. and Roderick, P., Improving Compliance with International Environmental Law (Earthscan London 1996) 147 at p.160.

274 Whaling Convention, Article VIII.1 and VIII.3.
} 
Parties are also obliged to report to the Commission on the details of infractions of the Convention under their jurisdiction, and to provide information on penalties imposed..$^{275}$

In addition, the Convention imposes domestic monitoring and verification obligations on the Parties. ${ }^{276}$ Initially, Parties were obliged to have two national observers on each 'factory ship' to which the Convention applies and 'adequate inspection' levels at land stations. ${ }^{277}$ However, this system was open to abuse by national authorities. The International Observers Scheme was subsequently adopted in 1972, between the major whaling countries, for the mutual exchange of observers in the Southern Hemisphere, North Pacific, North Atlantic and Antarctic. The observers were obliged to submit compliance and noncompliance reports to the Commission at the end of the season, and report serious infractions. ${ }^{278}$ This system was also open to abuse (e.g. many Soviet vessels simply operated in secret), and it lapsed in 1986 when the last of the bilateral agreements establishing it lapsed. ${ }^{279}$ The Scientific Committee has since embarked upon the task of developing management objectives and procedures (i.e. the Revised Management Procedure (RMP)) and a new inspection and observation system, which would involve an international inspection and observer system. ${ }^{280}$

\section{(b) Multilateral Non-Compliance Procedure}

There is currently no non-compliance procedure.

\section{(c) Non-Compliance Response Measures}

As there is no NCP, there are also no multilateral non-compliance response measures under the Whaling Convention.

However, independently from a formal NCP, measures have been taken against States taking actions that conflict with the aims of the Convention. Due to the strong political sensitivities associated with commercial whaling, especially in 'western' countries, some Parties have resorted unilaterally to political pressure or sanctions against States offending against Commission resolutions, such as trade and fisheries access restrictions. ${ }^{281}$ Parties have adopted measures against unregulated and unreported 'pirate whaling' in a series of resolutions between 1976 and 1981 to boycott the importation of whaling goods from

275 Whaling Convention, Article IX.4 and Schedule, item 15.

276 Article IX.4 and Item 1 of Schedule 1.

277 Whaling Convention Schedule, item 1.

278 Gregory Rose and Paleokrassis G.'Compliance with International Environmental Obligations - A Case Study of the International Whaling Convention' James Cameron, Werksman J. and Roderick, P., Improving Compliance with International Environmental Law (Earthscan London 1996) 147 at p.165.

279 IWC $38^{\text {th }}$ report (1988), p 1 (38 ${ }^{\text {th }}$ Meeting 1986).

280 Gregory Rose and Paleokrassis G.'Compliance with International Environmental Obligations - A Case Study of the International Whaling Convention' James Cameron, Werksman J. and Roderick, P., Improving Compliance with International Environmental Law (Earthscan London 1996) 147 at p.160.

281 Id., at p. 171 . 
non-member countries. ${ }^{282}$ NGOs have also been relatively effective in their boycott campaigns in response to whaling operations conducted by Japan and Norway. ${ }^{283}$

In addition to the General Fund credited or charged with all income and expenditure, the Whaling Convention's Financial Regulations create a Research Fund and a Voluntary Fund for Small Cetaceans. ${ }^{284}$ The Research Fund collects voluntary contributions for research and scientific investigation. The Voluntary Fund, created at its $46^{\text {th }}$ Annual Meeting, allows developing countries to participate in future small cetacean work.

\section{(d) Dispute Resolution}

There is no formal dispute resolution procedure in the Whaling Convention.

282 Id., at p.172.

283 Id., p.171.

284 IWC Website, < $<$ ttp://www.iwcoffice.org/commission/procedure.htm $>$ (17/9/05). 


\section{London Convention on the Prevention of Marine Pollution by Dumping of Wastes and Other Matter 1972}

\section{Overview}

The Convention on the Prevention of Marine Pollution by Dumping of Wastes and Other Matter came into force on 30 August 1975. Under Article I, Parties must promote the effective control of all sources of pollution of the marine environment. Article II obliges the Parties to take individual and collective measures to prevent marine pollution caused by dumping. Article IV.1 (a) provides that Parties must prohibit the dumping of the wastes listed in Annex I. ${ }^{285}$ Generally, the dumping of the wastes listed in Annex II requires a special permit while the dumping of all other wastes requires a general permit. Permits are only issued after the Party considers the factors specified in Annex III. The provisions of Article IV do not apply in certain circumstances, i.e. when it is necessary to secure human life or vessels in cases of force majeure. ${ }^{286}$ In 1996, Parties adopted the Protocol to the London Convention, which is more restrictive than the Convention. It supersedes for and among the Contracting Parties the convention. It entered into force 24 March 2006.

\section{Compliance Mechamisms}

\section{(a) Performance Review Information}

Parties are required to designate an appropriate authority to keep records of the nature and quantity of waste that is dumped, including the location, time and method of dumping. ${ }^{287}$ Under Article VI.4, Parties are obliged, either directly or through a Secretariat established under a regional agreement, to report this information to the Organisation, i.e. the London Convention Secretariat, as well as the criteria that they have adopted for the purpose of issuing permits. The prohibition of dumping for substances not mentioned in Annex I and dumping in cases of force majeure and emergencies should be referred to the Organisation. ${ }^{288}$

Each national authority is obliged to monitor the condition of the seas either individually or with other Parties. ${ }^{289}$ Under Article VII.3, the Parties agree to cooperate in the development of procedures for the reporting of vessels and aircraft observed dumping in contravention of the Convention.

285 London Convention, Article V.2.

286 London Convention, Article V.1. See also Article V.2, which states that a Party may issue a special permit as an exception to article IV

(1) (a) in emergencies.

287 London Convention, Article IV.1(c).

288 London Convention, Articles IV.3, V.1 and V.2.

289 London Convention, Article VI.1(d). 
There is no non-compliance procedure under the London Convention ${ }^{290}$.

\section{(c) Non-Compliance Response Measures}

Technical Assistance Article IX provides that the Parties must promote, through collaboration within the Organisation and other international bodies, support for those Parties that request assistance for the training of scientific and technical personnel, technology for research, monitoring and the disposal and treatment of waste. At the consultative meeting in 1996, the Parties voted to establish a Technical Cooperation Programme as well as a Long-Term Strategy for Technical Cooperation activities. ${ }^{291}$

Penalties Under Article X, Parties undertake to develop procedures for the assessment of liability and the settlement of disputes regarding dumping, in accordance with the international legal principles relating to state responsibility for damage to the environment. There is a similar provision in the London Protocol under Article 15. In addition, under Article 11, the London Protocol provides for the development of a NCP within two years of its entry into force.

\section{(d) Dispute Resolution}

Under Article XI, Parties must consider procedures for the settlement of disputes at the First Consultative Meeting. A dispute resolution procedure was adopted at the Third Consultative Meeting in 1978 as an amendment to the Convention but it never came into force. The amendment provides that if negotiations fail, the dispute must be submitted to the International Court of Justice or to arbitration in accordance with the arbitration procedures in Annex III, if one of the Parties so requests. ${ }^{292}$ This amendment instead formed the basis of the Arbitral Procedure in Annex 3 to the London Protocol. ${ }^{293}$

290 The Protocal recognizes the importance of implememtation and Article 11 details compliance procedures under which, no later than two years after entry into force of the Protocol, the Meeting of Contracting Parties "shall establish those procedures and mechanisms necessary to assess and promote compliance".

291 List of London Convention Resolutions, <http://www.londonconvention.org/> (25/10/05).

$292 \mathrm{Gr}$. J.Timagenis International Control of Marine Pollution (Dobbs Ferry NY 1980) p.282.

293 List of London Convention Resolutions, <http://www.londonconvention.org/> (25/10/05). 


\section{United Nations Convention on the Law of The Sea 1982}

\section{Overview}

The United Nations Convention on the Law of the Sea (UNCLOS) entered into force on 16 November 1994. The product of nine years of negotiations, UNCLOS codified customary law and treaty law stemming from the Geneva Conventions on the Law of the Sea ${ }^{294}$ into 320 articles and nine annexes. It created new legal regimes in respect of the 200-mile exclusive economic zone and the 12-mile territorial sea, exploitation of the deep seabed, transit through international straits, archipelagic and landlocked States, marine pollution, marine fisheries management and the continental shelf. ${ }^{295}$ Part XII of UNCLOS focuses solely on control of marine pollution and, together with Part XV, which concerns dispute settlement, is considered here.

Part XII contains provisions on preventing, reducing and controlling marine pollution. Article 204 obliges Parties to observe measure, evaluate and analyse, by recognised scientific methods, the risks or effects of pollution of the marine environment. In essence, Article 204 imposes impact assessment and monitoring obligations in respect of the risks or effects of pollution. Article 205 requires Parties to publish reports on the results obtained pursuant to Article 204 and provide them to 'competent international organisations.' It has been left to subsequent instruments to flesh out the details of the marine pollution regime.

\section{Compliance Mechanisms}

\section{(a) Performance Review Information}

There are no performance review obligations incumbent upon the Parties. The UN Secretary-General provides an annual report to the General Assembly concerning the implementation of UNCLOS.

\section{(b) Multilateral Non-Compliance Procedure}

UNCLOS and its MOP have not established a multilateral non-compliance procedure.

\section{(c) Non-Compliance Response Mechanisms}

Although UNCLOS does not set out any non-compliance response mechanisms, it does contain implementation support provisions that promote assistance to Parties in the discharge of their primary marine environmental obligations. Those provisions are noted

294 Geneva Conventions on the Territorial Sea and the Contiguous Zone 1958, 516 UNTS 205 on the High Seas 1958, 450 UNTS 82, on the Continental Shelf 1958, 499 UNTS 311 and on Fishing and Conservation of the Living Resources of the High Seas 1958, 599 UNTS 285.

295 Harris, D.J, Cases and Materials on International Law, $5^{\text {th }}$ Edition, Sweet \& Maxwell, London, 1998, p.370. 
here because they support implementation, not because they set out non-compliance responses. The provisions relate to technical assistance and legal liability for breaches causing damage to a Party. There are no financial assistance provisions and no multilateral processes.

Technical Assistance UNCLOS contains technical assistance provisions in relation to marine conservation and pollution, marine research and exploitation of the deep seabed. In relation to marine conservation and pollution, Article 61.5 states that available scientific information relevant to the conservation of fish stocks and catch and fishing statistics must be exchanged on a regular basis. There are provisions for technical assistance to developing Parties. ${ }^{296}$ Further, Parties have a duty to cooperate with other States in the conservation and management of living resources in the high seas. ${ }^{297}$ States whose nationals exploit living resources in the same area must enter into negotiations with a view to conserving the resources so exploited. ${ }^{298}$ In relation to marine research, Part XIV provides for the development and transfer of marine technology and calls on Parties to cooperate and facilitate exchanges through existing bilateral, regional or multilateral programmes. ${ }^{299}$

Penalties. Under UNCLOS, Parties are to be mutually liable under international laws for their failures to fulfil their obligations to protect and conserve the marine environment. ${ }^{300}$ They must ensure that recourse to compensation is available in accordance with their national laws. ${ }^{301}$ In addition, Parties are liable for damages caused by failures to ensure that their activities undertaken in the seabed area comply with Part XI. ${ }^{302}$ Finally, they are to be liable in respect of failing to adhere to the Convention's procedures on the conduct of marine scientific research. ${ }^{303}$ In none of these cases, however, does UNCLOS go beyond statements of general principles to specify the procedures for establishing and imposing liability.

\section{(d) Dispute Resolution}

The UNCLOS dispute resolution system is extraordinary for its comprehensive, compulsory and binding nature. The dispute resolution procedure comprises two parts. Section 1 of Part XV contains general provisions relating to the peaceful settlement of disputes. Section 2 of Part XV contains provisions concerning compulsory dispute resolution procedures.

Under Section 1, Article 279 states that the Parties must settle any disputes between them regarding the interpretation or application of the Convention in accordance with Article 2(3) of the UN Charter and by any of the means indicated in Article 33(1) of the UN Charter. ${ }^{304}$ Article 280 provides that Parties have the right to settle any dispute between them through peaceful means of their choice, while Article 283 reiterates this point, stat-

\footnotetext{
296 UNCLOS, Article 202.

297 UNCLOS, Article 117.

298 UNCLOS, Article 118.

299 UNCLOS, Articles 266 and 270.

300 UNCLOS, Article 235.1.

301 UNCLOS, Article 235.2.

302 UNCLOS, Article 139.

303 UNCLOS, Article 263.

304 United Nations Charter, Article 33 states that the 'Parties to any dispute, the continuance of which is likely to endanger the maintenance of international peace and security, shall, first of all, seek a solution by negotiation, enquiry, mediation, conciliation, arbitration, judicial settlement, resort to regional agencies or arrangements, or other peaceful means of their own choice.'
} 
ing that, when a dispute arises, the Parties must 'proceed expeditiously to an exchange of views regarding its settlement by negotiation or other peaceful means.' Those 'other peaceful means' may have been agreed to in advance. For example, the European Union would submit any fisheries dispute arising between members to the European Court of Justice. ${ }^{305}$ If they have not been agreed to, Parties can opt for any judicial or non-judicial procedures. $^{306}$

If the Parties fail to resolve the dispute once these agreed procedures have been undertaken, one of the Parties can invite the other to submit to the conciliation procedure outlined in Article 284 and Annex V. If the invitation is accepted, each Party can nominate four conciliators from who each must choose two. The four conciliators then choose a fifth person who acts as the chairman. The conciliators have one year to make a report and recommendations.

If conciliation fails or the invitation is rejected, Parties then have the right to invoke the compulsory dispute settlement procedures in Section 2 of Part XV. The compulsory procedures entail binding decisions. Articles 286 and 287 oblige the Parties to have recourse to the compulsory procedures if the peaceful means that they chose to resolve the matter failed. However, this obligation has exceptions:

- Article 297(1) states that Parties cannot invoke the compulsory procedures for a dispute concerning the exercise of another Party's rights or jurisdiction within its exclusive economic zone (EEZ), unless it is alleged that: the State has contravened the Convention with respect to the freedoms and rights of navigation, overflight or the laying of submarine cables and pipelines, or in regard to other internationally lawful uses of the sea outlined in Article 58; in exercising any such freedoms the State has contravened the Convention on national laws adopted in conformity with the Convention; or the State has exercised its jurisdiction inconsistently with internationally adopted rules on marine pollution.

- Article 297(2) states that Parties are not obliged to submit disputes concerning the refusal to give permission to conduct scientific research in their EEZs or continental shelves. If the dispute is not submitted to the compulsory procedures, it must be submitted to the conciliation procedure under Annex V.

- The compulsory procedures are not applicable to disputes arising from failures to determine total allowable catches and coastal harvesting capacities, allocating surpluses to other States and the terms of conservation measures. However, where it is alleged that a State has failed to ensure that its EEZ fish stocks are not seriously endangered, or it has arbitrarily refused to determine total allowable catches or harvesting capacity or to allocate a surplus to other States, the 'compulsory conciliation procedure' may be invoked. ${ }^{307}$

305 E.D. Brown The International Law of the Sea - Vol. 1 Introductory Manual (Dartmouth Aldershot 1994) p.454. 306 E.D. Brown The International Law of the Sea - Vol. 1 Introductory Manual (Dartmouth Aldershot 1994) p.454. 307 UNCLOS, Article 297(3). 
Parties can also opt out of the compulsory dispute resolution procedures for disputes concerning sea boundary delimitation and claims to historic waters, military and law enforcement activities and the exercise of Security Council functions. ${ }^{308}$ Disputes falling within the first category may be referred to conciliation at the request of one of the Parties if a resolution is not achieved within a reasonable period of time through negotiation. ${ }^{309}$ Article 298 allows Parties to impose these limitations when signing, ratifying or acceding to the Convention or anytime thereafter.

Parties are given a choice of forum. They can choose to have the matter heard before the International Tribunal for the Law of the Sea, the International Court of Justice, an arbitral tribunal established in accordance with Annex VII or a special arbitral tribunal established in accordance with Annex VIII. ${ }^{310}$ These bodies apply the rules of the Convention and the rules of international law, although Article 293 allows the Parties to request a decision that is made on the general principles of equity and fairness. Parties must declare which of the four bodies they choose as a dispute resolution mechanism at any time. ${ }^{311}$ However, where a Party has not made an election, it is deemed to accept arbitration under Annex VII. ${ }^{312}$

The Tribunal was established under Annex VI and has 21 members who are elected by the Parties. ${ }^{313}$ However, only 11 members are required at any plenary session, although the Tribunal has the power to establish smaller 'chambers' to deal with specific issues. ${ }^{314}$ Thus, the Tribunal has a chamber of summary procedure and chambers for fisheries, environmental disputes and sea-bed disputes. ${ }^{315}$ Disputes concerning the exploration of the international seabed must be submitted to the Seabed Disputes Chamber of the Tribunal and not to any other process. ${ }^{316}$

An arbitral tribunal under Annex VII may be established for disputes between States and disputes involving international organisations. Each UNCLOS Party nominates four people to sit on the panel from the Parties to the dispute must each choose one person. ${ }^{317}$ Three members are then chosen jointly. ${ }^{318}$ The award is final and without appeal unless the Parties have agreed to an appellate procedure. ${ }^{319}$

Disputes concerning fisheries, protecting and preserving the marine environment, marine scientific research or navigation must be submitted for special arbitration in accordance with Annex VIII. ${ }^{320}$ There are four lists dealing with one of the above categories and all Parties to the Convention may nominate two experts in a relevant field to each of these

\footnotetext{
308 UNCLOS, Article 298.

309 UNCLOS, Article 298.1(a).

310 UNCLOS, Article 287.1.

311 UNCLOS, Article 287.1.

312 UNCLOS, Article 287.3.

313 UNCLOS, Annex VI, Article 2.

314 UNCLOS, Annex VI, Article 13.1.

315 UNCLOS, Annex VI, Article 15.

316 UNCLOS, Article 188.

317 UNCLOS, Annex VII, Article 2.

318 UNCLOS, Annex VII, Article 3.

319 UNCLOS, Annex VII, Article 11.

320 UNCLOS, Annex VIII, Article 1.
} 
lists. ${ }^{321}$ Parties may then choose two arbitrators for each case. ${ }^{322}$ The special arbitral tribunal can be used as a fact-finding body. ${ }^{323}$ The findings are binding and if requested, the tribunal can formulate non-binding recommendations. ${ }^{324}$

321 UNCLOS, Annex VIII, Article 2.

322 UNCLOS, Annex VIII, Article 3.

323 UNCLOS, Annex VIII, Article 5.2.

324 UNCLOS, Annex VIII, Article 5.1 and 5.3. 


\section{Agreement for the Implementation of the Provisions of the United Nations Convention on the Law of the Sea of 10 December 1982 Relating to the Conservation and Management of Straddling Fish Stocks and Highly Migratory Fish Stocks 1995}

\section{Overview}

The Agreement for the Implementation of the Provisions of the United Nations Convention on the Law of the Sea of 10 December 1982 relating to the Conservation and Management of Straddling Fish Stocks and Highly Migratory Fish Stocks (the Fish Stocks Agreement) entered into force on 11 December 2001. It aims to ensure the long-term conservation and sustainable use of straddling fish stocks, i.e. stocks that straddle high seas and zones under national jurisdiction, and of highly migratory species, i.e. as listed in UNCLOS Annex II. It focuses on areas beyond national jurisdiction although Articles 6 and 7 apply to the conservation and management of such stocks within areas under national jurisdiction. ${ }^{325}$

Article 5 outlines general principles. Parties must: adopt measures to ensure long-term sustainability of straddling fish stocks and highly migratory fish stocks and to promote the objective of their optimum utilisation; ensure that such measures are based on the best scientific evidence available and are designed to maintain or restore stocks at levels capable of producing the maximum sustainable yield; apply the precautionary approach in Article 6; assess the impact of fishing and environmental factors on target stocks; adopt conservation and management measures to maintain or restore such species above sustainable levels; minimise pollution, waste, catch by lost or abandoned gear or catch of non-target species; take measures to protect biodiversity in the marine environment and to eliminate over-fishing; and promote and conduct scientific research and develop appropriate technologies to support conservation and management.

Article 9 provides a framework for cooperating in or establishing sub-regional or regional fisheries management organisations and arrangements while Article 10 sets out their functions. Some of these functions include agreeing on standards for collection, reporting, verification and exchange of data, compiling and disseminating accurate and complete statistical information in accordance with Annex I and establishing cooperative mechanisms for monitoring, control, surveillance and enforcement. ${ }^{326}$

Under Article 18, a State whose vessels fish in the high seas must take measures to ensure that vessels flying its flag comply with sub-regional and regional conservation and management measures and that any such vessels do not engage in activity which undermine the effectiveness of those measures. Such measures include national laws and policies, including the establishment of licensing systems as well as monitoring and inspection schemes.

325 Fish Stocks Agreement, Articles 2 and 3.1.

326 Fish Stocks Agreement, Article 10(e), (f) and (h). 


\section{Compliance Mechanisms}

\section{(a) Performance Review Information}

The Fish Stocks Agreement does not impose requirements upon its Parties to prepare or submit performance review information. Instead, its information requirements concern (1) conduct and sharing of relevant scientific research and (2) review at the internal national level of domestic fishing unit performance. These two types of information contribute to an informed review of national performance but, of themselves, do not amount to a performance review.

In relation to information concerning scientific baselines for the design of sustainable fisheries management measures, Parties must collect and share complete and accurate data on fishing activities on, inter alia, vessel position, catch of target and non-target species, and fishing effort, as set out in Annex I. They must also submit information from national and international research programs. ${ }^{327}$ They must develop data collection and research programs to assess the impact of fishing on non-target and associated or dependent species and their environment ${ }^{328}$ and must enhance the monitoring of uncertain stocks in order to review their status and the efficacy of conservation and management measures and establish mechanisms for the verification of catch data. States are also to ensure that fishing vessels flying their flag collect and exchange scientific, technical and statistical data with respect to fisheries for straddling fish stocks and highly migratory fish stocks; ensure that data are collected with sufficient detail to facilitate effective stock assessment; and provide such information to sub-regional or regional fisheries management organisations or arrangements and to verify the accuracy of such data. ${ }^{329}$ Parties must take appropriate measures to verify the data that is supplied. In addition, Parties must agree, either directly or through sub-regional or regional fisheries management organisations or arrangements on data specifications and format and develop and share analytical techniques and stock assessment methods.

In relation to performance review of the operations of domestic fishing units, the Parties and regional fishing organisations are required to collect operational information to meet their obligations to conduct effective monitoring, control and surveillance within their jurisdictions. ${ }^{330}$ Under Article 18.3, Parties are obliged to monitor vessels flying their flag, their fishing operations and related activities by, inter alia, implementing national inspection schemes, observer programs and vessel monitoring systems. They must also verify the catch of target and non-target species through observer programs, inspection schemes, unloading reports, supervision of trans-shipment and monitoring of landed catches and market statistics. Subregional and regional fisheries management organisations and arrangements must agree on verification standards for fish stocks. ${ }^{331}$ Further, these subregional and regional fisheries management organisations and arrangements are required

327 Fish Stocks Agreement, Article 5(j).

328 Fish Stocks Agreement, Article 6.2(d).

329 Fish Stocks Agreement, Article 14.

330 Article 5(l).

331 Article 10(e). 
to develop appropriate monitoring, control, surveillance and enforcement procedures. ${ }^{332}$ Finally, under Articles 20.1 and 21, Parties may establish boarding and inspection procedures through regional bodies for boarding and inspection for the purpose of ensuring compliance with conservation and management measures.

\section{(b) Multilateral Non-Compliance Procedure}

The Fish Stocks Agreement does not institute a NCP. Part VI of the Fish Stocks Agreement requires the design of compliance and enforcement systems. These systems do not relate to the compliance of Parties with the Agreement but, rather, to the compliance of a State's fishing vessels with sub-regional and regional conservation management measures. ${ }^{333}$

\section{(c) Non-Compliance Response Measures}

Despite not having a NCP, the Fish Stocks Agreement does set in place certain technical and financial assistance obligations to help developing country Parties meet their commitments. They are not responsive to a finding of non-compliance and, therefore, are not non-compliance response measures. However, they have been included here to give a full picture of measures available to assist a Party with its compliance with the Fish Stocks Agreements.

Technical Assistance Parties acknowledge the special assistance which developing Parties require in conserving and managing straddling fish stocks. ${ }^{334}$ Assistance is to be in the form of financial assistance, human resources development, technical assistance, transfer of technology and advisory and consultative services. ${ }^{335}$

Financial Assistance Article 26 requires Parties to cooperate to establish special funds to assist developing The United Nations General Assembly urged States Parties to the Fish Stocks Agreement to develop terms of reference for a voluntary trust fund within the United Nations system, which would assist developing Parties in meeting their obligations. ${ }^{336}$ At their second informal consultations, the Parties to the Agreement agreed on the terms of reference for an Assistance Fund, and recommended that the General Assembly establish it. ${ }^{337}$

\section{(d) Dispute Resolution}

Like UNCLOS, there is an obligation on Parties to settle disputes peacefully. ${ }^{338}$ Disputes of a technical nature can be referred to an ad hoc expert panel established by them. ${ }^{339}$ However, the compulsory dispute resolution procedure established in Part XV of UNCLOS applies to any dispute between Parties over the interpretation of the Fish Stocks Agreement

332 Article 10(h). See also Article 16.1.

333 Fish Stocks Agreement, Articles 19-23.

334 Fish Stocks Agreement, Article 24.

335 Fish Stocks Agreement, Article 25.2.

336 Resolution 57/143 (17 December 2002). See also UN Website,<http://www.un.org/depts/los/convention_agreements/fishstocktrustfund/fishstocktrustfund.htm $>$ (8/9/05).

337 See also UN Website, <http://www.un.org/depts/los/convention_agreements/fishstocktrustfund/fishstocktrustfund.htm > (8/9/05). 338 Fish Stocks Agreement, Article 27.

339 Fish Stocks Agreement, Article 29. 
or of any sub-regional, regional or global fisheries agreement relating to straddling fish stocks or highly migratory fish stocks to which they are Parties. ${ }^{340}$ Parties must adopt a procedure pursuant to Article 287 of UNCLOS. ${ }^{341}$

340 Fish Stocks Agreement, Articles 30.1 and 30.2.

341 Fish Stocks Agreement, Article 30.3. 
100 COMPLIANCE MECHANISMS UNDER SELECTED MULTILATERAL ENVIRONMENTAL AGREEMENTS 


\section{Chapter III. Comparative Analysis}


102 COMPLIANCE MECHANISMS UNDER SELECTED MULTILATERAL ENVIRONMENTAL AGREEMENTS 


\section{Comparative Analysis}

\section{Overview}

This chapter compares the components of compliance mechanisms by category across MEAs. Where available, the academic, governmental and inter-governmental literature concerning the operational qualities of particular MEA compliance mechanisms is surveyed. As discussed in Chapter II, there are four categories of components in compliance mechanisms.

(a) Performance review information obligations in MEAs require Parties to report on their implementation performance and to provide a range of related statistical data to the Secretariat or COP/MOP. Other compliance-related information obligations involve third-party verification or monitoring of a Party's performance.

(b) Multilateral non-compliance procedures are institutional mechanisms set up to examine performance review information and make determinations as to a Party's compliance status. These procedures may be formal, entailing a special committee to investigate allegations of non-compliance and make recommendations. Others, however, are informal and ad hoc.

(c) Once a NCP has made a determination that a Party is substantially noncompliant, it may suggest responses. These outputs may take the form of recommendations of a Committee to the COP/MOP or the adoption of relevant resolutions by the COP/MOP. The non-compliance response measures adopted under a NCP vary. They include a range of incentives and disincentives, or 'carrots and sticks'.

(d) Finally, there are dispute resolution procedures. These are adversarial and arise between Parties without engaging the COP or Secretariat.

Table 3.1 synthesises some of the information contained in Chapter II to provide a broad overview of the framework for compliance in each MEA. Greater depth concerning the nature of the occurrence of each component of the compliance mechanism is provided in the following sections of this chapter. 
Table 3.1. Overview of MEA Compliance Frameworks

\begin{tabular}{|c|c|c|c|c|}
\hline Convention & $\begin{array}{l}\text { National } \\
\text { Performance } \\
\text { Information }\end{array}$ & $\begin{array}{c}\text { Multilateral } \\
\text { Non- } \\
\text { Compliance } \\
\text { Procedures }\end{array}$ & $\begin{array}{c}\text { Non- } \\
\text { Compliance } \\
\text { Response } \\
\text { Measures }\end{array}$ & $\begin{array}{c}\text { Dispute } \\
\text { Resolution } \\
\text { Procedures }\end{array}$ \\
\hline Ramsar & $\sqrt{ }$ & $\sqrt{ }$ & $\sqrt{ }$ & \\
\hline $\begin{array}{l}\text { World } \\
\text { Heritage }\end{array}$ & $\sqrt{ }$ & $\sqrt{ }$ & $\sqrt{ }$ & $\sqrt{ }$ \\
\hline CITES & $\sqrt{ }$ & $\sqrt{ }$ & $\sqrt{ }$ & $\sqrt{ }$ \\
\hline CMS & $\sqrt{ }$ & $\sqrt{ }$ & & $\sqrt{ }$ \\
\hline $\mathrm{CBD}$ & $\sqrt{ }$ & & & $\sqrt{ }$ \\
\hline UNCCD & $\sqrt{ }$ & Pending & 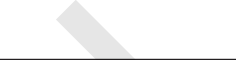 & $\sqrt{ }$ \\
\hline ITPGRFA & & Pending & 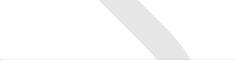 & $\sqrt{ }$ \\
\hline Basel & $\sqrt{ }$ & $\sqrt{ }$ & $\sqrt{ }$ & $\sqrt{ }$ \\
\hline $\mathrm{PIC}$ & & Pending & 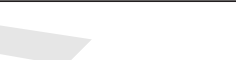 & $\sqrt{ }$ \\
\hline Biosafety & $\sqrt{ }$ & $\sqrt{ }$ & $\sqrt{ }$ & $\sqrt{ }$ \\
\hline POPs & $\sqrt{ }$ & Pending & & $\sqrt{ }$ \\
\hline Vienna Ozone & $\sqrt{ }$ & 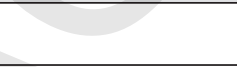 & & $\sqrt{ }$ \\
\hline $\begin{array}{l}\text { Montreal } \\
\text { Protocol }\end{array}$ & $\sqrt{ }$ & $\checkmark V$ & $\sqrt{ }$ & $\sqrt{ }$ \\
\hline UNFCCC & $\sqrt{ }$ & $\sqrt{ }$ & $\sqrt{ }$ & $\sqrt{ }$ \\
\hline Kyoto Protocol & $\sqrt{ }$ & $\sqrt{ }$ & $\sqrt{ }$ & $\sqrt{ }$ \\
\hline Whaling & $\sqrt{ }$ & $\sqrt{ }$ & & \\
\hline London & $\sqrt{ }$ & & & \\
\hline UNCLOS & & & & $\sqrt{ }$ \\
\hline Fish Stocks & & & & $\sqrt{ }$ \\
\hline
\end{tabular}




\section{National Performance Information}

Information on a Party's performance is essential to determine whether it is complying with its obligations. As noted in Chapter II, the provision of related information is often also required at other phases in the implementation of an MEA, i.e. as part of the primary operations requiring information exchange, as part of the provision of technical assistance, or for overall review and redesign of the regime. A particular group of data can be used across several phases of the implementation of the MEA. For example, information on national compliance will be useful at the MEA regime review stage. Reliable information is central to the operation of an MEA and this is especially true regarding compliance, as the core of any compliance mechanism is information on performance.

\section{Self-Reporting}

Most MEAs oblige Parties to provide the secretariat with annual reports that the Parties themselves prepare on their national implementation. These may involve details on the development of national programs, policies and measures (see: CITES, CMS, Ramsar Convention, CBD, Biosafety Protocol, Basel Convention, Vienna Convention, Montreal Protocol, UNFCCC, Kyoto Protocol, Fish Stocks Agreement and Whaling Convention). In particular, UNCCD and the POPs Convention specifically require the Parties to submit information specifically on national implementation plans.

Some Conventions require Parties to submit further scientific, technical and transactional data to the Secretariat. For example, CITES requires Parties to submit annual import/export statistics, while the Fish Stocks Agreement and the Whaling Convention require Parties to submit annual catch/permit reports. The Basel Convention obliges Parties to submit detailed information on their exports, imports, and disposal of hazardous wastes and other wastes on an annual basis. CMS obliges Parties to provide data on the numbers of migratory species passing through their respective jurisdictions. The Montreal Protocol, UNFCCC and Kyoto Protocol require Parties to submit initial baseline and annual production data for listed pollutants. While this data can be used to interpret performance information, in itself it is not performance information.

Only three MEAs do not impose obligations on their Parties to prepare reports on their respective individual performances. These are the ITPGRFA, the PIC Convention and UNCLOS. The ITPGRFA obliges Parties to provide only transactional information to each other on the resources being supplied under its Multilateral System. Similarly, the PIC Convention obliges Parties to provide the Secretariat with information on specific import decisions rather than annual reports. That information is then circulated to the other Parties. In both cases, the information required is operational data to facilitate transactions regulated under the treaty, rather than a system of reflective reporting of national performance. UNCLOS is a framework Convention, leaving reporting requirements to be developed by other, usually regional, organizations.

Generally, specific instructions on the content and format of national performance reports are available from the Secretariat or from the MEA Website. Some Secretariat Websites (e.g. CBD, CITES, Ramsar and Basel) provide report templates that require Parties to tick boxes 
in response to specific questions or require the Parties to otherwise attach information. The majority of MEA websites have posted guidelines that specify the type of information to be included in reports. ${ }^{342}$ For example, the World Heritage Convention has guidelines that specify the purpose, format and general requirements of periodic reports. ${ }^{343}$

\section{Third-party Verification}

Verification is the process of testing the accuracy of performance information provided, usually through on-site inspections. Some MEAs have verification requirements. For example, the Ramsar and UNFCCC/Kyoto Secretariats conduct on-site verifications, mainly to obtain performance information. ${ }^{344}$ The Whaling Convention is currently in the process of developing a new verification procedure. The process is undertaken by a third Party, such as the Secretariat or an NGO, or by them in combination with other Parties to the treaty.

\section{Third-party Monitoring}

In contrast to self-reporting, third-party monitoring of performance engages a non-Party in reporting on national implementation of MEA obligations. In contrast to verification, performance monitoring may address a Party's establishment of systems to implement the MEA but does not involve review of accuracy of particular information for its own sake. (Third-party monitoring of national performance must also be distinguished from third-party monitoring of environmental conditions, which is sometimes undertaken by independent scientific and technical bodies that work in cooperation with the MEA.) Thirdparty monitoring of performance is uncommon, perhaps because it is resource intensive. Under CITES, third Parties - TRAFFIC (an NGO affiliated to WWF) and the WCO - have roles in monitoring compliance. The Ramsar Convention introduces third-party monitoring of degraded wetlands as a non-compliance response ${ }^{345}$, and the Whaling Convention is currently developing a new monitoring procedure.

\section{Non-Compliance Response Information}

Failures to comply with obligations concerning submission of national performance information undermine the regime of an MEA because the information deficit can conceal national non-performance of primary operational obligations. Consequently, failure to comply with performance review obligations is a substantive default that can trigger an MEA's NCP, as is the case under CITES and the Montreal and Kyoto Protocols. Upon

342 CMS, <http://www.cms.int/bodies/COP/cop7/list_of_docs/pdf/en/CP7CF7_06_2_national_report.pdf>;World Heritage, <http:// whc.unesco.org/reporting/prexpl.htm $>$; Ramsar, $<$ http://www.ramsar.org/cop9_nrform_ready_e.htm $>; C B D,<$ http://www.biodiv. org/world/intro.asp $>$; Biosafety, $<$ http://www.biodiv.org/biosafety/cop-mop/result.aspx?id=8291>; POPs, < http://www.pops. int/documents/guidance/>;PIC, <http://www.pic.int/en/viewpage.asp?ld_Cat=104\&mTitre=FORMS+\%26+GUIDANCE >;Vienna, $<$ http://hq.unep.org/ozone/Information_for_the_Parties/3A_data_reporting.asp $>$; Montreal Protocol, <http://hq.unep.org/ozone/ pdfs/Handbook-on-Data-Report-from-UNEP-TIE.pdf $>$;UNFCCC, <http://unfccc.int/national reports/items/1408.php >; and Kyoto, $<$ http://unfccc.int/national_reports/accounting_reporting_and_review_under_the_kyoto_protocol/items/1029.php > (25/10/05).

343 World Heritage, <http://whc.unesco.org/reporting/prexpl.htm>; POPs, <http://www.pops.int/documents/guidance/> (25/10/05).

344 The Basel Convention provision entitled 'Verification' (Art. 19) addresses a trigger mechanism for the NCP. The Fish Stocks Agreement includes an obligation on Parties to develop their own national verification procedures with respect to vessels flying their own flags (Art.18.3). This concerns national implementation rather than performance information.

345 Annex 1 to Recommendation 4.7. 
processing through the NCPs, a response that imposes further performance information obligations on the defaulting Party can result.

The information required under a NCP can be additional to that ordinarily required, or simply require the original performance information as part of a package of additional measures. For example, the NCPs of the Biosafety and Kyoto Protocols require that the defaulting Party submit a compliance action plan outlining how the non-compliant Party will achieve compliance within a set timeframe. ${ }^{346}$ The Basel Convention mandates its Compliance Committee to elaborate, in response to a submission, a voluntary compliance action plan and to review its implementation, which may impose more stringent performance reporting obligations for the Party in question (if it chooses to accept the plan). The CITES Secretariat conducts ad hoc verification missions to assess a Party's compliance with its obligations, both as a primary implementation support and as a non-compliance response. ${ }^{347}$

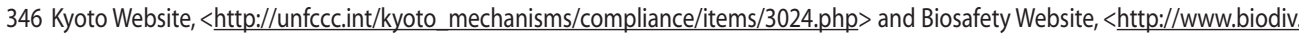
org/biosafety/issues/compliance2.aspx > (25/10/05).

347 Reeves, R, Policing International Trade in Endangered Species: the CITES Treaty and Compliance, Earthscan Publications, London, 2002, p.75. 
Table 3.2. Performance Review Information

\begin{tabular}{|c|c|c|c|c|c|c|c|c|}
\hline \multirow[t]{2}{*}{$\begin{array}{l}\text { Conven- } \\
\text { tion }\end{array}$} & \multicolumn{2}{|c|}{$\begin{array}{l}\text { Review } \\
\text { Format }\end{array}$} & \multicolumn{3}{|c|}{$\begin{array}{c}\text { National } \\
\text { Performance } \\
\text { Review }\end{array}$} & \multicolumn{3}{|c|}{$\begin{array}{c}\text { Non-Compliance } \\
\text { Response Information }\end{array}$} \\
\hline & Template & Guidelines & $\begin{array}{l}\text { Report- } \\
\quad \text { ing }\end{array}$ & $\begin{array}{c}3^{\text {rd }} \text { Party } \\
\text { Verifica- } \\
\text { tion }\end{array}$ & $\begin{array}{l}3^{\text {rd }} \text { Party } \\
\text { Monitor- } \\
\text { ing }\end{array}$ & Reporting & $\begin{array}{l}3^{\text {rd }} \text { Party } \\
\text { Verification }\end{array}$ & $\begin{array}{l}3^{\text {rd }} \text { Party } \\
\text { Monitor- } \\
\text { ing }\end{array}$ \\
\hline Ramsar & $\sqrt{ }$ & & $\sqrt{ }$ & & $\sqrt{ }$ & & & $\sqrt{ }$ \\
\hline $\begin{array}{l}\text { World } \\
\text { Heritage }\end{array}$ & & $\sqrt{ }$ & $\sqrt{ }$ & & $\sqrt{ }$ & & & $\sqrt{ }$ \\
\hline CITES & $\sqrt{ }$ & & $\sqrt{ }$ & $\sqrt{ }$ & $\sqrt{ }$ & & $\sqrt{ }$ & \\
\hline CMS & & $\sqrt{ }$ & $\sqrt{ }$ & & & & & \\
\hline CBD & & $\sqrt{ }$ & $\sqrt{ }$ & & & & & \\
\hline UNCCD & & Pending & $\sqrt{ }$ & & & & & \\
\hline ITPGRFA & & & & $\sqrt{ }$ & & & & \\
\hline Basel & $\sqrt{ }$ & $\sqrt{ }$ & $\sqrt{ }$ & $\sqrt{ }$ & $\sqrt{ }$ & & & \\
\hline PIC & & & & & & & & \\
\hline Biosafety & & $\sqrt{ }$ & $\sqrt{ }$ & 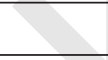 & 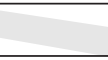 & $\sqrt{ }$ & & \\
\hline POPs & & $\sqrt{ }$ & $\sqrt{ }$ & 7 & & & & \\
\hline & & & 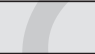 & & 8 & & & \\
\hline Vienna & & $\sqrt{ }$ & $\sqrt{ }$ & & & & & \\
\hline $\begin{array}{l}\text { Montreal } \\
\text { Protocol }\end{array}$ & & $\sqrt{ }$ & $\sqrt{ }$ & & & & & \\
\hline UNFCCC & & $\sqrt{ }$ & $\sqrt{ }$ & $\sqrt{ }$ & & & & \\
\hline $\begin{array}{l}\text { Kyoto } \\
\text { Protocol }\end{array}$ & & $\sqrt{ }$ & $\sqrt{ }$ & $\sqrt{ }$ & $\sqrt{ }$ & $\sqrt{ }$ & & \\
\hline Whaling & & & $\sqrt{ }$ & $\sqrt{ }$ & $\sqrt{ }$ & & & \\
\hline London & & & $\sqrt{ }$ & & & & & \\
\hline UNCLOS & & & & & & & & \\
\hline Fish Stocks & & & & & & & & \\
\hline
\end{tabular}

Table 3.2 focuses on performance information provisions under the headings of Review Format, Performance Review and Non-Compliance Response Information. It should be noted that there is a divergence among MEAs that regulate international transactions. The CITES, Basel Convention and Montreal Protocol each require the Parties to include information on regulated transactions in their national performance reports. In contrast, the PIC Convention and ITPGRFA do not require Parties to include in the details of regulated 
transactions. The latter omissions generate significant gaps in the available performance information for those treaties.

Potential interlinkages in gathering performance review information arise between MEAs engaged in regulating closely related activities. For example, where MEAs regulate overlapping sites, species, substances or emissions, there is heightened potential for coordination. This performance review information will be most useful across MEAs when review requires the provision of statistical, transactional or other quantifiable data, rather than qualitative descriptive evaluations. The latter are typically more related to descriptions of policy measures that are customised to particular MEAs and may also be less factually objective.

In relation to self-reporting, the interlinkages may be created in the form of harmonization of reporting formats and joint MEA reporting by a Party. Extensive work has been undertaken by the World Conservation Monitoring Centre and the United Nations University on harmonization of reporting formats. This work is canvassed in Chapter 4. (It should also be noted that where self-reporting addresses a transnational ecosystem, joint reports might be appropriate.)

In relation to monitoring and verification, potential interlinkages exist in carrying out thirdparty monitoring operations and verification missions. Thus, while on mission, a verification team might be multi-tasked to assess aspects of compliance common to several MEAs. For example, world natural heritage sites, wetlands, migratory species and biodiversity reserves might be inspected on a single mission. Similarly, customs controls might be inspected in relation to capacity to comply with MEAs concerning international trade in endangered species, hazardous and other wastes, POPs, PIC chemicals and ODS.

UNEP might usefully establish a roster of technical experts to conduct monitoring and verifications for the MEAs that it administers. Analogy can be made with the peer reviews that are conducted by the OECD Secretariat on progress in all member countries and three non-member countries. ${ }^{348}$ These reviews are conducted cyclically to assess whether the reviewed country is meeting its domestic environmental regulations and international environmental obligations. Multi-tasking a monitoring or verification mission across MEA Secretariats would be little more difficult than bringing together a team of experts for different MEAs administered by one organisation. However, the approval of the governing body of each MEA concerned would be required, to provide that one organization with a mandate to undertake such monitoring or verification.

348 OECD Website, <http://www.oecd.org/topic/0,2686,en $264934307111111137465,00$. html > (25/10/05). 


\section{Multilateral Non-Compliance Response Procedures}

Non-Compliance Procedures require administration by a body established under the MEA. That body is usually the COP/MOP but it may be assisted by a specialised compliance committee that the COP/MOP has established by resolution for that purpose. The compliance committees consist of one to two dozen members elected by the COP/MOP according to geographically representative formulae that are varied or adjusted to meet the MEA concerns and interests to be represented. Regional groupings sometimes nominate for election individuals with legal expertise, or with expertise of the subject-matter of the MEA. Although regionally representative, the members sit in their individual capacities. Alternatively, where members do not serve in their individual capacity, they are stated to serve "objectively" (e.g. Basel Convention Compliance Committee).

MEAs that do not have specialised compliance committees may incorporate a NCP administered directly by the COP/MOP. Specialised MEA compliance committees, usually named the Implementation Committee or Compliance Committee, operate during the meeting of a COP/MOP in most cases. They consider cases of non-compliance referred to them, reach a determination on the compliance status of the Party and make a recommendation to the COP/MOP for appropriate responsive action. Thus, the determination and recommendation of the non-compliance committee must be approved by the COP/MOP. The COP/MOPs for CITES, the Biosafety Protocol, the Basel Convention, the Montreal Protocol, the UNFCCC and the Kyoto Protocol all have such specialised committees. For the Basel Convention, referral to the COP is a supplementary measure, when facilitation measures have not been successful or are insufficient to address the issue in question. Its Compliance Committee may also provide, on its own behalf, advice, non-binding recommendations and information to the Party whose compliance is in question and after coordinating with that Party.

A suggestion that a Party is non-compliant can come to the attention of a body administering a NCP in a variety of ways. The Party experiencing compliance difficulties itself can initiate the procedure. Otherwise, the Party's non-compliance might come to the attention of any of the other Parties or the Secretariat, which refer the matter to the NCP. A thirdparty body performing a monitoring role can report cases of possible non-compliance to the Secretariat, which may then invoke the NCP. For example, under CITES, the Secretariat receives and may pass on information on non-compliance from TRAFFIC and other NGOs and, under the Kyoto Protocol, expert review teams may trigger the NCP.

Table 3.3 shows the MEAs that have adopted NCPs. It elaborates on how they are triggered and the body that administers them.

Thirteen of the MEAs have developed, or are in the process of developing, NCPs to deal with instances of apparent non-compliance. However, potential for interlinkages between NCPs is slight. Each is specific to the political context of its MEA, i.e. to the sensitive balance struck during its negotiation processes and to the composition of its COP/MOP or elected sub-committee membership. Thus, it would be premature (if not inappropriate) to seek to harmonize NCPs or combine committees across MEAs. However, two other types of NCP interlinkages might be possible. 
First, closer coordination between MEA secretariats could enhance their capacity to trigger NCPs. For example, evidence of corruption of customs authorities resulting in a Party's non-compliance concerning its trade-related obligations might implicate that Party in similar non-compliance under more than one MEA. Protocols for coordination of performance information between secretariats could enable them to be more effective in triggering their respective NCPs. Such coordination would be likely to be useful across MEAs within a cluster but could also be useful across MEAs that regulate related activities, such as international trade. 
Table 3.3. Multilateral Non-Compliance Response Procedures

\begin{tabular}{|c|c|c|c|c|c|c|c|}
\hline \multirow[t]{2}{*}{ Convention } & \multicolumn{2}{|c|}{ Procedure } & \multicolumn{3}{|c|}{ Trigger Body } & \multicolumn{2}{|c|}{$\begin{array}{c}\text { Decision- } \\
\text { Making Body }\end{array}$} \\
\hline & Established & Pending & $\begin{array}{c}\text { Any } \\
\text { Member }\end{array}$ & Secretariat & Other & $C O P$ & Committee \\
\hline Ramsar & $\sqrt{ }$ & & & $\sqrt{ }$ & & $\sqrt{ }$ & \\
\hline World Heritage & $\sqrt{ }$ & & $\sqrt{ }$ & $\sqrt{ }$ & $\sqrt{ }$ & $\sqrt{ }$ & \\
\hline CITES & $\sqrt{ }$ & & $\sqrt{ }$ & $\sqrt{ }$ & $\sqrt{ }$ & $\sqrt{ }$ & $\sqrt{ }$ \\
\hline CMS & $\sqrt{ }$ & & $\sqrt{ }$ & $\sqrt{ }$ & & $\sqrt{ }$ & \\
\hline \multicolumn{8}{|l|}{ CBD } \\
\hline UNCCD & & $\sqrt{ }$ & & & & & \\
\hline ITPGRFA & & $\sqrt{ }$ & & & & & \\
\hline Basel & $\sqrt{ }$ & & $\sqrt{ }$ & $\sqrt{ }$ & & $\sqrt{ }$ & $\sqrt{ }$ \\
\hline PIC & & $\sqrt{ }$ & & & & & \\
\hline Biosafety & $\sqrt{ }$ & & $\sqrt{ }$ & & 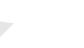 & $\sqrt{ }$ & $\sqrt{ }$ \\
\hline \multicolumn{8}{|l|}{ POPs } \\
\hline \multicolumn{8}{|l|}{ Vienna } \\
\hline $\begin{array}{l}\text { Montreal Pro- } \\
\text { tocol }\end{array}$ & $\sqrt{ }$ & & $\sqrt{ }$ & $\sqrt{ }$ & & $\sqrt{ }$ & $\sqrt{ }$ \\
\hline UNFCCC & $\sqrt{ }$ & & $\sqrt{ }$ & $\sqrt{ }$ & & $\sqrt{ }$ & $\sqrt{ }$ \\
\hline Kyoto Protocol & $\sqrt{ }$ & V & $\sqrt{ }$ & $\sqrt{ }$ & $\sqrt{ }$ & $\sqrt{ }$ & $\sqrt{ }$ \\
\hline \multicolumn{8}{|l|}{ Whaling } \\
\hline \multicolumn{8}{|l|}{ London } \\
\hline \multicolumn{8}{|l|}{ UNCLOS } \\
\hline Fish Stocks & & & & & & & \\
\hline
\end{tabular}

Second, NCP decision-making bodies could coordinate their responses so as to maximise their effect for the non-compliant Party. Thus, the coordination of implementation assistance across MEAs to address non-compliance caused by a systemic lack of environmental capacity would be more effective than piecemeal or duplicative implementation assistance. Similarly, the coordination of penalties would have greater impact. Again, such 
coordination would be likely to be useful across MEAs within a cluster but could also be useful across MEAs that regulate related activities. Coordination of non-compliance responses is discussed in more detail immediately below.

\section{Non-Compliance Response Measures}

Once a determination of non-compliance is made under a NCP, it is in most cases the COP/MOP that formally decides upon or adopts the Committee's recommended response measures. These typically take the form of targeted implementation assistance. Less common are response measures in the form of penalties.

\section{Implementation Assistance}

The forms of implementation assistance are provision of information, technical support and financial assistance. For the purposes of this study, technical support is broadly defined to include capacity building and training, cooperation in scientific endeavours and research, or transfer of technology.

Implementation assistance is usually available under an MEA at earlier stages in the implementation cycle, as basic implementation assistance, rather than as a response to non-compliance. All of the MEAs surveyed in this paper provide some measure of basic implementation assistance to Parties in need at those earlier stages. Upon a determination of non-compliance, targeted implementation assistance to a non-compliant Party might be prioritized and made subject to conditions. Thus, arrangements under an MEA for the provision of basic implementation assistance can be specifically directed, as the output of a NCP, to help fix a Party's non-compliance problems.

For the purposes of this study of compliance mechanisms, it is only implementation assistance that is an output of the NCP that it is addressed. However, as the NCP's output typically draws upon general arrangements for assistance that operate under an MEA at earlier stages of the implementation cycle, those general arrangements must be noted. Of particular relevance is implementation assistance to help non-compliant Parties meet their performance review obligations. For that reason, Table 3.4 identifies assistance to meet performance review requirements separately from other technical and financial assistance. It also compares the provision of implementation assistance at the earlier stages of implementation with assistance that is an output of the NCP.

As can be seen in Table 3.4, every MEA contains implementation support assistance obligations. All but one MEA has a funding mechanism to provide financial assistance to Parties for the implementation of approved projects and programs. Thus, all MEAs that include a NCP can draw upon their existing technical and financial support arrangements in crafting non-compliance response measures.

It follows that, just as Parties to MEAs might coordinate their technical and financial support arrangements so as to maximise their positive impacts, those same arrangements could be coordinated in the context of non-compliance response measures. Where a 
systemic lack of environmental capacity is considered to be the cause of non-compliance, coordination of responsive assistance across related MEAs would be more effective than piecemeal or duplicative efforts. In fact, non-compliance measures could be easier to coordinate across MEAs than general implementation assistance measures. This is because they are nominated as priorities by NCP determinations and they are fewer in number than general requests for assistance (because they carry the stigma of non-compliance). 


\begin{tabular}{|c|c|c|c|c|}
\hline & \multicolumn{2}{|c|}{$\begin{array}{c}\text { Non-Compliance } \\
\text { Response Assistance }\end{array}$} & \multicolumn{2}{|c|}{ Primary Implementation Assistance } \\
\hline & Technical & Financial & Technical & Financial \\
\hline Ramsar & $\sqrt{ }$ & & $\begin{array}{l}\text { Implementation guidelines } \\
\text { developed by Ramsar } \\
\text { Bureau; information } \\
\text { exchange and CHM }\end{array}$ & $\begin{array}{l}\text { Ramsar Small } \\
\text { Grants Fund }\end{array}$ \\
\hline $\begin{array}{l}\text { World } \\
\text { Heritage }\end{array}$ & $\sqrt{ }$ & $\begin{array}{l}\text { Emergency } \\
\text { Assistance }\end{array}$ & $\begin{array}{l}\text { Technical and scientific } \\
\text { cooperation and capacity } \\
\text { building }\end{array}$ & $\begin{array}{l}\text { World Heritage } \\
\text { Fund, Reserve Fund } \\
\text { and Funds in Trust }\end{array}$ \\
\hline CITES & $\sqrt{ }$ & & Capacity building & Trust fund \\
\hline CMS & & & $\begin{array}{l}\text { Capacity building (Global } \\
\text { Information System and } \\
\text { Register) Technical and } \\
\text { Scientific on migratory } \\
\text { species (Parties lists, etc.) }\end{array}$ & $\begin{array}{l}\text { Trust fund\& } \\
\text { Voluntary } \\
\text { contributions Trust } \\
\text { Fund }\end{array}$ \\
\hline CBD & & & $\begin{array}{l}\text { Technical and scientific } \\
\text { cooperation, capacity } \\
\text { building, technology } \\
\text { transfer and development } \\
\text { of guidelines; CHM }\end{array}$ & $\begin{array}{l}\text { Global Environment } \\
\text { Facility }\end{array}$ \\
\hline UNCCD & & & $\begin{array}{l}\text { Technical and scien- } \\
\text { tific cooperation, capacity } \\
\text { building, technology de- } \\
\text { velopment and transfers; } \\
\text { coordinate, collect and } \\
\text { exchange data }\end{array}$ & Global Mechanism \\
\hline ITPGRFA & & 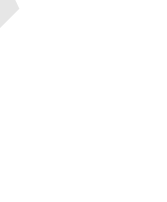 & $\begin{array}{l}\text { Technical and scientific } \\
\text { cooperation, capacity } \\
\text { building and technology } \\
\text { transfer; Global } \\
\text { Information System }\end{array}$ & Trust Fund \\
\hline Basel & $\begin{array}{l}\text { Technical } \\
\text { and } \\
\text { performance } \\
\text { reporting } \\
\text { assistance }\end{array}$ & $\sqrt{ }$ & $\begin{array}{l}\text { Establishment of regional } \\
\text { centres for training and } \\
\text { technology transfers; } \\
\text { information sharing }\end{array}$ & $\begin{array}{l}\text { Trust Fund for the } \\
\text { Implementation } \\
\text { of the Convention } \\
\text { and Technical } \\
\text { Cooperation } \\
\text { Trust Fund to } \\
\text { Assist Developing } \\
\text { Countries }\end{array}$ \\
\hline
\end{tabular}




\begin{tabular}{|c|c|c|c|c|}
\hline PIC & & & $\begin{array}{l}\text { Capacity building and } \\
\text { information exchange }\end{array}$ & Pending \\
\hline $\begin{array}{l}\text { Biosafety } \\
\text { Protocol }\end{array}$ & $\sqrt{ }$ & $\sqrt{ }$ & $\begin{array}{l}\text { Scientific and technical } \\
\text { cooperation and capacity } \\
\text { building; CHM and perfor- } \\
\text { mance review reports }\end{array}$ & $\begin{array}{l}\text { Global Environment } \\
\text { Facility }\end{array}$ \\
\hline POPs & & & $\begin{array}{l}\text { Capacity building and } \\
\text { information exchange }\end{array}$ & $\begin{array}{l}\text { Global Environment } \\
\text { Facility Interim }\end{array}$ \\
\hline Vienna & & & $\begin{array}{l}\text { Technical and scientific } \\
\text { cooperation, training and } \\
\text { technology transfers; infor- } \\
\text { mation exchange }\end{array}$ & Trust Fund \\
\hline $\begin{array}{l}\text { Montreal } \\
\text { Protocol }\end{array}$ & $\begin{array}{l}\text { Techni- } \\
\text { cal and } \\
\text { performance } \\
\text { reporting } \\
\text { assistance }\end{array}$ & $\sqrt{ }$ & $\begin{array}{l}\text { Technical cooperation } \\
\text { and technology transfers; } \\
\text { information exchange }\end{array}$ & $\begin{array}{l}\text { Multilateral } \\
\text { Fund and Global } \\
\text { Environment } \\
\text { Facility }\end{array}$ \\
\hline UNFCCC & $\sqrt{ }$ & $\sqrt{ }$ & $\begin{array}{l}\text { Technology transfers and } \\
\text { CHM }\end{array}$ & $\begin{array}{l}\text { Global Environment } \\
\text { Facility, Special } \\
\text { Climate Change } \\
\text { Fund and the } \\
\text { Least Developed } \\
\text { Countries Fund }\end{array}$ \\
\hline $\begin{array}{l}\text { Kyoto } \\
\text { Protocol }\end{array}$ & $\sqrt{ }$ & $\sqrt{ }$ & $\begin{array}{l}\text { Technical and scientific } \\
\text { research and cooperation, } \\
\text { technology transfers and } \\
\text { capacity building }\end{array}$ & $\begin{array}{l}\text { Global Environment } \\
\text { Facility and } \\
\text { Adaptation Fund }\end{array}$ \\
\hline $\begin{array}{l}\text { Whaling } \\
\text { Conven- } \\
\text { tion }\end{array}$ & & & & $\begin{array}{l}\text { Research, General } \\
\text { and Voluntary } \\
\text { Funds }\end{array}$ \\
\hline London & & & $\begin{array}{l}\text { Technical Cooperation } \\
\text { Programme }\end{array}$ & \\
\hline UNCLOS & & & $\begin{array}{l}\text { Technical and scientific } \\
\text { cooperation to develop- } \\
\text { ing Parties, transfer of } \\
\text { marine and deep sea-bed } \\
\text { technologies; information } \\
\text { exchange }\end{array}$ & \\
\hline $\begin{array}{l}\text { Fish } \\
\text { Stocks }\end{array}$ & & & $\begin{array}{l}\text { Human resources } \\
\text { development, technology } \\
\text { transfers and advisory } \\
\text { and consultative services } \\
\text { for developing countries; } \\
\text { information exchange }\end{array}$ & Assistance Fund \\
\hline
\end{tabular}




\section{Non-Compliance Penalties}

MEAs with an established NCP often enable the imposition of penalties on non-compliant Parties. The penalties imposed under these procedures can be grouped into four categories: Warnings; Suspension of Privileges; Trade Sanctions; and Liability.

Warnings can be considered as the first along a spectrum of severity in the penalties that may be applied. As a next step, some MEAs provide for suspension of Parties' rights and privileges, notably, participation in voting or committees (see CITES, World Heritage Convention and the Montreal Protocol). The imposition of trade sanctions encompasses the suspension of trading privileges and other economic rights regulated by the MEA. ${ }^{349}$ Finally, the imposition of liability requires non-compliant Parties to compensate for their non-compliance. This liability can take two forms: greater burdens in meeting the MEA obligations (see Kyoto Protocol) or reparations for any damage caused

Table 3.5. Non-Compliance Penalties

\begin{tabular}{|c|c|c|c|c|}
\hline Convention & Warning & $\begin{array}{l}\text { Suspension of } \\
\text { Privileges }\end{array}$ & $\begin{array}{c}\text { Trade } \\
\text { Sanctions }\end{array}$ & Liability \\
\hline \multicolumn{5}{|l|}{ Ramsar } \\
\hline World Heritage & & $\begin{array}{l}\text { Exclusion of mem- } \\
\text { bership from World } \\
\text { Heritage Committee }\end{array}$ & & \\
\hline CITES & $\sqrt{ }$ & $\begin{array}{l}\text { Secretariat takes } \\
\text { control of issuing } \\
\text { permits }\end{array}$ & $\begin{array}{l}\text { Suspension of } \\
\text { trade in CITES- } \\
\text { listed species } \\
\text { and imposition } \\
\text { of conditions }\end{array}$ & \\
\hline \multicolumn{5}{|l|}{ CMS } \\
\hline \multicolumn{5}{|l|}{ CBD } \\
\hline \multicolumn{5}{|l|}{ UNCCD } \\
\hline ITPGRFA & & & & \\
\hline
\end{tabular}

349 It should be noted that the Whaling Convention does not have a multilateral NCP that can apply non-compliance response measures but that Parties tend to use unilateral trade sanctions in conjunction with diplomatic and/or political pressure to achieve the desired outcomes. 


\begin{tabular}{|c|c|c|c|c|}
\hline Basel & $\sqrt{ }$ & & & $\begin{array}{l}\text { Re-import il- } \\
\text { legal exports. } \\
\text { Liability Pro- } \\
\text { tocol. }\end{array}$ \\
\hline \multicolumn{5}{|l|}{$\mathrm{PIC}$} \\
\hline Biosafety & $\sqrt{ }$ & & & $\begin{array}{l}\text { Liability Proto- } \\
\text { col pending. }\end{array}$ \\
\hline \multicolumn{5}{|l|}{ POPs } \\
\hline \multicolumn{5}{|l|}{ Vienna } \\
\hline Montreal Protocol & $\sqrt{ }$ & $\begin{array}{l}\text { Suspension of rights } \\
\text { in institutional } \\
\text { arrangements, } \\
\text { financial mechanism } \\
\text { and transfer of } \\
\text { technology }\end{array}$ & $\begin{array}{l}\text { Suspension } \\
\text { of trade, } \\
\text { production and } \\
\text { consumption } \\
\text { rights }\end{array}$ & \\
\hline \multicolumn{5}{|l|}{ UNFCCC } \\
\hline Kyoto Protocol & & & $\begin{array}{l}\text { Suspending } \\
\text { right to trade } \\
\text { in and use } \\
\text { flexibility } \\
\text { mechanisms }\end{array}$ & $\begin{array}{l}\text { Carry-over of } \\
\text { obligations }\end{array}$ \\
\hline $\begin{array}{l}\text { Whaling Conven- } \\
\text { tion }\end{array}$ & $\begin{array}{l}\text { Diplomatic } \\
\text { pressure. }\end{array}$ & & $\begin{array}{l}\text { Unilateral fish- } \\
\text { eries trade or } \\
\text { access restric- } \\
\text { tions }\end{array}$ & \\
\hline London & & & & $\begin{array}{l}\text { Liability subject } \\
\text { to further nego- } \\
\text { tiation: Article } \\
\text { X. }\end{array}$ \\
\hline UNCLOS & & & & $\begin{array}{l}\text { Several related } \\
\text { liability treaties. }\end{array}$ \\
\hline Fish Stocks & & & & \\
\hline
\end{tabular}

Liability to make reparations for any damage caused is not truly part of a multilateral NCP in any MEA. Rather it is a responsibility that is articulated in the MEA or its protocols and that is determined bilaterally, often in an adversarial process. Thus, determinations of liability are usually outputs of a dispute resolution process rather than an NCP. However, liability to make reparations is surveyed here, in the context of non-compliance penalties, because in effect exposure to liability is a disincentive to non-compliance. 
A coordinated approach across MEAs to the imposition of penalties against a Party that is recurrently non-compliant would have greater impact than ad hoc penalties. As noted above, coordination would be likely to be useful across MEAs within a cluster but could also be useful across MEAs that regulate common activities, such as international trade or manufacturing.

A coordinated approach to the suspension of privileges, where these are properly mandated by a COP/MOP, would strengthen the deterrent effect of penalties. Thus, for MEAs regulating related activities, the respective COP/MOPs might, by prior agreement, suspend the privileges of a Party under each MEA when that Party is determined by one of the COP/MOPs to be non-compliant (Such a coordinated approach to penalties would also strengthen the deterrent impact of penalties for related regional MEAs that are applicable in one region or across several regions.)

\section{Dispute Resolution Procedures}

Dispute resolution procedures vary in sophistication, from simple provisions that require Parties to negotiate bilaterally to resolve disputes peacefully, to the elaborate, compulsory binding third-party dispute resolution procedures that can be found in the United Nations Convention on the Law of the Sea. They are grouped in three clusters of compulsory procedures: Negotiation, Conciliation and Arbitration. At one end of the spectrum, CITES and CMS have dispute settlement provisions that provide that in the event of a dispute, Parties must submit to negotiation. They may voluntarily submit to the Permanent Court of Arbitration if negotiations fail. Thus, there is no obligation to pursue binding arbitration. At the other end of the spectrum is UNCLOS, which has compulsory, binding arbitration for specific disputes (i.e. disputes concerning the seabed). Generally, however, the arbitration procedure is invoked if the dispute has not been resolved through negotiation. Conciliation is an option where negotiations fail, but is invoked only if one Party requests it and the other accepts the invitation. Compulsory conciliation has emerged as the preferred compromise struck by the negotiators of MEAs.

The invocation of compulsory dispute resolution procedures signals a crisis in environmental diplomacy. In addition, the outcomes of such procedures remain unpredictable and potentially expensive. Therefore, with few exceptions, the provisions of MEAs on binding dispute resolution tend to be weak and/or permissive. States are generally reluctant to formulate legal obligations in MEAs that might compel them to submit their environmental conflicts to binding dispute resolution procedures for the reasons stated above. The increasing trend towards the use of multilateral NCPs, as opposed to adversarial dispute settlement procedures, seems to herald a new focus in international environmental law on managing political relationships so as to maintain the viability and integrity of an MEA. 
Table 3.6 Summarises Dispute Resolution Procedures.

\begin{tabular}{|c|c|c|c|c|c|c|}
\hline \multirow[t]{2}{*}{ Convention } & \multicolumn{2}{|c|}{ Negotiation } & \multicolumn{2}{|c|}{ Conciliation } & \multicolumn{2}{|c|}{$\begin{array}{c}\text { Binding } \\
\text { Arbitration }\end{array}$} \\
\hline & Voluntary & Compulsory & Voluntary & Compulsory & Voluntary & Compulsory \\
\hline \multicolumn{7}{|l|}{ Ramsar } \\
\hline \multicolumn{7}{|l|}{ World Heritage } \\
\hline CITES & & $\sqrt{ }$ & & & $\sqrt{ }$ & \\
\hline CMS & & $\sqrt{ }$ & & & $\sqrt{ }$ & \\
\hline CBD & & $\sqrt{ }$ & & $\sqrt{ }$ & $\sqrt{ }$ & \\
\hline UNCCD & & $\sqrt{ }$ & & $\sqrt{ }$ & $\sqrt{ }$ & \\
\hline ITPGRFA & & $\sqrt{ }$ & & $\sqrt{ }$ & $\sqrt{ }$ & \\
\hline Basel & & $\sqrt{ }$ & $\sqrt{ }$ & & $\sqrt{ }$ & \\
\hline PIC & & $\sqrt{ }$ & & $\sqrt{ }$ & $\sqrt{ }$ & \\
\hline Biosafety Protocol & & $\sqrt{ }$ & & $\sqrt{ }$ & $\sqrt{ }$ & \\
\hline POPs & & $\sqrt{ }$ & & $\sqrt{ }$ & $\sqrt{ }$ & \\
\hline Vienna & & $\sqrt{ }$ & & $\sqrt{ }$ & $\sqrt{ }$ & \\
\hline Montreal Protocol & & $\sqrt{ }$ & & $\sqrt{ }$ & $\sqrt{ }$ & \\
\hline UNFCCC & & $\sqrt{ }$ & & $\sqrt{ }$ & $\sqrt{ }$ & \\
\hline Kyoto Protocol & & $\sqrt{ }$ & & $\sqrt{ }$ & $\sqrt{ }$ & \\
\hline $\begin{array}{l}\text { Whaling Conven- } \\
\text { tion }\end{array}$ & & & & & & \\
\hline London & & & & & & \\
\hline UNCLOS & & $\sqrt{ }$ & $\sqrt{ }$ & & & $\sqrt{ }$ \\
\hline Fish Stocks & & $\sqrt{ }$ & $\sqrt{ }$ & & & $\sqrt{ }$ \\
\hline
\end{tabular}

As Table 6 illustrates, all but four Conventions have provisions on settling disputes between Parties. The London Convention has developed a dispute settlement procedure but it has never entered into force. With the exception of the dispute resolution procedures under UNCLOS and the Fish Stocks Agreement, the MEA dispute resolutions procedures are 
weak and tend to orientate Parties towards the voluntary, less adversarial methods of negotiation and conciliation.

Given that dispute resolution procedures tend to comprise mainly compulsory conciliation and voluntary binding arbitration, potential linkages are feasible in respect of common dispute resolution bodies. For example, MEAs within each cluster could specify the same arbitration body within their respective arbitration annexes. The arbitration body could include the Permanent Court of Arbitration. The marine environment cluster could utilise the Law of the Sea Tribunal. However, this may be of little utility as there appears to be widespread avoidance of binding dispute resolution. Furthermore, some may consider that the composition of an arbitration body should be determined having regard to the dispute in question and, thus, prefer to continue to rely on mechanisms for the establishment of ad hoc arbitration bodies. Instead, greater emphasis is placed on non-compliance responses to ensure that Parties comply with the Convention and that they collectively manage each other's compliance efforts. 

Chapter IV.

Synthesis and Analysis of Law and Practice 



\section{Synthesis and Analysis of Law and Practice}

This Chapter examines international practice in interlinking MEAs to achieve synergies between their approaches to compliance. It does this by surveying current international institutional efforts to promote interlinkages. These institutional efforts fall into two categories: those conducted by broad-mandate, multi-sectoral international organisations, and those conducted by the individual MEA Secretariats themselves. The chapter also notes examples of national practice in interlinking domestic compliance activities across MEAs.

\section{International Efforts towards Interlinkages in Compliance}

The focus of this report is on interlinkages between MEA compliance systems. Therefore, for the purposes of this chapter's survey of international practice in interlinking MEA compliance systems, a distinction is maintained between interlinkage of actual MEA compliance systems, as compared to interlinkage of MEA implementation efforts more generally. Where interlinkages between MEA information systems have been promoted, these are treated here as related to compliance information systems, as performance information is a subset of the wider body of information related to implementation. It must be recognised that international efforts to interlink MEA compliance systems form a subset of international efforts to produce synergies in national implementation of MEAs.

Further, as the focus is on interlinkages between MEA compliance systems, we are concerned with international, rather than domestic sub-national compliance arrangements. Domestic compliance systems form a part of national implementation that serves to meet international obligations.

\section{International Organisations}

The primary multi-sectoral international organisations engaged in promoting interlinkages are the United Nations Environment Programme, United Nations Development Programme, United Nations University, the World Conservation Monitoring Centre and the World Customs Organisation.

In 1997, UNDP convened an Expert Meeting on Synergies in National Implementation between the Rio Agreements to seek ways to create synergies for the implementation of the CBD, UNFCCC, UNCCD and the Forest Principles at the national level. ${ }^{350}$ The meeting was based on the key ideas that recognising synergies is an important part of implement-

350 "Legislative complementarity and harmonization of biodiversity-related multilateral environmental agreements", UNEP/UNDP/

GEF Biodiversity Planning Support Program, 1 February 2002, pp.49-50, <http://www.unon.org/dgefftp/NCSAResources/

Conventions\%20Literature/UNCBD/CBD\%200bligations\%20\&\%20other\%20MEAs\%20Feb02.pdf> (19/10/05). 
ing MEAs and that in-country capacity building is fundamental to promoting synergies. ${ }^{351}$ Four workshops covered topics such as institutional requirements and structures, capacity requirements, national planning requirements and information and reporting requirements. ${ }^{352}$ The final workshop, on information and reporting requirements, discussed the commonalities in the data sets between the Rio agreements and proposed information system models that would explore synergies during the various steps in the data collection and dissemination process: data need analysis; cross-comparison to identify synergy; identifying gaps; data integration; creating information products; policy development; policy implementation; reporting; and review. ${ }^{353}$ Overall, the meeting resulted in the proposal of measures to improve national implementation, reduce duplication and increase harmonisation. ${ }^{354}$

Following the Expert Meeting, the World Conservation Monitoring Centre produced the 1997 Feasibility Study for the Information Management Infrastructure for biodiversityrelated MEAs. ${ }^{355}$ The study was commissioned by UNEP and the Secretariats of the CBD, CITES, CMS, Ramsar Convention and the World Heritage Convention to review the information and reporting requirements of the Parties under each Convention and propose options for harmonisation. ${ }^{356}$ Commonalities in information were noted between CITES and the CMS with regard to overlapping species and the World Heritage Convention and the Ramsar Convention in relation to sites. ${ }^{357}$ The study ultimately recommended streamlining of national performance reporting under the conventions by clarifying the reporting requirements of each $\mathrm{MEA}$, developing and testing an integrated handbook for national

351 "Legislative complementarity and harmonization of biodiversity-related multilateral environmental agreements", UNEP/UNDP/ GEF Biodiversity Planning Support Program, 1 February 2002, pp. 49-50, <http://www.unon.org/dgefftp/NCSAResources/ Conventions\%20Literature/UNCBD/CBD\%200bligations\%20\&\%20other\%20MEAs\%20Feb02.pdf> (19/10/05).

352 "Synergies in National Implementation of the Rio Agreements", Sustainable Energy and Environment Division Website, <http://www. undp.org/seed/quide/synergies/siner3.htm $>$ (19/10/05).

353 "Synergies in National Implementation of the Rio Agreements", Sustainable Energy and Environment Division Website, <http://www. undp.org/seed/guide/synergies/siner3.htm > (19/10/05).

354 "Synergies in National Implementation of the Rio Agreements", Sustainable Energy and Environment Division Website, <http://www. undp.org/seed/guide/synergies/siner3.htm > (19/10/05). The first workshop on institutional requirements and structures discussed the potential of creating synergies in the areas of awareness raising, education, reporting, data gathering and inventories, public participation, research and training. Mechanisms that were canvassed to facilitate integrated environmental planning included:a cross-sectoral national committee; separate institutions conducting joint task forces to avoid duplication; or one high-level institution that is responsible for all instruments. The second workshop on capacity requirements discussed capacity building initiatives to assist countries in complying with international obligations pertaining to monitoring, policy and law reform, impact assessment and research, reporting, education and public awareness and training. The workshop identified the key indicators of a country's existing capacity to plan, implement and monitor implementation initiatives as including: knowledge and technical skills among decisionmakers on the country's environmental problems; the degree to which existing plans are participatory and involve stakeholders; familiarity and skill in using existing planning tools; and clearly defined roles and responsibilities between the public and private sectors and civil society. The workshop ultimately recommended improving capacity in human resources, infrastructure development and cooperation and coordination through technical assistance, information exchange and technology transfers. The third workshop proposed three options on national planning strategies: producing separate plans for each instrument; developing an umbrella plan encompassing all the Rio agreements; develop a mechanism to absorb the planning process for each instrument into existing plans and frameworks.

355 "Legislative complementarity and harmonization of biodiversity-related multilateral environmental agreements",UNEP/UNDP/ GEF Biodiversity Planning Support Program, 1 February 2002, pp. 50-52, <http://www.unon.org/dgefftp/NCSAResources/ Conventions\%20Literature/UNCBD/CBD\%200bligations\%20\&\%20other\%20MEAs\%20Feb02.pdf> (19/10/05).

356 "Legislative complementarity and harmonization of biodiversity-related multilateral environmental agreements", UNEP/UNDP/ GEF Biodiversity Planning Support Program, 1 February 2002, pp. 50-52, <http://www.unon.org/dgefftp/NCSAResources/ Conventions\%20Literature/UNCBD/CBD\%200bligations\%20\&\%20other\%20MEAs\%20Feb02.pdf> (19/10/05).

357 J. Harrison and M. Collins, "Harmonizing the information management infrastructure for biodiversity-related treaties",WCMC Website, $<$ http://www.unep-wcmc.org/latenews/previous/japanpaper.pdf\#xml=/cgi-bin/pdf_hl?STEMMER=en\&RGB=ffO0ff\&WORDS=feasibili ty+study+\&DB=unep-wcmc\&URL=http://www.unep-wcmc.org/latenews/previous/japanpaper.pdf $>$ (19/10/05). 
reporting and capacity building in national biodiversity information banks. ${ }^{358}$ It also recommended the development of an MEA information resource, covering five priority areas including: harmonising document cover sheets; adopting standard definitions; harmonising web sites; developing a meta-database to indicate the information that is available and its location; and developing an inter-convention website and search engine. ${ }^{359}$ Finally, the study proposed developing a lessons-learned network to encourage the sharing of experience. $^{360}$

The WCMC has since maintained the leading role in developing interlinkages and synergies for implementation of biodiversity-related MEAs. It provides support to the biodiversity-related MEAs by exploring ways to harmonize their information management and national reporting obligations, most notably through reports and workshops. ${ }^{361}$ For example, UNEP convened a workshop in 2000 entitled 'Towards the Harmonization of National Reporting', which led to the development of pilot projects in four countries. ${ }^{362}$ Another workshop was convened in 2004 to review the conclusions and recommendations of the pilot projects and to discuss future harmonization priorities. ${ }^{363}$

In 1997 UNU established the Interlinkages Initiative. In 1999, it held an International Conference on Synergies and Coordination. ${ }^{364}$ The objectives of the Conference were to, inter alia, examine existing initiatives on synergies and interlinkages and promote discussion on these issues among relevant stakeholders. ${ }^{365}$ The conference was divided into four working groups to cover information systems and exchange, financing, issues management, and scientific mechanisms, with each working group producing a series of recommendations on ways forward. ${ }^{366}$ Since the Conference, UNU has continued with its work on exploring potential synergies. Other outcomes of the Interlinkages Initiative include applied research and case studies on identifying constraints and overcoming challenges in implementing MEAs, holding of workshops, capacity-building activities, and engagement in related consultancies and policy design. ${ }^{367}$ The information systems aspects of this work relates directly to compliance interlinkages.

The UNEP Division of Environmental Conventions was established in 1999 to identify synergies between MEAs at the global, national and regional levels, and to promote increased

358 J. Harrison and M. Collins, "Harmonizing the information management infrastructure for biodiversity-related treaties,"WCMC Website, $<$ http://www.unep-wcmc.org/latenews/previous/japanpaper.pdf\#xml=/cgi-bin/pdf hl?STEMMER=en\&RGB=ff0off\&WORDS=feasibili ty+study+\&DB=unep-wcmc\&URL=http://www.unep-wcmc.org/latenews/previous/japanpaper.pdf $>$ (19/10/05).

359 J. Harrison and M. Collins, "Harmonizing the information management infrastructure for biodiversity-related treaties",WCMC Website, $<$ http://www.unep-wcmc.org/latenews/previous/japanpaper.pdf\#xml=/cgi-bin/pdf hl?STEMMER=en\&RGB=ff00ff\&WORDS=feasibili ty+study+\&DB=unep-wcmc\&URL=http://www.unep-wcmc.org/latenews/previous/japanpaper.pdf> (19/10/05).

$360 \mathrm{~J}$. Harrison and M. Collins, "Harmonizing the information management infrastructure for biodiversity-related treaties", WCMC Website, $<$ http://www.unep-wcmc.org/latenews/previous/japanpaper.pdf\#xml=/cgi-bin/pdf hl?STEMMER=en\&RGB=ff0off\&WORDS=feasibili ty+study+\&DB=unep-wcmc\&URL=http://www.unep-wcmc.org/latenews/previous/japanpaper.pdf> (19/10/05).

361 http://www.unep-wcmc.org/ under 'Harmonization of National Reporting' (6/11/05).

362 http://www.unep-wcmc.org/ under 'Harmonization of National Reporting' (6/11/05).

363 http://www.unep-wcmc.org/ under 'Harmonization of National Reporting' (6/11/05).

364 http://www.unu.edu/inter-linkages/1999/frameset.htm (6/11/05).

365 http://www.unu.edu/inter-linkages/1999/frameset.htm (6/11/05.)

366 Interlinkages: Synergies and Coordination between Multilateral Environmental Agreements, UNU, Tokyo, Japan, 1999, p.6 at http://www. unu.edu/inter-linkages/1999/frameset.htm (6/11/05).

367 http://www.unu.edu/inter-linkages/ilink/frameset.htm (6/11/05.) 
cooperation between UNEP and MEAs, harmonized information systems and coordinated approaches to capacity building. ${ }^{368}$

The World Customs Organisation (WCO), an intergovernmental organisation established in 1952 to improve customs administration, ${ }^{369}$ signed a Memorandum of Understanding with UNEP in 2003 that recognised the need for customs officers around the world to be better equipped at detecting environmental crime. ${ }^{370}$ To that end, the Green Customs Project is a joint initiative between the WCO, Interpol, the CITES and Basel Secretariats and the UNEP Division of Technology, Industry and Economics and Division of Environmental Conventions, which aims to train customs officers in identifying and dealing with illegal trade in wildlife and hazardous substances. ${ }^{371}$ This national customs strengthening exercise seeks to develop national implementation capacity but does not focus on MEA compliance systems at the international level.

\section{MEA Secretariats}

In 2001, a Joint Liaison Group (JLG) between the CBD, UNCCD and UNFCCC was established with the aim of exchanging information as well as exploring synergies and opportunities for cooperation between the Conventions. ${ }^{372}$ The JLG has produced a joint paper entitled 'Options for Enhanced Cooperation among the Three Rio Conventions', ${ }^{373}$ which has recommended, inter alia, the development of joint working groups and actions plans, cooperation between national focal points and between scientific subsidiary bodies. $^{374}$ Biannual meetings are held between the secretariats of five biodiversity-related MEAS (CBD, CMS, CITES, World Heritage and Ramsar) that form the Biodiversity Liaison Group. ${ }^{375}$ They are considering possible cooperation in harmonization of national reporting, including performance reporting.

Interlinkages between specific MEA Secretariats are set out below. Information concerning interlinkages between them to assist general implementation is provided but is distinguished from compliance interlinkages. Treaty provisions governing relations with other MEAs are also noted.

\section{Nature Conservation}

Among MEAs, the most intense interlinkage activity takes place within the biodiversityrelated cluster.

\footnotetext{
368 http://www.unep.org/dec/support/index.html and http://www.unep.org/dec/support/interlinkages.html (5/11/05)

369 Fact Sheet - "The World Customs Organisation" at http://www.wcoomd.org/ie/En/AboutUs/aboutus.html (5/11/05).

370 http://www.wcoomd.org/ie/En/search/search.html (5/11/05).

371 UNEP World Conservation Monitoring Centre, Synergies and Cooperation: A status report on activities promoting synergies and cooperation between Multilateral Environmental Agreements, in particular biodiversity-related conventions, and related mechanisms, May 2004, p.36.

372 http://www.biodiv.org/cooperation/liason.shtml (5/11/05).

373 http://www.biodiv.org/doc/meetings/sbstta/sbstta-10/information/sbstta-10-inf-09-en.pdf.

374 http://www.biodiv.org/cooperation/liason.shtml.

375 Joint Web Site of the Biodiversity Related Conventions Biodiversity Liaison Group http://www.biodiv.org/cooperation/related-conventions/blg.shtml.
} 


\section{(a) Ramsar Convention}

Compliance Ramsar Convention COP Resolution 7.4 relating to partnerships and cooperation with other conventions promotes harmonised information management infrastructures.

Implementation The Ramsar Bureau has signed MOUs with the following secretariats: CMS in February 1997; UNCCD in December 1998; and the World Heritage Centre in May 1999. A Memorandum of Cooperation between the Ramsar Bureau and the CBD Secretariat was signed in January 1996 and a Joint Work Plan for 1998-1999 was developed and endorsed by COP-4 (1990). COP Resolution 7.4 endorses the Joint Work Plan with the CBD and requests that the Bureau give priority in its programme of work for the next triennium to the development of joint actions with the CMS, and to the implementation of the MOUs with the Secretariat of the UNCCD and the World Heritage Centre. It also requests the development of a Memorandum of Cooperation with the UNFCCC.

\section{(b) World Heritage}

Implementation The World Heritage Centre has signed MOUs with the Ramsar Secretariat and the CMS Secretariat. A MOU is in development with the CBD Secretariat. Operational Guidelines 42 and 43 of the World Heritage Committee stress the need for appropriate coordination and information sharing with other conservation instruments including the Ramsar Convention and CITES. ${ }^{376}$ To facilitate coordination, the Committee may invite representatives of the intergovernmental bodies under such conventions to attend its meetings as observers and appoints its own representatives to observe at meetings of the other intergovernmental bodies when invited to do so.

\section{(c) CITES}

Compliance CITES COP Decision 13.92 directs the CITES Secretariat to collaborate with the Secretariats of other biodiversity-related conventions to ensure the harmonization of information management and reporting.

Implementation The CITES Secretariat cooperates with the Secretariats to the Basel Convention and Montreal Protocol to combat illegal trade. ${ }^{377}$ The CITES Secretariat also cooperates closely with the Ramsar Bureau. ${ }^{378}$ CITES COP Resolution 13.3 calls upon the

376 UNEP World Conservation Monitoring Centre, Synergies and Cooperation: A status report on activities promoting synergies and cooperation between Multilateral Environmental Agreements, in particular biodiversity-related conventions, and related mechanisms, May 2004, p.95.

377 UNEP World Conservation Monitoring Centre, Synergies and Cooperation: A status report on activities promoting synergies and cooperation between Multilateral Environmental Agreements, in particular biodiversity-related conventions, and related mechanisms, May 2004, p. 78.

378 UNEP World Conservation Monitoring Centre, Synergies and Cooperation: A status report on activities promoting synergies and cooperation between Multilateral Environmental Agreements, in particular biodiversity-related conventions, and related mechanisms, May 2004 , p. 77. 
Secretariat to regularly review the Memorandum of Understanding (MOU) between the Secretariats of CITES and the CMS; to seek submissions from CITES Parties on a joint work programme with the CMS Secretariat and to invite the CMS Secretariat to meetings pertaining to commonly protected species. In relation to the CBD Secretariat, a Memorandum of Cooperation with an attached Work Plan for Implementation of Joint Activities has been adopted.

\section{(d) CMS}

Compliance: CMS COP-6 (1999) established the CMS Information Management System, which is maintained by UNEP-WCMC. The Information Management System collects data and information from expert organisations, CMS national reports and other biodiversity agreements such as the CBD and CITES and offers Parties information on: species listed in the Appendices; species groups and issues relevant to CMS; links to the CBD's ClearingHouse Mechanism; and information provided by Parties on the implementation of resolutions and recommendations and the mobilisation of financial and technical resources. ${ }^{379}$

Implementation An MOU on co-operation between the CMS and CBD Secretariats was signed on 13 June 1996. CMS COP Resolution 6.4 requested the Secretariat to actively 'foster synergy between global environmental conventions, giving particular emphasis to the relationship with the Convention on Biological Diversity.' CMS COP-7 (2002) invited the CMS Secretariat to collaborate with the Secretariat of the CBD to integrate migratory species into the latter's National Biodiversity Strategies and Action Plans. ${ }^{380}$ An MOU between the CMS and Ramsar Secretariats was signed on 18 February 1997, ${ }^{381}$ between the CMS and CITES Secretariats on 18 September 2002, and between the CMS and UNCCD Secretariats on 2 September 2003. ${ }^{382}$ There is also a MOU between the CMS Secretariat and World Heritage Committee and there are joint programmes between the CMS Secretariat and the CBD, CITES and Ramsar Secretariats. ${ }^{383}$

\section{(e) CBD}

Compliance COP-4 (1998) directed the Executive Secretary to improve information exchange synergies with other biodiversity-related conventions. ${ }^{384}$ At COP-5 (2000), the Informal Advisory Committee was directed to facilitate and encourage cooperation with other international and regional information networks and initiatives. ${ }^{385}$ To this end, UNEP-

379 UNEP World Conservation Monitoring Centre, Synergies and Cooperation: A status report on activities promoting synergies and cooperation between Multilateral Environmental Agreements, in particular biodiversity-related conventions, and related mechanisms, May 2004, p. 87.

380 UNEP World Conservation Monitoring Centre, Synergies and Cooperation: A status report on activities promoting synergies and cooperation between Multilateral Environmental Agreements, in particular biodiversity-related conventions, and related mechanisms, May 2004, p. 84.

381 Ramsar Website, <http://www.ramsar.org/key_cms mou.htm $>$ (8/9/05).

382 CMS Website, <http://www.cms.int/bodies/ScC/12th scientific council/12th ScC documents.htm $>$ (8/9/05).

$383 \mathrm{http}: / /$ www.biodiv.org/cooperation/related-conventions/mandates.shtml\# (5/11/05).

384 CBD Decision IV/2.

385 CBD Decision V/14. 
WCMC has recommended the development of a biodiversity-related MEA database or clearing-house mechanism to streamline national reporting. ${ }^{386}$

Implementation Given the broad scope of issues that are covered in the CBD, COP-4 (1998) sought to address its rapidly over-loaded decision-making process by intensifying relationships with other Conventions. ${ }^{387}$ There are Memoranda of Understanding/ Cooperation and Joint Programmes between the CBD Secretariat and the Secretariats to the CITES, CMS, Ramsar Convention, and World Heritage Convention. ${ }^{388}$

Decision $\mathrm{VI} / 20$ reinforces the need to design and implement mutually supportive activities with other conventions and international organisations. Those noted include the: UNFCCC; UNCCD; Ramsar Convention; CMS; and CITES. With Decision VII/26, the COP extended the mandate of the Working Group on Review of Implementation of the Convention to examine ways of increasing cooperation between the biodiversity-related Secretariats.

Legal Article 22 of the CBD provides that its provisions do not affect its Parties' rights and obligations under other international agreements, unless exercise of those rights or obligations would cause damage or serious threat to biological diversity. Its provisions are to be implemented consistently with UNCLOS, discussed below. In that respect, cooperative arrangements have been concluded for marine and coastal biodiversity, including a joint study between the CBD Secretariat and the United Nations Division of Ocean Affairs and Law of the Sea on the relationship between the CBD and UNCLOS regarding the conservation and sustainable use of deep seabed biodiversity. ${ }^{389}$ Article 28 allows Parties to adopt protocols to the CBD. However, Parties to any protocol must first be Parties to the CBD. ${ }^{390}$

\section{(f) UNCCD}

Implementation The UNCCD Secretariat has signed MOUs with the Secretariats to the Ramsar Convention, the UNFCCC, the CBD and the CMS. Parties are encouraged to coordinate activities under UNCCD with those under other relevant international agreements, particularly the UNFCCC and CBD. ${ }^{391}$

\section{(g) ITPGRFA}

Implementation The Treaty states that its objectives will be attained by closely linking its implementation to the work of the Food and Agriculture Organisation of the United Nations and to the CBD. ${ }^{392}$ Article 17.1 ties the Global Information System for Plant

386 UNEP World Conservation Monitoring Centre, Synergies and Cooperation: A status report on activities promoting synergies and cooperation between Multilateral Environmental Agreements, in particular biodiversity-related conventions, and related mechanisms, May 2004, p.56.

387 CBD Decision IV/15.

388 http://www.biodiv.org/cooperation/related-conventions/mandates.shtml\# (5/11/05).

389 UNEP World Conservation Monitoring Centre, Synergies and Cooperation: A status report on activities promoting synergies and cooperation between Multilateral Environmental Agreements, in particular biodiversity-related conventions, and related mechanisms, May 2004, p. 66.

390 CBD Article 32.

391 UNCCD, Article 8.

392 PGRFA Treaty, Article 1.2. 
Genetic Resources with the clearing-house mechanism established under the CBD. Article 19.3 directs the Governing Body to establish and maintain close links with the CBD COP, take note of relevant CBD COP decisions and inform the CBD COP of 'matters regarding the implementation of this Treaty.'

\section{Hazardous Substances Management}

In 2002 the UNEP Governing Council adopted Decision SS.VII/3, which established a 'Strategic Approach to International Chemicals Management' (SAICM). ${ }^{393}$ Paragraph 1 of the Decision states that there is a need to develop a strategic approach and endorses the Intergovernmental Forum on Chemical Safety Bahia Declaration and Priorities for Action Beyond 2000 as the foundation of the approach. The Strategic Approach is to take into account the economic, social and environmental factors of chemical management as well as sustainable development. ${ }^{394}$ In 2003, Decision 22/4 IV called for a draft approach to be prepared for discussion at preparatory meetings with a view to eventually convening an international conference. ${ }^{395}$ An International Conference on Chemicals Management will take place in Dubai in early 2006. ${ }^{396}$

\section{(a) Basel}

Implementation The Secretariats to the Basel Convention, CITES and the Montreal Protocol work together to combat illegal trade and have signed an MOU to that effect. ${ }^{397}$ The Basel, POPs Convention and the PIC Convention Secretariats, discussed below, undertake joint activities including regional and sub-regional workshops on the integrated implementation of the three Conventions. ${ }^{398}$ The Basel Convention Parties have engaged in cooperation with the IMO and the ILO concerning the issue of ship recycling. Furthermore, the Secretariat works with the World Customs Organization on the HNS code, to facilitate the detection of non-compliance, and coordinated approaches between the two organizations. The Basel Convention Regional Centres play an important role in implementing a wide variety of activities, in accordance with directions of the COP, to facilitate implementation of, and compliance with, the Convention by Parties, and to coordinate with relevant activities of regional organizations and mechanisms.

Legal Parties may enter into bilateral, multilateral and regional agreements and arrangements provided such agreements do not derogate from the ESM of hazardous and other wastes as required by the Basel Convention. ${ }^{399}$ They may also adopt national legislation classifying wastes as hazardous that are not covered by the Convention annexes.

$393 \mathrm{http}: / /$ www.chem.unep.ch/saicm/ (5/11/05).

394 Decision 22/4 IV, paragraph 1.

395 Decision 22/4 IV paragraphs 2 and 3.

396 http://www.chem.unep.ch/saicm/ (5/11/05).

397 UNEP World Conservation Monitoring Centre, Synergies and Cooperation: A status report on activities promoting synergies and cooperation between Multilateral Environmental Agreements, in particular biodiversity-related conventions, and related mechanisms, May 2004, p.78.

398 UNEP World Conservation Monitoring Centre, Synergies and Cooperation: A status report on activities promoting synergies and cooperation between Multilateral Environmental Agreements, in particular biodiversity-related conventions, and related mechanisms, May 2004, p. 125.

399 Basel Article 11. 
Implementation Coordinated implementation activities have been undertaken with the Basel and POPs Conventions. ${ }^{400}$ At COP-1 (2004), the Parties to the PIC Convention decided to invite other relevant regional entities, in particular the Basel Convention regional centres and regional coordinating centres, international organisations and MEAs to participate in a regional delivery system. ${ }^{401}$

\section{(c) Biosafety Protocol}

Legal The provisions of the CBD relating to its protocols apply to the Biosafety Protocol. 402 Parties may enter into bilateral, regional and multilateral agreements regarding the transboundary movement of LMOs provided they comply with the Protocol. ${ }^{403}$

\section{(d) POPs}

Implementation Joint activities are conducted between the Basel, POPs and PIC Conventions. ${ }^{404}$ The POPs Convention Secretariat is directed to cooperate closely with the Secretariat of the Basel Convention in relation to disposal of POPs. This includes establishing levels of destruction and irreversible transformation necessary to ensure that the characteristics of POPs (set out in Annexes A, B, C and D, paragraph 1 of the POPs Convention) are not exhibited; to determine criteria for environmentally sound disposal; and to ensure that Annex A, B and C chemicals are disposed of according to ESM principles. ${ }^{405}$

\section{Atmospheric Emissions Control}

\section{(a) Vienna Convention}

Legal Parties may not become a Party to any protocol under the Convention if they are not Parties to the Convention. ${ }^{406}$

400 UNEP World Conservation Monitoring Centre, Synergies and Cooperation: A status report on activities promoting synergies and cooperation between Multilateral Environmental Agreements, in particular biodiversity-related conventions, and related mechanisms, May 2004, p.125.

401 PIC Convention Decision 1/14.

402 Biosafety Protocol, Article 32.

403 Biosafety Protocol, Article 14.

404 UNEP World Conservation Monitoring Centre, Synergies and Cooperation: A status report on activities promoting synergies and cooperation between Multilateral Environmental Agreements, in particular biodiversity-related conventions, and related mechanisms, May 2004, p. 125 .

405 POP Convention, Article 6(2) and Decision I/5.

406 Vienna Convention, Article 16. 
Implementation The MOU concerning cooperative capacity building of customs controls with the Basel Convention and CITES has been previously noted. ${ }^{407}$ At MOP-10 (1998), Parties noted that the greenhouse gases included in Annex A of the Kyoto Protocol include hydrofluorocarbons (HFCs) and perfluorocarbons (PFCs) and that the Montreal Protocol's Technology and Economic Assessment Panel had identified HFCs and PFCs as alternatives to ozone-depleting substances. ${ }^{408}$ Decision X/16 requested the relevant Montreal Protocol committee to assess the implications of the inclusion of HFCs and PFCs in the Kyoto Protocol for the implementation of the Montreal Protocol and to continue to cooperate with the relevant bodies under the UNFCCC and Kyoto Protocol.

\section{(c) UNFCCC}

Implementation Decision 13/CP.8 affirms the need for enhanced cooperation between the UNFCCC, the CBD and the UNCCD and requests the UNFCCC Subsidiary Body for Scientific and Technical Advice to continue cooperating with the equivalent $\mathrm{CBD}$ and UNCCD bodies. A Joint Liaison Group has been established between the CBD, UNFCCC and UNCCD to explore coordination issues, with the Ramsar Convention having observer status. ${ }^{409}$

\section{(d) Kyoto Protocol}

Legal The legal relationship between the Kyoto Protocol's compliance mechanism and the UNFCCC's Multilateral Consultative Process is unclear, due to the overlap between the facilitative functions of each. The relationship between the Protocol's non-compliance mechanism and the dispute resolution procedures it inherited from the UNFCCC also remains to be explored. ${ }^{410}$ However, in terms of function, it can be assumed that the elaborate and established multilateral institution for the management of compliance operated by the Kyoto Compliance Committee will be preferred to the vague UNFCCC Multilateral Consultative Process and to adversarial confrontations under the UNFCCC dispute resolution procedures.

407 UNEP World Conservation Monitoring Centre, Synergies and Cooperation: A status report on activities promoting synergies and cooperation between Multilateral Environmental Agreements, in particular biodiversity-related conventions, and related mechanisms, May 2004, p.78.

408 See also UNU Report,'Inter-linkages between the Ozone and Climate Change Conventions', 2001.

409 UNEP World Conservation Monitoring Centre, Synergies and Cooperation: A status report on activities promoting synergies and cooperation between Multilateral Environmental Agreements, in particular biodiversity-related conventions, and related mechanisms, May 2004, p. 103.

410 See Fitzmaurice, M,'The Kyoto Protocol Compliance Regime and Treaty Law', Singapore Yearbook of International Law, Vol.8, 2004, p.23. 


\section{Marine Environment Protection}

\section{(a) Whaling}

Implementation At its meeting in 2000, the Commission noted the importance of co-operation with other organisations in scientific research and that the Commission has agreed an MOU with the CMS Secretariat. ${ }^{411}$

\section{(b) London Convention}

Implementation In 1991, the Parties to the London Convention voted to request the Basel Secretariat to consider the London Convention when preparing its technical guidelines. ${ }^{412}$ They have since cooperated with Basel Convention particularly concerning the scrapping of ships, the drafting of the 1996 Protocol to the London Convention and the Global Waste Inventory and Database.

\section{(c) UNCLOS}

Implementation Studies have been conducted into the relationship between the CBD and the UNCLOS, with specific regard to the conservation of marine biodiversity. ${ }^{413}$

\section{(d) Fish Stocks}

Legal Article 4 of the Fish Stocks Agreement states that the Agreement must be interpreted and applied consistently with UNCLOS.

411 IWC Website, <http://www.iwcoffice.org/meetings/meeting2000.htm\#coop > (17/9/05).

412 List of London Convention Resolutions, <http://www.londonconvention.org/> (25/10/05).

413 UNEP World Conservation Monitoring Centre, Synergies and Cooperation: A status report on activities promoting synergies and cooperation between Multilateral Environmental Agreements, in particular biodiversity-related conventions, and related mechanisms, May 2004 , p. 66. 
TABLE 4.1: Implementation Cooperation between MEA Secretariats

\section{KEY: $\quad$ Bold $=$ compliance interlinkages $\quad V=M O U$}

* = Other forms of cooperation (e.g. Joint Working Groups etc.)

- = Cooperation by virtue of Convention/Protocol relationship

\begin{tabular}{|c|c|c|c|c|c|c|c|c|c|c|c|c|c|c|c|c|c|c|c|}
\hline & हूँ & 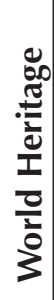 & 岂 & $\sum_{U}^{\infty}$ & คิ & 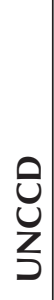 & $\begin{array}{l}\frac{\pi}{c} \\
\text { 品 } \\
\text { 先 }\end{array}$ & 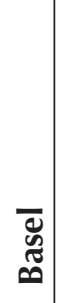 & $\frac{\cup}{a}$ & $\begin{array}{l}\frac{7}{\frac{\pi}{\pi}} \\
\frac{\pi}{\pi} \\
: \frac{0}{\infty}\end{array}$ & ڤิ) & & 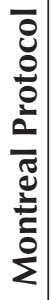 & $\begin{array}{l}u \\
u \\
u \\
\underline{Z} \\
\supset\end{array}$ & 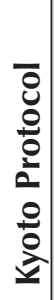 & 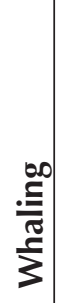 & 등 & $\begin{array}{l}\tilde{0} \\
\breve{u} \\
\underline{z}\end{array}$ & 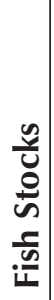 \\
\hline Ramsar & & $\sqrt{ }$ & $\sqrt{ }$ & $\sqrt{ } *$ & $\sqrt{ } *$ & $\sqrt{ }$ & & & & & & & & * & * & & & & \\
\hline $\begin{array}{l}\text { World } \\
\text { Heritage }\end{array}$ & $\sqrt{ }$ & & * & $\sqrt{*}$ & $\sqrt{*}$ & * & & & & & & & & & & & & & \\
\hline CITES & $\sqrt{ }$ & * & & $\sqrt{*}$ & $\sqrt{*}$ & 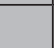 & & $\sqrt{ }$ & & & & & $\sqrt{ }$ & & & & & & \\
\hline $\mathrm{CMS}$ & $\sqrt{*}$ & $\sqrt{*}$ & $\sqrt{*}$ & & $\sqrt{*}$ & $\sqrt{ }$ & & & & & & 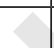 & 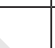 & 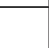 & . & $\sqrt{ }$ & & & \\
\hline CBD & $\sqrt{*}$ & $\sqrt{ } *$ & $\sqrt{ } *$ & $\sqrt{*}$ & & $\sqrt{ } *$ & * & & & $-*$ & & & 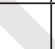 & * & * & & & $*$ & \\
\hline UNCCD & $\sqrt{ }$ & $*$ & & $\sqrt{ }$ & $\sqrt{*}$ & & & & & & 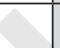 & & $\sqrt{ }$ & $\sqrt{ }$ & * & & & & \\
\hline ITPGRFA & & & & & * & & & & & & & - & & 1 & & & & & \\
\hline & & & & & & & & & & & & 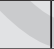 & 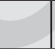 & & & & & & \\
\hline Basel & & & $\sqrt{ }$ & & & & & 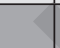 & * & & * & & $\sqrt{ }$ & & & & * & & \\
\hline $\mathrm{PIC}$ & & & & & & & & $*$ & 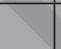 & & $*$ & $\square$ & & & & & & & \\
\hline Biosafety & & & & & -* & & & & & & & & & & & & & & \\
\hline POPs & & & & & & & & * & * & & & & & & & & & & \\
\hline Vienna & & & & & & 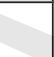 & & & & & & & - & & & & & & \\
\hline $\begin{array}{l}\text { Montreal } \\
\text { Protocol }\end{array}$ & & & $\sqrt{ }$ & & 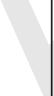 & $\sqrt{ }$ & & $\sqrt{ }$ & & & & - & & $*$ & * & & & & \\
\hline UNFCCC & * & & & & * & $\sqrt{ }$ & & & & & & & * & & - & & & & \\
\hline $\begin{array}{l}\text { Kyoto Pro- } \\
\text { tocol }\end{array}$ & * & & & & * & * & & & & & & & * & - & & & & & \\
\hline $\begin{array}{l}\text { Whaling } \\
\text { Conven- } \\
\text { tion }\end{array}$ & & & & $\sqrt{ }$ & & & & & & & & & & & & & & & \\
\hline $\begin{array}{l}\text { London } \\
\text { Conven- } \\
\text { tion }\end{array}$ & & & & & & & & * & & & & & & & & & & & \\
\hline UNCLOS & & & & & * & & & & & & & & & & & & & & \\
\hline $\begin{array}{l}\text { Fish } \\
\text { Stocks }\end{array}$ & & & & & & & & & & & & & & & & & & & \\
\hline
\end{tabular}


Table 4.1, above, shows that the greatest concentration of interlinkages between international compliance systems occurs between the biodiversity-related MEAs, other than the UNCCD. Those MEAs also enjoy the greatest concentration of interlinkages for general implementation. Again in relation to general implementation, the other areas of concentrated MEA interlinkages occur within clusters, i.e., the hazardous substances and atmosphere clusters, with the notable exception of the marine cluster. There is also a relatively high level of implementation interlinkage between the biodiversity-related and atmosphere clusters, comprising the only significant area of interlinkages that extend across clusters.

\section{National Efforts Supporting Interlinkages in Compliance}

At the national level, interlinkages in domestic compliance systems can be made to generate synergies across national efforts to implement MEAs. They are to be contrasted with multilateral compliance mechanisms. Domestic compliance systems operate at a level below the international personality of the State. They form a part of national implementation to meet international obligations.

Domestic compliance interlinkages pose a challenge to the national governance capabilities. This is because national governance structures are traditionally built upon distributions of responsibilities based on a concept of management sectors or portfolios. Those sectors or portfolios are usually firmly defined to limit the mandate of a government institution within its allotted management responsibilities. Building bridges across these institutional 'silos' can be difficult and resource intensive.

Some international organisations are engaged in national capacity building to enhance interlinkages in national implementation of MEAs. This capacity building frequently seeks to enhance general systems for domestic compliance with MEAs and, to a lesser extent, interlinkages between them. The work of the UNDP, UNEP and WCO has been mentioned above.

The International Network for Environmental Compliance and Enforcement (INECE) takes generic action to build national compliance and enforcement capabilities. It has developed a set of environmental compliance and enforcement (ECE) indicators for assessing program performance. They are societal response indicators that describe the "level of activity or commitment made by Government, and a set of results which contribute to an important social goal such as reducing or preventing environmental pollution." ${ }^{414}$ The INECE has also developed a guidebook to assist countries in identifying, developing and testing ECE indicators $^{415}$ and a guidebook to assist countries in developing and implementing compliance and enforcement strategies in relation to their own laws and policies. ${ }^{416}$ The latter guidebook discusses the key components of a country's compliance and enforcement program as: creating requirements that are enforceable; knowing who is subject to the requirements and setting priorities; promoting compliance in the regulated community;

414 "Performance Measurement Guidance for Compliance and Enforcement Practitioners,"INECE Website, <http://www.inece.org/indicators/guidance.pdf>, p.2 (19/10/05).

415 "Performance Measurement Guidance for Compliance and Enforcement Practitioners,"INECE Website, $<\underline{\text { http://www.inece.org/indica- }}$ tors/guidance.pdf $>$, p.2 (19/10/05).

416 "Principles of Environmental Enforcement", INECE Website, <http://www.inece.org/enforcementprinciples.html> (19/10/05). 
monitoring compliance with the requirements; responding to breaches; identifying roles and responsibilities; and evaluating the performance of the program. ${ }^{417}$

The UNU has conducted specific case studies of institutional coordination in relation to the implementation of MEAs that touch upon domestic compliance systems in Malaysia and Thailand, ${ }^{418}$ in the Pacific Islands ${ }^{419}$ and more broadly in Asia and the Pacific. ${ }^{420}$ It is beyond the scope of this paper to conduct detailed national case studies of domestic compliance interlinkages in the implementation of MEAs. However, a few regional sketches are set out to indicate the nature of national developments. These suggest that, except for countries in North America and Europe, domestic interlinkages are at early stages of development and mostly concern the establishment of integrated environmental monitoring databases rather than integration of performance information.

\section{(a) Asia and Pacific}

Environmental agencies have emerged in South East Asian countries to play a coordinating role between the various agencies tasked with environmental responsibilities, develop and implement policies and conduct awareness-raising activities. ${ }^{421}$ For example, both Malaysia and Thailand have developed institutional frameworks to deal with specific environmental issues, although there is a need for increased cross-sectoral harmonization. ${ }^{422}$ In Malaysia, the Inter-Agency Planning Group oversees the implementation of Agenda 21 while the Ministry of Science, Technology and the Environment formulates policy and deals with inter-ministerial coordination issues for the Rio Conventions. ${ }^{423}$ Thailand has a National Environmental Board, which oversees the implementation of MEAs through numerous committees and sub-committees, including the National Committee on the Convention of Biological Diversity and the National Committee on Climate Change. ${ }^{424}$

In South East Asia, national databases on natural resources and environment are developing, although problems exist in relation to lack of coordination, poor and uneven reporting, outdated information and lack of standardised methodologies. ${ }^{425}$ In the Lao People's

417 "Principles of Environmental Enforcement", INECE Website, <http://www.inece.org/enforcementprinciples.html> (19/10/05).

418 Brook Boyer Institutional Coordination, Multi-stakeholder Participation and the Implementation of MEAs: National Experiences of Malaysia and Thailand, United Nations University Paper prepared for the Regional Consultation / Workshop on Inter-linkages, Kuala Lumpur, 26-27 February 2001, Discussion Paper 2001-003.

419 Jerry Velasquez; Piest Uli and Mougeot, Jacques (edited by Shona E.H. Dodds and based on the draft national reports made by Martin Tsamenyi and Richard Kenchington) Synergies and Coordination among MEAs: Pacific Islands Case Study United Nations University 2002, Tokyo.

420 Brook Boyer; Velasquez, Jerry and Piest, Uli Synergies and Coordination among MEAs: Regional \& National Approaches in Asia and the Pacific United Nations University 2002, Tokyo.

421 Economic and Social commission for Asia and the Pacific State of the Environment in Asia and the Pacific 1995, Bangkok, p.469.

422 Brook Boyer Institutional Coordination, Multi-stakeholder Participation and the Implementation of MEAs: National Experiences of Malaysia and Thailand, United Nations University Paper prepared for the Regional Consultation / Workshop on Inter-linkages, Kuala Lumpur, 26-27 February 2001, Discussion Paper 2001-003, p.25.

423 Brook Boyer Institutional Coordination, Multi-stakeholder Participation and the Implementation of MEAs: National Experiences of Malaysia and Thailand, United Nations University Paper prepared for the Regional Consultation / Workshop on Inter-linkages, Kuala Lumpur, 26-27 February 2001, Discussion Paper 2001-003, p.9.

424 Brook Boyer Institutional Coordination, Multi-stakeholder Participation and the Implementation of MEAs: National Experiences of Malaysia and Thailand, United Nations University Paper prepared for the Regional Consultation / Workshop on Inter-linkages, Kuala Lumpur, 26-27 February 2001, Discussion Paper 2001-003, p.17.

425 Economic and Social commission for Asia and the Pacific State of the Environment in Asia and the Pacific 1995, Bangkok, p.534. 
Democratic Republic, for example, water, meteorological, soil and land databases have been streamlined into an integrated database that is managed by the Division of Inventory and Planning of the Department of Forestry. ${ }^{426}$ In Vietnam, the National Information and Documentation Centre manages two networks of environmental information. ${ }^{427}$ At the regional level, information and experiences are shared through organisations such as the Association of South East Asian Nations (ASEAN).

Most countries in South East Asia have monitoring systems for gathering environmental data. Malaysia routinely monitors air and water quality and has also developed a system of monitoring oil spills. ${ }^{428}$ Singapore and Thailand also have air quality monitoring systems. ${ }^{429}$ Vietnam has outlined a policy on environmental assessment in its National Action Plan on Environment and Sustainable Development. ${ }^{430}$ The Philippines has formulated its own Action Plan following UNCED recommendations. ${ }^{431}$ The International Environmental Affairs Staff of the Department of Environment and Natural Resources coordinate monitoring activities. ${ }^{432}$

Within South Asia, ministries of environment have been established in Bangladesh, Bhutan, India, the Maldives, Nepal and Sri Lanka to implement environmental laws and develop and implement policies aimed at environmental conservation. ${ }^{433}$ In Bhutan, a National Environment Commission was established in 1992, which is a high-level cross-sectoral body that is responsible for creating legislation and ensuring that the Government's international obligations with various Conventions are satisfied. ${ }^{434}$ Similarly, in Nepal, the National Planning Commission assesses and approves environmental policies, coordinates cross-sectoral activities and performs monitoring functions. ${ }^{435}$ There is regional progress in the collection and dissemination of environmental information. For example, India introduced its Environmental Information System in 1984, which uses a network of databases on ecological and biodiversity research to integrate national efforts to collect environmental data. ${ }^{436}$ At the regional level, the South Asian Cooperative Environment Program, established in 1982 by the Governments of South Asia, promotes cooperative activities to strengthen institutions and capacity and provide a forum for information exchange. ${ }^{437}$ Its activities are complemented by the activities of the South Asian Association for Regional Cooperation, which focuses on economic but also covers environmental cooperation. ${ }^{438}$

Within the Pacific, the UNU has recently noted significant information management problems. Databases exist but remain unconnected. No Pacific Island country has yet developed a standardized format for collecting and storing data. ${ }^{439}$ Palau has attempted to

426 Economic and Social commission for Asia and the Pacific State of the Environment in Asia and the Pacific 1995, Bangkok, p.531.

427 Economic and Social commission for Asia and the Pacific State of the Environment in Asia and the Pacific 1995, Bangkok, p.530.

428 Economic and Social commission for Asia and the Pacific State of the Environment in Asia and the Pacific 1995, Bangkok, p.524.

429 Economic and Social commission for Asia and the Pacific State of the Environment in Asia and the Pacific 1995, Bangkok, p.531.

430 Economic and Social commission for Asia and the Pacific State of the Environment in Asia and the Pacific 1995, Bangkok, p.531.

431 Economic and Social commission for Asia and the Pacific State of the Environment in Asia and the Pacific 1995, Bangkok, p.531.

432 UNU Inter-linkages Policy Brief No. 3, National and Regional Approaches to in Asia and the Pacific, 2002, p.9.

433 Regional Overview (CD).

434 Regional Overview (CD).

435 Regional Overview (CD).

436 Economic and Social commission for Asia and the Pacific State of the Environment in Asia and the Pacific 1995, Bangkok p.529.

437 Regional Overview (CD).

438 Regional Overview (CD).

439 UNU Inter-linkages Policy Brief 4, Pacific Islands Case Study, 2002, p.35. 
address some of these issues, at least in relation to the atmosphere MEAs, with the creation of the Office of Environmental Response and Coordination that acts as a national focal point for the dissemination of information to relevant national agencies. ${ }^{440}$

\section{(b) Europe}

The European Network for the Implementation and Enforcement of Environmental Law (IMPEL) is a network of regulators that focuses on training inspectors, exchanging information and experience between Member States and reviewing EU environmental legislation. ${ }^{441}$ IMPEL's role is recognised in the $6^{\text {th }}$ Environment Action Programme, which was passed by the European Parliament on 22 July 2002. Article 3.2 provides that the objectives of the Programme shall be pursued by addressing infringements of environmental legislation, promoting improved monitoring and inspection standards by Member States, systematically reviewing the application of environmental legislation across the Community and improving exchange of information on best practice on implementation including by IMPEL. Article 9.1 outlines priority international environmental areas and Article 9.2(j) states that these international objectives shall be achieved by means of promoting policy coherence. This involves linking the work done within the framework of different MEAs, including assessing inter-linkages between the biodiversity and climate change conventions.

\section{(c) North America}

The Commission for Environmental Cooperation (CEC) was created by the USA, Canada and Mexico under the North American Agreement on Environmental Cooperation to deal with regional environmental issues, trade and environmental conflicts and to promote environmental law enforcement. ${ }^{442}$ The CEC has a Law and Policy program to address compliance with and enforcement of environmental laws within the region ${ }^{443}$ and includes an Enforcement and Compliance Cooperation Program that aims to provide support to the North American Working Group on Enforcement and Compliance Cooperation. ${ }^{44}$ It focuses on capacity building in areas including CITES tracking and enforcement, wildlife training exchanges, smuggling ozone depleting substances and transboundary law enforcement cooperation workshop. ${ }^{445}$ The Working Group comprises senior level enforcement officials and members of the North American Wildlife Enforcement Group (NAWEG), which is a regional network of wildlife enforcement officials. ${ }^{446}$ Additionally, the CEC has organised projects on cooperating on north American air quality that focus on exchanging technical data and developing strategies to address common concerns. ${ }^{447}$

440 UNU Inter-linkages Policy Brief 4, Pacific Islands Case Study, 2002, p.29.

441 See IMPEL Website, <http://europa.eu.int/comm/environment/impel/about.htm\#introduction> and <http://europa.eu.int/comm/ environment/impel/about.htm\#activities $>$ (19/10/05).

442 Commission for Environmental Cooperation, <http://www.cec.org/who_we_are/index.cfm?varlan+english> (19/10/05).

443 Commission for Environmental Cooperation, $<$ http://www.cec.org/pubs docs/documents/index.cfm?varlan=english\&ID=1024 >

$(19 / 10 / 05)$.

444 Commission for Environmental Cooperation, < $<$ http://www.cec.org/programs_projects/law_policy/project/index.cfm?projectlD=32\& varlan=english $>(19 / 10 / 05)$.

445 "Enforcement and Compliance Cooperation", <http://www.cec.org/files/pdf/LAWPOLICY/421-03-05 en.pdf $>$ (19/10/05).

446 "Enforcement and Compliance Cooperation", <http://www.cec.org/files/pdf/LAWPOLICY/421-03-05_en.pdf > (19/10/05).

447 CEC Website, <http://www.cec.org/programs projects/pollutants health/project/index.cfm?project|D=22\&varlan=english>

$(19 / 10 / 05)$. 
There are also projects dedicated to capacity building for pollution prevention among key stakeholders. ${ }^{448}$

In Canada, the position of Commissioner for the Environment and Sustainable Development was established in 1995 within the Canadian Office of the Auditor General. ${ }^{449}$ The Commissioner provides performance audits to the Canadian Parliament on whether environmental policies are being implemented and delivering the desired results. The Commissioner has recently reviewed the Canadian Biodiversity Strategy 1996, ultimately identified a lack of information on what has been achieved under the policy and on what remains to be achieved. ${ }^{40}$ The Report noted that responsibility for biodiversity in Canada spans several departments ${ }^{451}$ and that there are also issues relating to cooperation between the levels of government within the Canadian Federation. Senior officers from across portfolios and Governmental tiers form a Biodiversity Working Group to develop and coordinate implementation plans. ${ }^{452}$ Environment Canada responded by building biodiversity into a key component in other environmental management sectors, including the Oceans Action Plan, National Forest Strategy, the Agricultural Policy Framework and the Invasive Alien Species Strategy. ${ }^{453}$ In June 2005, the Federal, Provincial and Territorial Ministers and Deputy Ministers of wildlife, forestry and fisheries and aquaculture agreed to collaborate on the implementation framework of the Biodiversity Strategy that focuses on outcomes. ${ }^{454}$

\section{(d) South America}

The INECE held its Sixth International Conference on Environmental Compliance and Enforcement in 2002. ${ }^{455}$ It demonstrated that, although most South American countries lack ECE indicators, they do have institutional mechanisms to coordinate environmental activities. $^{456}$ In Chile, for example, an Environmental National Commission was established as an inter-ministerial and cross-sectoral coordination body, consisting of a Council of Ministers with environmental functions, cross-sectoral Consulting Council and an Executive Direction. ${ }^{457}$ Brazil has an Environmental National System, which is composed of different levels of Government and executive organs at the Federal level. ${ }^{458}$ The World

448 CEC Website, <http://www.cec.org/programs_projects/pollutants_health/project/index.cfm?project|D=22\&varlan=english> $(19 / 10 / 05)$.

449 Office of the Auditor-General, http://www.oag-bvg.gc.ca/domino/cesd cedd.nsf/html/cesd index e.html (19/10/05).

450 "Canadian Biodiversity Strategy - A Follow-Up Audit", Report of the Commissioner of the Environment and Sustainability, <http:// www.oag-bvg.gc.ca/domino/reports.nsf/html/c20050903ce.html > (19/10/05), at 3.53.

451 "Canadian Biodiversity Strategy - A Follow-Up Audit," Report of the Commissioner of the Environment and Sustainability, $<\underline{\text { http:// }}$ www.oag-bvg.gc.ca/domino/reports.nsf/html/c20050903ce.html> (19/10/05), at 3.6.

452 "Canadian Biodiversity Strategy - A Follow-Up Audit", Report of the Commissioner of the Environment and Sustainability, <http:// www.oag-bvg.gc.ca/domino/reports.nsf/html/c20050903ce.html> (19/10/05), at 3.8.

453 "Canadian Biodiversity Strategy - A Follow-Up Audit", Report of the Commissioner of the Environment and Sustainability, $<$ http:// www.oag-bvg.gc.ca/domino/reports.nsf/html/c20050903ce.html> (19/10/05), at 3.53.

454 "Canadian Biodiversity Strategy - A Follow-Up Audit," Report of the Commissioner of the Environment and Sustainability, $<\underline{\text { http:// }}$ www.oag-bvg.gc.ca/domino/reports.nsf/html/c20050903ce.html> (19/10/05), at 3.53.

455 D. Zaelke, K Markowitz and T Higdon, "Strengthening Environmental Enforcement and Compliance Through Networks", p.121, FARN Website, < http://www.farn.org.ar/docs/p32/en17 Zaelke.pdf> (19/10/05).

456 Maria Eugenia Di Paola, "Towards a Program of Environmental Compliance and Enforcement in Latin America," p.23, FARM Website, $<$ http://www.farn.org.ar/docs/p32/en05_DiPaola1.pdf $>$ (19/10/05).

457 Maria Eugenia Di Paola, "Towards a Program of Environmental Compliance and Enforcement in Latin America", p.24, FARM Website, $<$ http://www.farn.org.ar/docs/p32/en05_DiPaola1.pdf $>$ (19/10/05).

458 Maria Eugenia Di Paola, "Towards a Program of Environmental Compliance and Enforcement in Latin America," p.25, FARM Website, $<$ http://www.farn.org.ar/docs/p32/en05 DiPaola1.pdf $>$ (19/10/05). 
Bank Institute Environmental Governance Program has also recently co-hosted workshops in Brazil to build capacity on compliance and enforcement, including compliance indicators. ${ }^{459}$ In Argentina, a Federal Environmental Council was created to exchange information and coordinate environmental policies. ${ }^{460}$ Additionally, Argentinean authorities have signed inter-Governmental agreements to coordinate environmental compliance across the levels of Government on the issue of hazardous wastes. ${ }^{461}$

459 INECE Website, <http://www.inece.org/region_americas_south.html> (19/10/05).

460 Maria Eugenia Di Paola, "Towards a Program of Environmental Compliance and Enforcement in Latin America," p.25, FARN Website, $<$ http://www.farn.org.ar/docs/p32/en05_DiPaola1.pdf > (19/10/05).

461 Maria Eugenia Di Paola, "Towards a Program of Environmental Compliance and Enforcement in Latin America," p.25, FARN Website, $<$ http://www.farn.org.ar/docs/p32/en05_DiPaola1.pdf > (19/10/05). 
www.unep.org

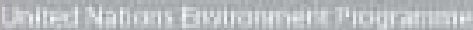

Ma Baricsh. Nurcobtoninha Kerwa

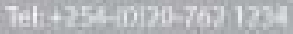

Fax +784 (0)20-762 3927

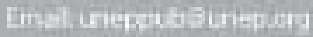

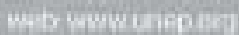

